

\title{
Gas Separation With Glass Membranes
}

Final Report

\author{
Daryl L. Roberts \\ I.C. Abraham \\ Y. Blum \\ J.D. Way
}

Work Performed Under Contract No.: DE-AC21-88MC25204

\author{
For \\ U.S. Department of Energy \\ Office of Fossil Energy \\ Morgantown Energy Technology Center \\ P.0. Box 880 \\ Morgantown, West Virginia 26507-0880 \\ By \\ SRI International \\ 333 Ravenswood Avenue \\ Menlo Park, California 94025-3493
}

May 1992 


\section{CONTENTS}

INTRODUCTION ............................................................... 1

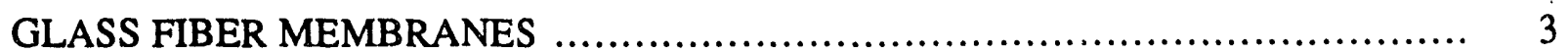

THEORY OF MULTICOMPONENT GAS PERMEATION THROUGH

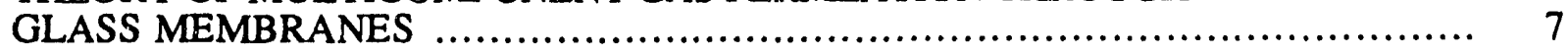

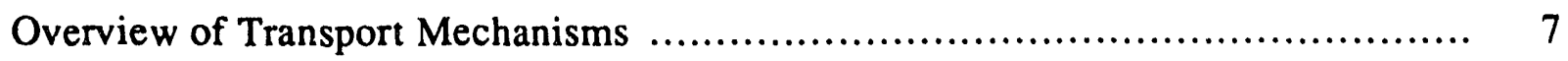

Flux Equation for Multicomponent Knudsen, Surface, and Molecular

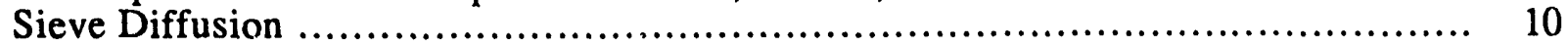

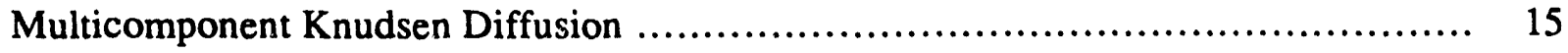

Multicomponent Surface Diffusion ............................................. 16

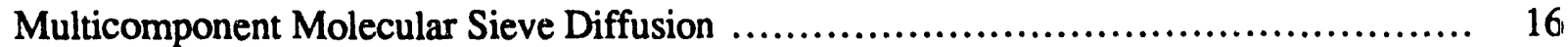

Commercial Manufacturing of Molecular Sieve Membranes ............................ 22,

PERMEATION TEST APPARATUS ............................................. 23

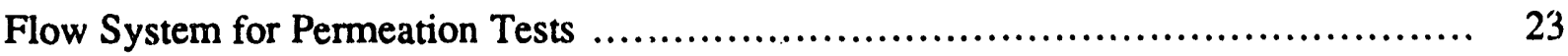

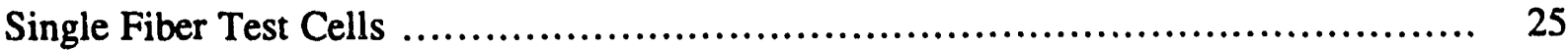

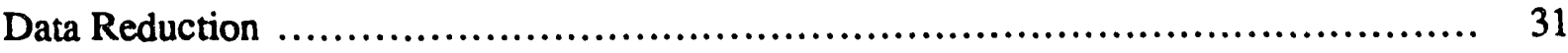

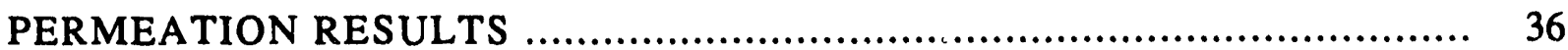

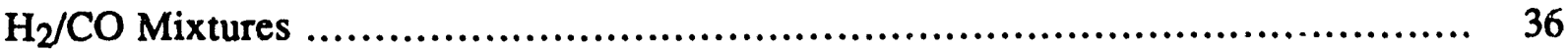

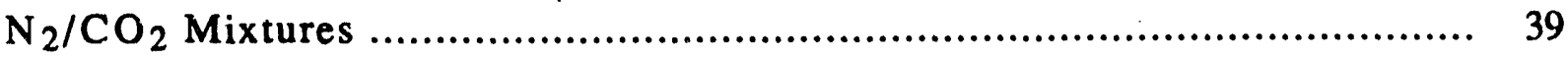

$\mathrm{NH}_{3} / \mathrm{N}_{2}$ Mixtures........................................................... 48

Pure Component Data ............................................................. 48

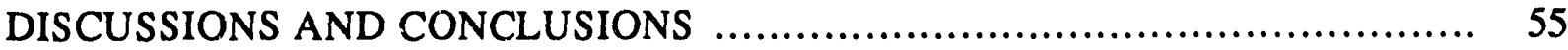

REFER

APPENDICES

A: DERIVATION OF CROSS TERM FOR MULTICOMPONENT SURFACE DIFFUSION FROM IDEAL ADSORBED SOLUTION THEORY

B: PROCEDURE FOR MAKING HIGH TEMPERATURE TEST CELLS WITH INTERNAL SEAL

C: TABULATIONS OF DATA; ALL MIXTURE AND PURE COMPONENT MEASUREMENTS

D: KINETIC DIAMETERS OF VARIOUS MOLECULES 


\section{FIGURES}

1 Cross section of glass hollow fiber membranes (PPG Industries) ................... 4

2 Estimated pore size distribution calculated using the Horvath-Kawazoe equation for both a $6 \AA$ zeolite and PPG fiber sample No. $4 \ldots \ldots \ldots \ldots \ldots \ldots \ldots \ldots$

3 Mechanisms of mass transfer through microporous membranes ....................... 8

4 Approximate operative pore size ranges for various mechanisms .................... 11

5 Conceptual diagram of diffusion through molecular-sized holes (molecular sieve diffusion) ................................................. 17

6 Detailed diagram of diffusion through molecular-sized pore $\ldots \ldots \ldots \ldots \ldots \ldots \ldots \ldots \ldots .20$

$7 \quad$ High temperature permeation apparatus ..................................... 24

8 A conventional seal method for hollow fiber membranes .......................... 27

9 Attempted fix for microporous potting compound problem $\ldots \ldots \ldots \ldots \ldots \ldots \ldots \ldots \ldots . .28$

10 Arrangement of test cell for seal diagnosis ............................................ 29

11 Detail of leak flow showing inadequacy of sealing glaze ...................... 30

12 Cross sectional view of fiber test cell assembly with details of internal seal .......... 32

13 Detail of two-material sealing technique ("bagel") ........................... 33

14 Influence of test cell preparation conditions on permeation performance ........... 38

15 Permeance/selectivity trade-off for $\mathrm{H}_{2} / \mathrm{CO}$ mixture separation ................... 40

16 Hysteresis phenomenon in high temperature cells ............................. 41

17 Hysteresis phenomenon in epoxy cells ........................................... 42

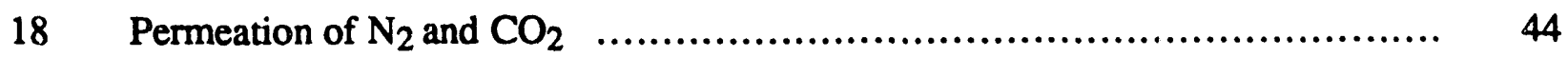

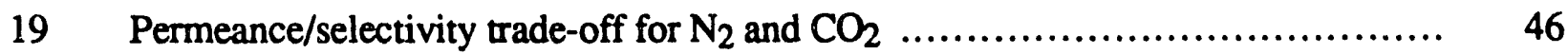

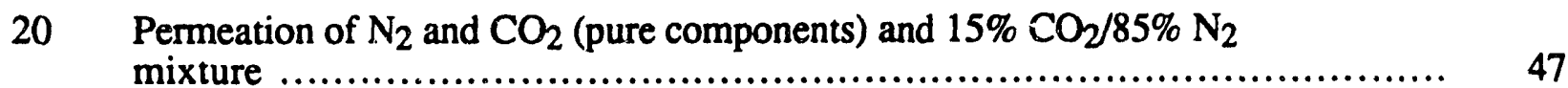

21 Performance of native fibers and high temperature cells for $\mathrm{NH}_{3}$ and $\mathrm{N}_{2} \ldots \ldots \ldots . .50$

22 Permeance/selectivity trade-off for $\mathrm{NH}_{3} / \mathrm{N}_{2}$ permeation $\ldots \ldots \ldots \ldots \ldots \ldots \ldots \ldots \ldots . . . \ldots 1$

23 Comparison of helium permeation in epoxy cells and high temperature cells

24 Comparison of normal high temperature cells to cells made with pretreated fibers

B-1 Schematic diagram of tripod fiber holder 


\section{TABLES}

1 Typical Composition for Coal Combustion and Coal Gasification Processes ...... 2

2 Results of Strain-at-Break Testing for PPG Hollow Fibers ................... 6

3 Lennard-Jones Parameters .............................................. 21

4 Coefficients of Thermal Expansion for Common Materials .................... 25

$5 \quad$ Non-Interference Tests for $\mathrm{He}, \mathrm{H}_{2}$, and $\mathrm{CO}$ Permeation ........................ 37

6 Temperature Dependence of $\mathrm{CO}_{2} / \mathrm{N}_{2}$ Selectivity with $15 \% \mathrm{CO}_{2} / 85 \% \mathrm{~N}_{2}$ Feed Mixture; High Temperature Cells .......................................... 45

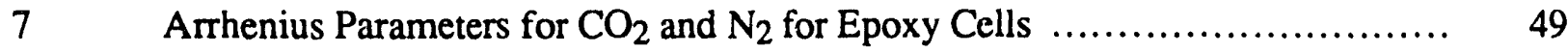

8 Arrhenius Parameters for $\mathrm{CO}_{2}$ and $\mathrm{N}_{2}$ Pure Component and Mixture Permeance Data; High Temperature Cells ..................................... 49

C-1-1 Permeation Performance for Fiber 1-21-91-1 with $20 \% \mathrm{H}_{2}, 20 \% \mathrm{CO}$, $60 \%$ He Feed Mixture ................................................. C-2

C-1-2 Permeation Performance for Fiber 1-21-91-2 with $20 \% \mathrm{H}_{2}, 20 \% \mathrm{CO}$, $60 \%$ He Feed Mixture ....................................................

C-1-3 Permeation Performance for Fiber 2-20-91-1 with $20 \% \mathrm{H}_{2}, 20 \% \mathrm{CO}$, $60 \%$ He Feed Mixture

C-1-4 Permeation Performance for Fiber 2-20-91-2 with $20 \% \mathrm{H}_{2}, 20 \% \mathrm{CO}$, $60 \%$ He Feed Mixture ...................................................... C-3

C-1-5 Performance of Fiber 2-6-91-1 Potted in High Temperature Epoxy ............. C-4

C-1-6 Performance of Fiber 2-6-91-2 Potted in High Temperature Epoxy ............. C-4

C-2-1 Performance Data for Cells Made with Epoxy Seal ........................... C-6

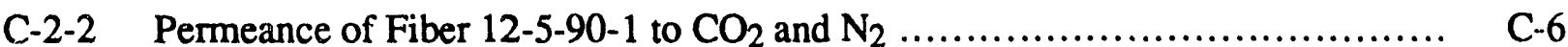

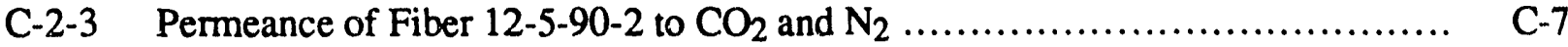

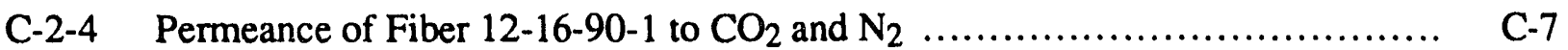

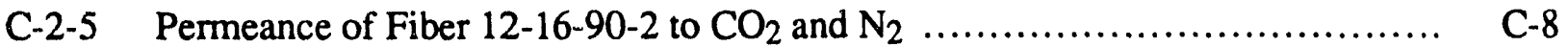

C-3-1 Permeance Behavior of Epoxy Cells ..................................... C-10

C-3-2 Permeance Behavior of Standard Cells ................................. C-11

C-4-1 Synthetic Air Separation with Epoxied Cells .............................. C-12

C-5-1 Pure Component Helium Permeance of High Temperature Test Cells .......... C-14

C-5-2 Pure Component Helium Permeance Data for Fibers 12-16-90-1 and

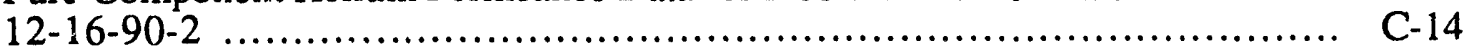

C-5-3 Permeation Data for Fibers Made with Inorganic Seals ....................... C-15

C-5-4 Data for Fibers Made with Inorganic Seals ............................... C-16 


\section{TABLES (Concluded)}

C-5-5 Permeation Data for Fibers Sealed with Aremco 662 Sealant ................... C-17

C-5-6 Permeation Data for Fibers Preheated to $1000^{\circ} \mathrm{F}$................................... C-18

C-5-7 Helium Permeation Data for Fibers Held in Epoxy-Seated Test Cells ............ C-19

C-5-8 Helium Permeation Data for Epoxy Test Cells ................................ C-20

C-6-1 Pure Component Data for Fiber 8914-08-10 ............................... C-22

C-6-2 Carbon Dioxide Permeation Data ............................................. C-23

C-6-3 Carbon Dioxide Permeation Data for Baseline Fibers with Epoxy Seals ......... C-24

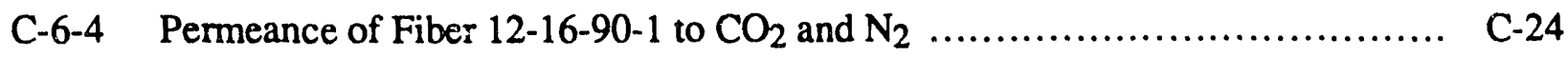

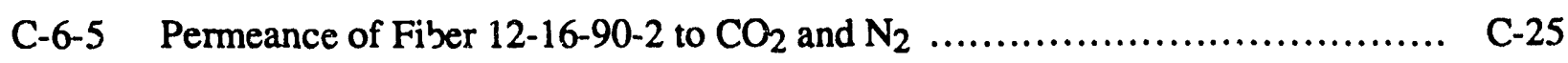

C-6-6 Permeance Performance of Carbon Monoxide ................................ C-25

D-1 Kinetic Diameters of Various Molecules ..................................... D-1 


\section{INTRODUCTION}

The Department of Energy (DOE) is seeking to develop high temperature, high pressure inorganic membrane technology to perform a variety of gas separation processes to improve the efficiency and economics of advanced power generation systems such as direct coal-fueled turbines (DCFT) and the integrated gasification combined cycle process (IGCC). The temperatures encountered in these power generation systems are far above the temperature range for organic membrane materials, which is typically $150^{\circ}$ to $200^{\circ} \mathrm{F}$ for polymers such as silicone rubber, polysulfone, and cellulose esters. Inorganic materials such as ceramics are therefore the most likely membrane materials for use at high temperatures. The possible operating conditions for the product gases from the combustion process in DCFT range in temperature from $1800^{\circ}$ to $2250^{\circ} \mathrm{F}$ and in pressure from 150 to 250 psia. The principal applications for ceramic membrane separation processes are the removal of sulfur and nitrogen oxides from gases before heat recovery and venting to the atmosphere. Because of the low concentrations of $\mathrm{SO}_{2}$ and $\mathrm{NO}_{x}$ produced, (typically less than $1 \%$ of each gas), membrane processes may be most efficiently used in series with an adsorption or scrubbing system as a "polishing" operation to reduce emissions to conform to environmental regulations.

The IGCC process consists of a gasifier to produce synthetic gas used to fuel a gas turbine generator. The temperature and pressure ranges encountered under reducing conditions are $1000^{\circ}$ to $2000^{\circ} \mathrm{F}$ and 200 to $1000 \mathrm{psia}$, respectively. There are several potential applications for a high temperature membrane separation process in the IGCC flowsheet. The membrane could be located downstream of the gasifier to remove acid gases, and to separate $\mathrm{N}_{2}$ and the fuel gas ( $\mathrm{CO}$ and $\mathrm{H}_{2}$ ), which would increase the heating value of the gas and reduce $\mathrm{NO}_{\mathrm{x}}$ formation. As mentioned above, a membrane process could also be used in series with a conventional gas scrubbing process to remove $\mathrm{CO}_{2}$ to reduce the size of the scrubbing process and improve overall process economics. Another potential use of a high temperature gas separation membrane would be to recover $\mathrm{H}_{2}$ as a product from mixtures with $\mathrm{N}_{2}, \mathrm{CO}$, and $\mathrm{CO}_{2}$.

This project focussed on silica glass fiber membranes made by PPG Industries (Pittsburgh, PA). These membranes are not made in commercial quantities, but samples were obtained for this project. The goals were both experimental and theoretical. The first objective was to develop a rational theory for the performance of these membranes. With existing theories as a starting point, a new theory was devised to explain the unusual "molecular sieving" behavior exhibited by these glass membranes (Way and Roberts, 1992). 
An apparatus was then devised for making permeation performance measurements at conditions of interest to DOE (temperatures to $2000^{\circ} \mathrm{F}$; pressures to $1000 \mathrm{psia}$ ). With this apparatus, gas mixtures could be made typical of coal combustion or coal gasification processes (Table 1), these gases could be passed into a membrane test cell, and the separation performance determined. Data were obtained for $\mathrm{H}_{2} / \mathrm{CO}, \mathrm{N}_{2} / \mathrm{CO}_{2}, \mathrm{O}_{2} / \mathrm{N}_{2}$, and $\mathrm{NH}_{3} / \mathrm{N}_{2}$ mixtures and for a variety of pure component gases $\left(\mathrm{He}, \mathrm{H}_{2}, \mathrm{CO}_{2}, \mathrm{~N}_{2}, \mathrm{CO}, \mathrm{NH}_{3}\right)$. Multicomponent data representing a full syn-gas mixture were not taken, but the available data indicate that the components do not interfere with each other. Therefore, the performance of a full syn-gas mixture can reasonably be deduced from the binary and pure component data. The most challenging part of the project turned out to be the sealing of the membrane at high temperatures and pressures. This seal technique will be explained in some detail. The report concludes with an overview of the practical potential of these membranes and of inorganic membranes in general for DOE and other applications.

\section{Table 1}

TYPICAL COMPOSITION FOR COAL COMBUSTION AND COAL GASIFICATION PROCESSES

\section{Temperature System Pressure \\ Gas Composition (Vol \%)}

\section{DCFT* Process}

$1800^{\circ}-2250^{\circ} \mathrm{F}$

$150-250$ psia
IGcct Process

$1000^{\circ}-2000^{\circ} \mathrm{F}$

$200-1000$ psia

$\begin{array}{lcr}\mathrm{N}_{2} & 75.0 & 48.0 \\ \mathrm{O}_{2} & 2.5 & <0.1 \\ \mathrm{CO}_{2} & 15.0 & 5.0 \\ \mathrm{CO} & <0.5 & 21.0 \\ \mathrm{H}_{2} & <0.1 & 20.0 \\ \mathrm{H}_{2} \mathrm{O} & 7.0 & 1.0 \\ \mathrm{SO}_{2} & 0.5 & 0.0 \\ \mathrm{NO}_{x} & 0.1-0.3 & 0.0 \\ \mathrm{CH}_{4} & 0.0 & 4.5 \\ \mathrm{H}_{2} \mathrm{~S} & 0.0 & 0.5 \\ \mathrm{NH}_{3} & 0.0 & 0.3\end{array}$

- Direct coal fired turbine.

$\dagger$ Integrated gasification combined cycle. 


\section{GLASS FIBER MEMBRANES}

PPG Industries produced the glass fiber membranes by spinning a hollow filament of glass fiber from a glass melt containing nonsilica, leachable components (Hammel et al., 1989; Hammel, 1989; Barch and Marshall, 1990). These nonsilica components (such as $\mathrm{ZrO}_{2}, \mathrm{~B}_{2} \mathrm{O}_{3}$ ) and the composition of the glass melt are chosen so that separate phases do not form while the glass solidifies during the fiber forming process. Consequently, the nonsilica components remain atomically dispersed in the silica matrix. When the glass fibers are soaked in concentrated $\mathrm{HCl}$ solution (e.g., $4 \mathrm{~N} \mathrm{HCl}$ ), the nonsilica components are leached and only a minor portion of the silica matrix is etched. Hence the resulting "pore" structure in the fiber wall consists essentially of a three-dimensional array of atomic-sized defects in a silica matrix. These defects have sizes on the order of the size of normal gas molecules ( $3 \AA$ to $7 \AA$ ), and hence the pores allow smaller gases to permeate quickly and larger gases to be essentially blocked.

Fibers tested in this study typically had a 35- $\mu \mathrm{m}$ O.D. and a $24-\mu \mathrm{m}$ I.D. (Figure 1). Under the scanning electron microscope (SEM), the walls of these fibers appear dense and isotropic. Indeed, the nature of the pore distribution (size and space) remains virtually unknown for these materials, since standard methods (e.g., $\mathrm{N}_{2} \mathrm{BET}$ isotherms) cannot measure pores below about $15 \AA$, where most of the pores in this material are believed (on the basis of separation data) to reside. Way, et al., (1992) have measured the adsorption of argon on these materials and on molecular sieves and have curve fit the data according to an assumed adsorption energy potential distribution (Hathaway and Davis, 1990; Horvath and Kawazoe, 1983). The results of these measurements and computations indicate pores in the 4-8 $\AA$ range (Figure 2).

The fibers have a reasonable strength as determined by pulling them to the break point on an Instron Universal Material Testing machine (Table 2). However, the variability from fiber to fiber was a bit bothersome. This variability was not studied in detail, and therefore no statistics are available. 

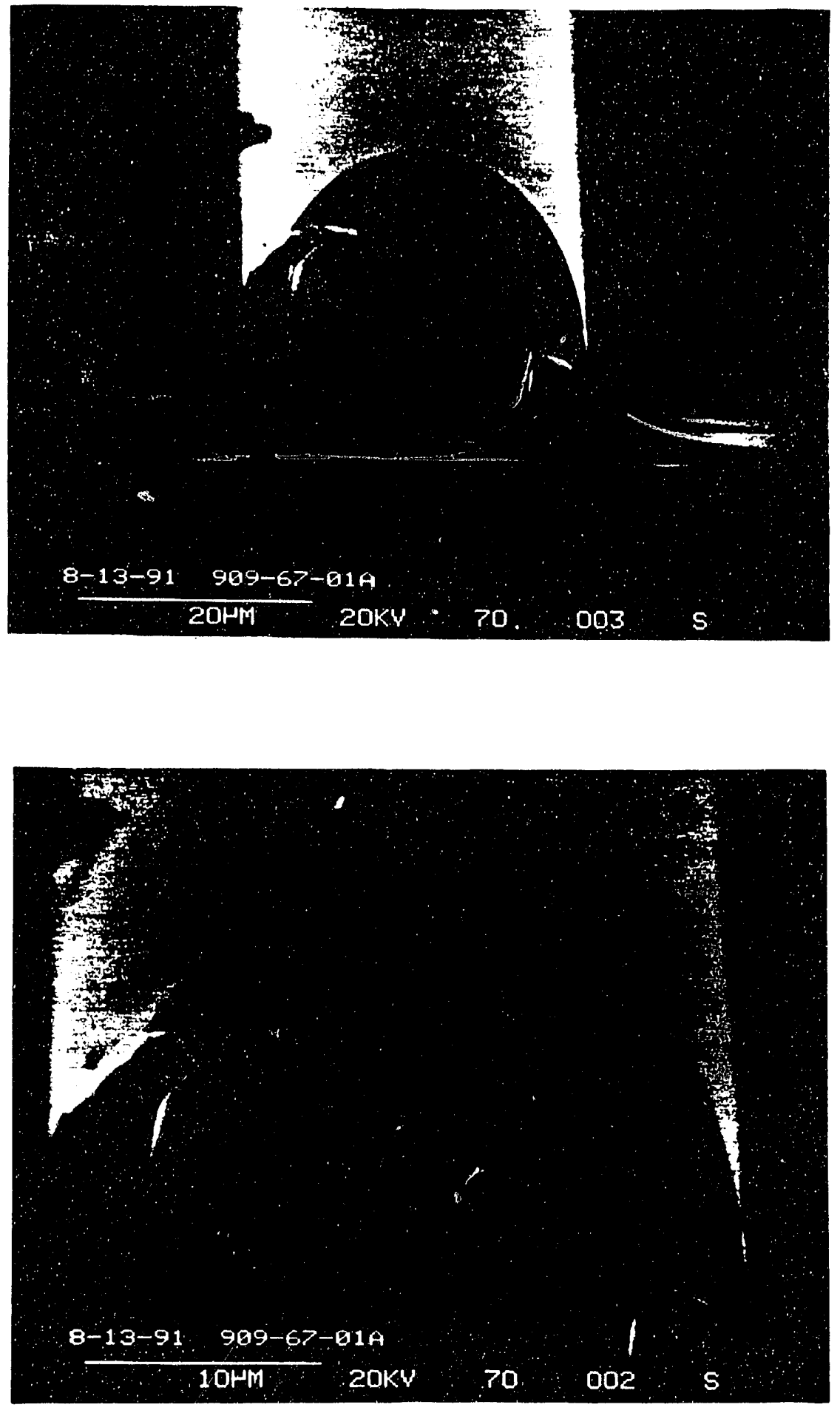

RP-6773-58

Figure 1. Cross-section of glass hollow fiber membranes (PPG Industries). Typical outer diameter is $40 \mu \mathrm{m}$; typical wall thickness is $5 \mu \mathrm{m}$. 


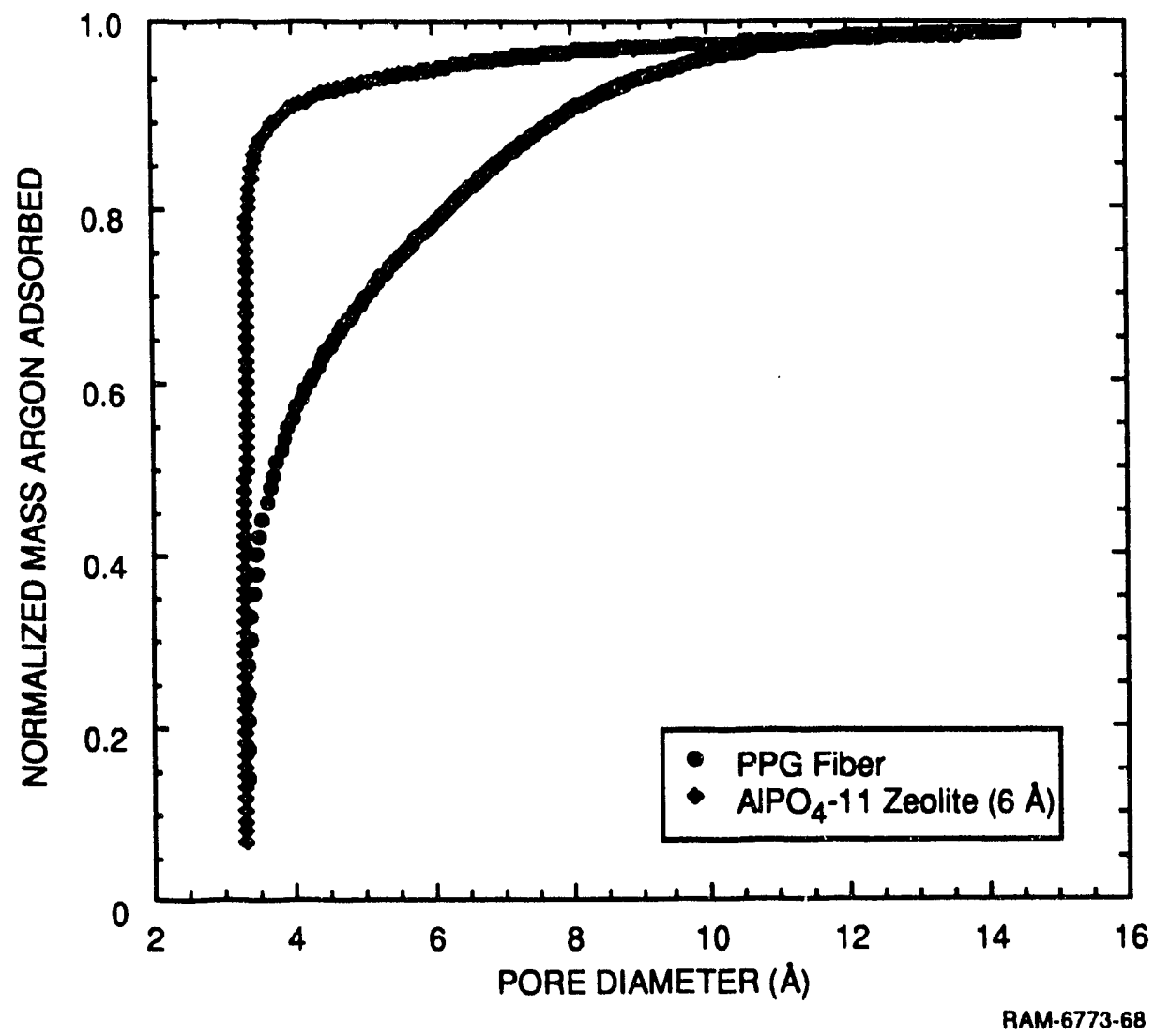

Figure 2. Estimated pore size distribution calculated using the HorvathKawazoe equation for both a $6 \AA$ zeolite and PPG fiber sample No. 4. (Source: Way et al., 1992) 


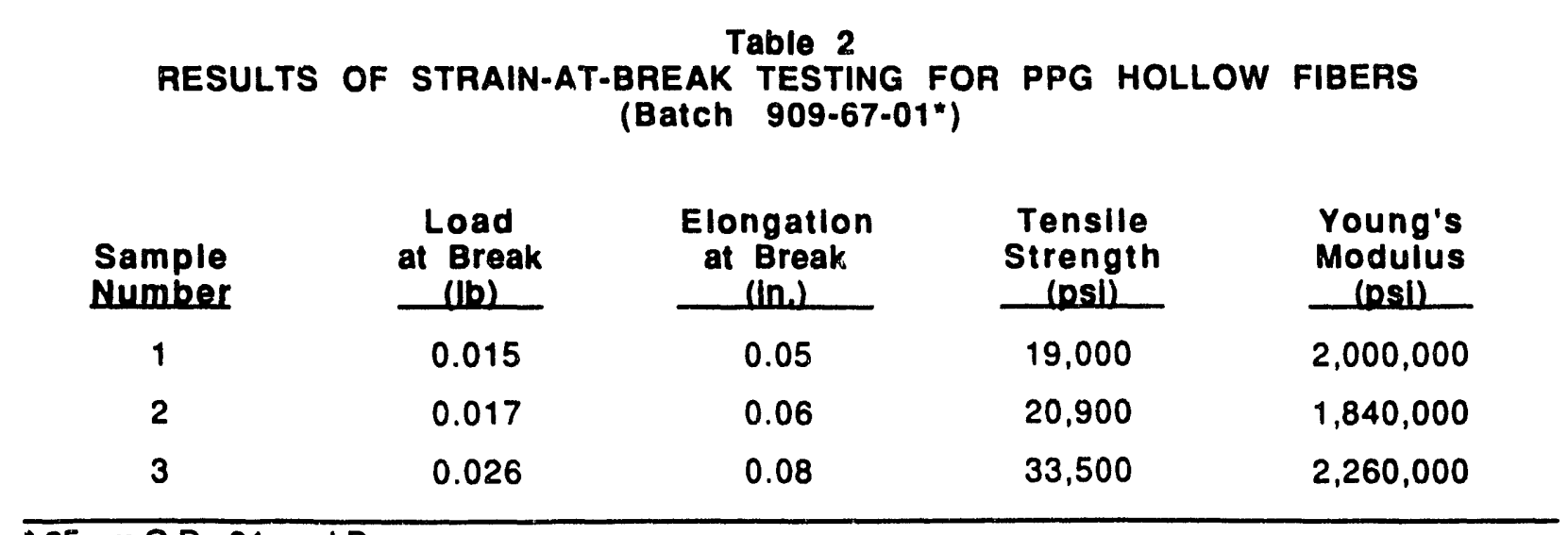

" $35 \mu \mathrm{m}$ O.D., $24 \mu \mathrm{m}$ I.D. 


\section{THEORY OF MULTICOMPONENT GAS PERMEATION THROUGH GLASS MEMBRANES}

The separation of gas mixtures with inorganic membranes has received substantial attention in the recent past because of the possibilities for high temperature gas separations not achievable with ordinary membranes or other gas separation techniques. Possible applications include $\mathrm{H}_{2}$ recovery in refining operations (including water-gas shift processes) and removal of $\mathrm{H}_{2} \mathrm{~S}$ or $\mathrm{NH}_{3}$ in gasification/combined cycle processes.

Whereas some literature exists on mechanisms for transport through inorganic membranes (Hwang and Kammermeyer, 1984), there is no literature guidance on multicomponent gas mixtures such as would be encountered in practical applications. Therefore, simple theories are described below for the permeation of multicomponent gas mixtures through inorganic membranes. Because of the dearth of literature data on such membranes, it is not possible to prove these theories. Nevertheless, an appeal to what is known helps to establish the validity of the concepts put forward. Last, the implications of the theory are discussed for designing and manufacturing commercial inorganic gas separation membranes.

\section{OVERVIEW OF TRANSPORT MECHANISMS}

Motion of a gas through a microporous barrier is generally accomplished with a pressure difference between the sides of the microporous barrier. At minimum, there is a partial pressure difference ${ }^{*}$ for at least one of the species. For barriers with holes fine enough that forced convective flow can be ignored, four separate mechanisms of transport can be envisioned; Knudsen diffusion, surface diffusion, capillary condensation, and molecular sieving; (Figure 3). At the temperatures of interest to DOE, capillary condensation is likely irrelevant and is omitted from the following discussion. The Knudsen diffusion mechanism results from free molecular motion wherein the molecules of gas collide much more frequently with the wall than with each other. This condition obtains when the mean free path of the gas, $\lambda$, is much larger than the pore diameter. This mechanism is well understood (Knudsen, 1909; Hwang and Kammermeyer, 1984), and its primary result is that, when all other factors are equal, the ratio of the flux of species $i$ to that of species $j$ is given by the inverse of the square root of their molecular weight (M) ratio. More specifically, the selectivity, $\alpha_{\mathrm{ij}}$, of the barrier is given by

$$
\alpha_{i j}=\left(M_{i} / M_{j}\right)^{-1 / 2}
$$

\footnotetext{
* The general case is a difference in chemical potential.
} 
$\therefore$ Knuosen dithusion

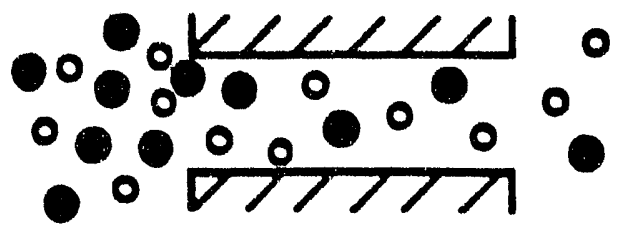

2. Surtace diffusion

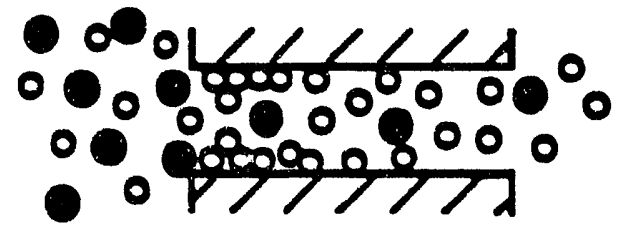

3. Capillary condensation with liquid flow

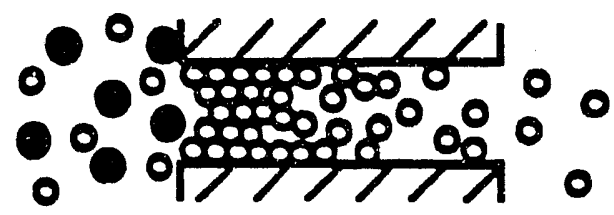

4. Molecular sieving

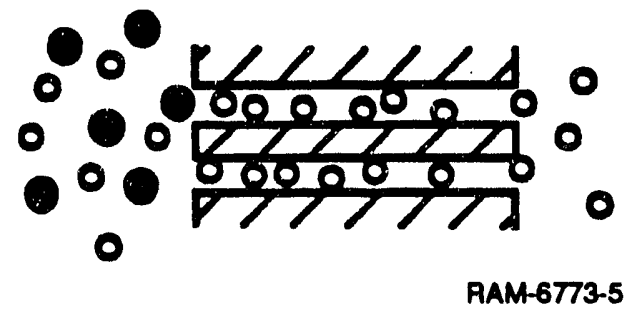

Figure 3. Mechanisms of mass transfer through membranes.

The pore walls of rigid inorganic membranes are stationary, whereas those of polymer membranes exhibit thermal motion. Mechanisms clearly delineated for rigid membranes. 
Because most gaseous species have a molecular weight between 10 and 100 , selectivities are small, and it is not possible to find a gas mixture wherein an economical separation can be made by Knudsen diffusion. Nevertheless, under wartime government funding, the separation of $U^{235}$ from $U^{238}$ was accomplished by this means for lack of a better method (Smyth, 1946; Benedict et al., 1981). A key result of the Knudsen mechanism is that no chemical information is necessary to computic the flux. The molecules are treated like billiard balls, and the pore walls are treated like a billiard table edge with elastic collision properties.

The surface diffusion mechanism refers to the ability of molecules to reside on the surface and hop from point to point "along" the surface, with no apparent residence time in the bulk gas phase above the surface. The surface chemistry of the microporous barrier plays a key role in this mechanism. Surface diffusion can be thought of as occurring when the energy state of the diffusing species is largely dominated by the interaction with the surface. Surface diffusion has largely been associated with the fields of catalysis, adsorption, and electronic device manufacturing (Clark, 1970; Barrer, 1978; Yang, 1987; Sze, 1983). Nevertheless, it is recognized in the membrane literature (Kammermeyer, 1968; Kammermeyer and Wyrick, 1958). Until recently, however, no material other than Vycor glass appeared to exhibit this phenomenon (Uhlhorn, et al., 1988).

The chemistry of the internal pore surface of the barrier and how the surface interacts with diffusing species can be studied by observation of the ability of the barrier to adsorb gases. Consequently, any theory of surface diffusion can be expected to incorporate some aspect of the thermodynamics of adsorbed phases (i.e., adsorption isotherms). Surface diffusion can occur regardless of the size of the pore but is negligible when transport through the bulk of the pore is dominating. As a result, the distance from one side of a pore to the other must generally be much less than 10 atomic diameters before surface diffusion will be significant. This fact leads often to the misconception that surface diffusion "depends" on pore size.

Molecular sieving refers, in its most absolute sense, to the complete blocking of transport of a certain size or shape of molecule and the free passage of smaller or differently shaped molecules. Molecular sieving is strongly and clearly exhibited by zeolites (Barrer, 1978). Other materials (e.g., molecular sieve carbons) exhibit an element of this behavior in their ability to adsorb molecules of slightly difference sizes at dramatically different rates (Nakano, et al., 1991). In molecular sieving, the diffusing molecule is in close and regular contact with both sides of the pore wall (in contrast to surface diffusion, where the diffusing species interact with only one surface at a time). In zeolites, this "pore wall" is the aperture to the inner zeolite cage. In a microporous barrier, a molecule will encounter a series of such "apertures" as it diffuses across the 
barrier, simply because the barrier is three-dimensional and nonuniform in its pore size distribution. Indeed, in an irregular, heterogeneous array of interconnected pores, it is conceivable that a diffusing species would encounter a variety of constrictions wherein molecular sieving is dominant and regions which are intermediate to these restrictions and where surface diffusion or Knudsen diffusion is dominant. In any case, when the pore size is on the order of 2 to 3 molecular diameters, molecular sieving will control the transport.

Although pore size is only a qualitative guide, it is useful to plot the range of pore sizes in which each of the mechanisms is dominant (Figure 4). The broad range shown for the Knudsen mechanism reflects the wide range of mean free path that is encountered in many applications. For example, in a coal gasifier application, the pressure may be 515 psia on one side of the barrier, and 15 psia on the other. At these pressures and at $2000^{\circ} \mathrm{F}$, the mean free path will vary from about 90 $\AA$ on the high pressure sicie of the barrier to $3000 \AA$ on the low pressure side. This variation in the mean free path could be a complication in some situations. For membranes capable of exhibiting molecular sieving, the variation in mean free path across the film is, however, of no importance.

\section{FLUX EQUATION FOR MULTICOMPONENT KNUDSEN, SURFACE, AND MOLECULAR SIEVE DIFFUSION}

A good starting point is the simple relationship

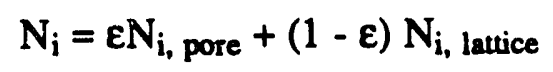

where $\varepsilon$ is the area void fraction, $N_{i}$, pore is the flux through the pores of the membrane (moles per unit pore area per unit time), $\mathrm{N}_{\mathrm{i}}$, latice is the flux through the solid lattice of the membrane (moles per unit solid area per unit time), and $\mathrm{N}_{\mathrm{i}}$ is the total flux of species $\mathrm{i}$ through the membrane (moles per unit total area per unit time). Generally speaking, the diffusion through a solid is much slower than that through any kind of pore (Barrer, 1951). Hence, we negiect lattice diffusion. However, in the limit of very small pores, molecular sieving will behave like solid lattice diffusion.

Capillary condensation is not addressed here in detail because it is likely to be insignificant in a wide range of applications. Permeating molecules may exist in the gas phase near or far from the internal surfaces of the microporous barrier, and they may exist on the surface. Transport through the gas phase is controlled by the Knudsen or molecular sieving mechanism, and transport on the surface is controlled by surface diffusion. The net flux of species $i$ is given by the sum of the surface and gas phase fluxes:

$$
N_{i}=-\varepsilon D_{i} \nabla C_{i}-\varepsilon A D_{i}^{s} \nabla C_{i}^{s}
$$




\section{Surface}

Diffusion

\section{Molecular Sieving}

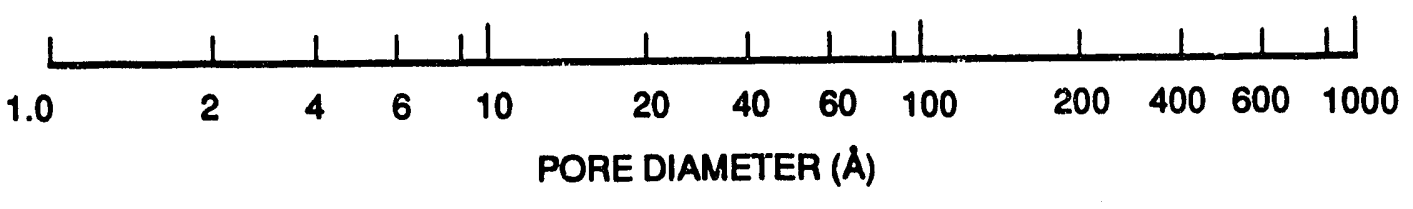

Figure 4. Approximate operative pore size ranges for various mechanisms.

We have assumed a typical penetrant diameter of $4 \mathrm{~A}$ for placing the range for surface diffusion and molecular sieving. 
where $D_{i}$ is the diffusion coefficient for species $i$ in the internal pore gas phase, $C_{i}$ is the concentration of species $i$ in the internal pore gas phase, $A$ is the area of internal pore surface per unit total membrane volume, $D_{i}^{S}$ is the surface diffusion coefficient of species $i$ on the internal pore surface, and $C_{i}^{s}$ is the concentration (moles per unit area) of species $i$ on the internal pore surface.

Previous investigators (Reed and Ehrlich, 1981) have taken the viewpoint of expressing the surface concentration in terms of a fractional coverage, $\theta$. The equations derived by Reed and Ehrlich (e.g., Eq. 12, on p. 591 of that reference) are special cases for simple surface thermodynamics. This approach does not apply for multicomponent adsorption because the amount of any species $i$ that can be adsorbed by a surface depends on the concentrations of the other species present.

The quantity $\mathrm{AC}_{\mathrm{i}}^{\mathrm{s}}$ is related to the moles of species $\mathrm{i}$ adsorbed per unit mass of adsorbent, $\mathrm{n}_{\mathrm{i}}$, by the equation

$$
A C_{i}^{s}=\rho_{s}(1-\varepsilon) n_{i}
$$

where $\rho_{S}$ is the mass density of the native adsorbent material (assuming the area void fraction, $\varepsilon$, equals the volume void fraction). The quantity $n_{\mathrm{i}}$ can be measured experimentally. Hence, the flux can be written

$$
N_{i}=-\varepsilon D_{i} \nabla C_{i}-\varepsilon D_{i}^{s} \rho_{s}(1-\varepsilon) \nabla n_{i}
$$

The gradient of the adsorbed quantity of species $\mathrm{i}, \nabla \mathrm{n}_{\mathrm{i}}$, is related to the gradient of the gas phase concentrations. In a one-dimensional system (that is, one spatial dimension),

$$
\nabla n_{i}=\frac{d n_{i}}{d r}
$$

(the symbol " $r$ " designates the one spatial dimension). So, with the chain rule,

$$
\frac{d n_{i}}{d r}=\sum_{j=1}^{N} \frac{\partial n_{i}}{\partial C_{j}} \frac{d C_{j}}{d r}
$$

For an ideal gas, Eq. 7 becomes

$$
\frac{d n_{i}}{d r}=R T \sum_{j=1}^{N} \frac{\partial n_{i}}{\partial P_{j}} \frac{d C_{j}}{d r}
$$

where $P_{j}$ is the partial pressure of species $j, R$ is the universal gas constant, and $T$ is the absolute temperature. 
Therefore, the flux in a one-dimensional system is given by

$$
N_{i}=-\varepsilon D_{i} \frac{d C_{i}}{d r}-\varepsilon D_{i}^{s} R T \rho_{s}(1-\varepsilon) \sum_{j=1}^{N} \frac{\partial n_{i}}{\partial P_{j}} \frac{d C_{j}}{d r}
$$

In a three-dimensional space, Eq. 9 can be generalized to

$$
\bar{N}=-\varepsilon[D] \cdot \nabla \bar{C}-\varepsilon \rho_{s}(1-\varepsilon)\left[D^{s}\right] \cdot([M] \cdot \nabla \bar{C})
$$

where the diffusion coefficient matrices, $[D]$ and $\left[D^{s}\right]$, are diagonal

$$
\begin{aligned}
& {[D]=\left(\begin{array}{cccc}
D_{1} & & & 0 \\
& D_{2} & \ddots & \\
0 & & & D_{N}
\end{array}\right)} \\
& {\left[D^{s}\right]=\left(\begin{array}{cccc}
D_{1}^{s} & & & 0 \\
& D_{2}^{s} & & \\
& & \ddots & \\
0 & & & D_{N}^{s}
\end{array}\right)}
\end{aligned}
$$

the concentration vector $\overline{\mathrm{C}}$ is given by a column vector

$$
\overline{\mathrm{C}}=\left(\begin{array}{c}
\mathrm{C}_{1} \\
\mathrm{C}_{2} \\
\vdots \\
\mathrm{C}_{\mathrm{N}}
\end{array}\right)
$$

the flux vector $\bar{N}$ is given by the column vector

$$
\left(\begin{array}{c}
N_{1} \\
N_{2} \\
\vdots \\
N_{N}
\end{array}\right)
$$

and $\mathrm{M}$ is an $\mathrm{N} \times \mathrm{N}$ matrix with entries

$$
M_{i j}=R T \frac{\partial n_{i}}{\partial P_{j}}
$$

( $\mathrm{i}=$ row, $\mathrm{j}=$ column). 
The physical meaning of the partial derivative $\partial \mathrm{n}_{\mathrm{i}} / \partial \mathrm{P}_{\mathrm{j}}$ in Eqs. 8 and 15 is the change in the number of moles of species $i$ on the surface for a given change in the partial pressure of any species $\mathrm{j}$ above the surface. For a single component gas, this term is the slope of the pure component isotherm, derived from experimental data. For a multicomponent gas, this term could also, in principle, be determined from multicomponent adsorption data. In practice, multicomponent data are very difficult to obtain. Since one needs to take a nearly infinite number of data points to map the range of compositions one may encounter in a given application, there is a strong incentive to relate multicomponent isotherms (represented by the term $\partial \mathrm{n}_{i} / \partial \mathrm{P}_{\mathrm{j}}$ ) to pure-component isotherms.

Whereas it can be seen from Eq. 10 that the flux of species $i$ through the membrane can be written in terms of the familiar gradient of the gas phase concentration, an interesting simplified formula can be obtained in the case of constant diffusion coefficients and in one spatial dimension. In general, when there is no chemical reaction in the membrane, we have

$$
\nabla \cdot N_{i}=0
$$

Consequently, Eq. 5 becomes

$$
D_{i} \nabla^{2} C_{i}+D_{i}^{s} \rho_{s}(1-\varepsilon) \nabla^{2} n_{i}=0
$$

where it is assumed that the products $\varepsilon D_{i}$ and $\varepsilon D_{i}^{s} \rho_{s}(1-\varepsilon)$ are both constant (i.e., have no spatial variation). One might expect the assumption of constant diffusivities to be inaccurate when the transport is dominated by molecular sieving. Nevertheless, in one-dimensional flat sheet or hollow fiber membrane geometries, Eq. 17 can be integrated to give the flux of each species in terms of the known boundary concentrations of the diffusing species:

For a flat sheet,

$$
N_{i}=\frac{\varepsilon D_{i}}{L}\left[C_{i}(0)-C_{i}(L)\right]+\frac{\varepsilon D_{i}^{s}}{L} \rho_{s}(1-\varepsilon)\left[n_{i}(0)-n_{i}(L)\right]
$$

and for a hollow fiber,

$$
N_{i}=\frac{\varepsilon D_{i}}{r_{0} \ln \left(\frac{r_{0}}{r_{i}}\right)}\left[C_{i}\left(r_{0}\right)-C_{i}\left(r_{i}\right)\right]+\frac{\varepsilon D_{i}^{s} \rho_{s}(1-\varepsilon)}{r_{0} \ln \left(\frac{r_{0}}{r_{i}}\right)}\left[n_{i}\left(r_{0}\right)-n_{i}\left(r_{i}\right)\right]
$$


where the flat sheet thickness is $\mathrm{L}$, the hollow fiber outer radius is $\mathrm{r}_{0}$, and the hollow fiber inner radius is $r_{i}$. In these equations, the gas phase concentration terms $C_{i}(0), C_{i}(L)$ or $C_{i}\left(r_{0}\right), C_{i}\left(r_{i}\right)$ and the adsorption terms $n_{i}(0), n_{i}(L)$, or $n_{i}\left(r_{0}\right), n_{i}\left(r_{i}\right)$ are known in terms of the gas phase partial pressures on the boundaries $P_{i}(0), P_{i}(L)$ or $P_{i}\left(r_{0}\right), P_{i}\left(r_{i}\right)$. The adsorbed amounts, $n_{i}$, are related to the known gas phase partial pressures $\left(\mathrm{P}_{1}, \mathrm{P}_{2}, \ldots \mathrm{P}_{\mathrm{i}}, \ldots \mathrm{P}_{\mathrm{N}}\right)$ by multicomponent isotherms.

These isotherms can be measured experimentally but are preferably calculated from single component data by some theory such as the ideal adsorbed solution (IAS) theory (Myers and Prausnitz, 1965).

The diffusion coefficient $D_{i}$ in Eqs. 18 or 19 will be the standard Knudsen diffusion coefficient when the pore size is much smaller than the mean free path but larger than 3 or 4 molecular diameters (where molecular sieving takes over). For Knudsen diffusion, the diffusion coefficient is given by (Knudsen, 1909)

$$
\mathrm{D}_{\mathrm{i}, \mathrm{Kn}}=\frac{8 \mathrm{r}}{3}\left(\frac{\mathrm{RT}}{2 \pi \mathrm{M}_{\mathrm{i}}}\right)^{1 / 2}
$$

For molecular sieving, the value of $D_{i}$ will depend on the activation energy for passing through a pore (see below). Since pore size varies throughout any real microporous barrier, $D_{i}$ can be expected to depend on location within the barrier. In Knudsen diffusion and molecular sieving, there is (at least to a first approximation) no effect of the presence of other diffusing species. Experimental data given below support this expectation. Therefore, only surface diffusion, in which the amount of adsorbed species i depends on the partial pressures of all species, will exhibit multicomponent effects.

\section{MULTICOMPONENT KNUDSEN DIFFUSION}

Multicomponent Knudsen diffusion is no different than single component Knudsen diffusion, since the essence of the theory is that molecules strike the walls of the pores much more frequently than they strike each other. Therefore, for right-angle cylindrical pores of radius $r$, the diffusion coefficient is given by (Knudsen, 1909)

$$
D_{i, K n}=\left(\frac{8 r}{3}\right)\left(\frac{R T}{2 \pi M_{i}}\right)^{1 / 2}
$$

For real microporous barriers, the geometry is complex and a single value of $r$ is insufficient to describe the transport. Nevertheless, there are methods of establishing a "geometric factor," $G_{i}$, so that 


$$
D_{i, K n}=G_{i}\left(\frac{R T}{2 \pi M_{i}}\right)^{1 / 2}
$$

The Knudsen diffusion coefficient depends on $\mathrm{T}^{1 / 2}$.

\section{MULTICOMPONENT SURFACE DIFFUSION}

According to previous investigators, the flux by way of surface diffusion for a pure component through a microporous membrane follows the form

$$
N_{i}^{s}=K_{i}\left(\frac{T}{M_{i}}\right)^{1 / 2} \exp \left(\frac{\Delta_{i}}{T}\right)
$$

where $M_{i}$ is the molecular weight of species $i$ and $K_{i}$ and $\Delta_{i}$ are characteristic constants for species $i$, these constants depending on the molecular diameter (Hwang, 1966; Tock and Kammermeyer, 1969). Experimental verification of this approach to surface diffusion has been satisfactory (Tock and Kammermeyer, 1969; Hwang and Kammermeyer, 1984). For binary or multicomponent mixtures, application of this theory requires the assumption that the individual species are noninteracting on the surface. However, the higher the pressure, the less adequate such an assumption is.

To account generally for multicomponent behavior, ideal adsorbed solution (IAS) theory can be used for the multicomponent thermodynamics of the adsorbed phase (Myers and Prausnitz, 1965). Appendix A gives a detailed derivation of the adsorption term, $\partial \mathrm{n}_{\mathrm{j}} / \partial \mathrm{P}_{\mathrm{j}}$, that appears in the flux equation (Eq. 9). With these expressions for $\partial n_{j} / \partial P_{j}$, the surface diffusion contribution to the flux can, in principle, be computed. The temperature dependence of the surface diffusion is quite complex, but it is expected to decrease in importance above $550^{\circ} \mathrm{F}$.

\section{MULTICOMPONENT MOLECULAR SIEVE DIFFUSION}

Molecular sieving is an activated process wherein a given diffusing species experiences an activation energy barrier, $E_{i}$, to passing through a constriction in the microporous media. $A$ diagram of this concept (Figure 5) indicates that a diffusing molecule may be forced to pass through a number of such constrictions in a real microporous barrier. Furthermore, the rate of transport is likely to be controlled by the constriction with the largest activation energy. In this controlling constriction, the pores are so small that no other gas species is present. Hence, single component and multicomponent molecular sieving are expected to be the same. However, the location and size of the controlling activation energy barrier can be different for each species. Because of the three-dimensional and nonuniform nature of the pore structure, the diffusion coefficient likely varies substantially with position in the membrane. 


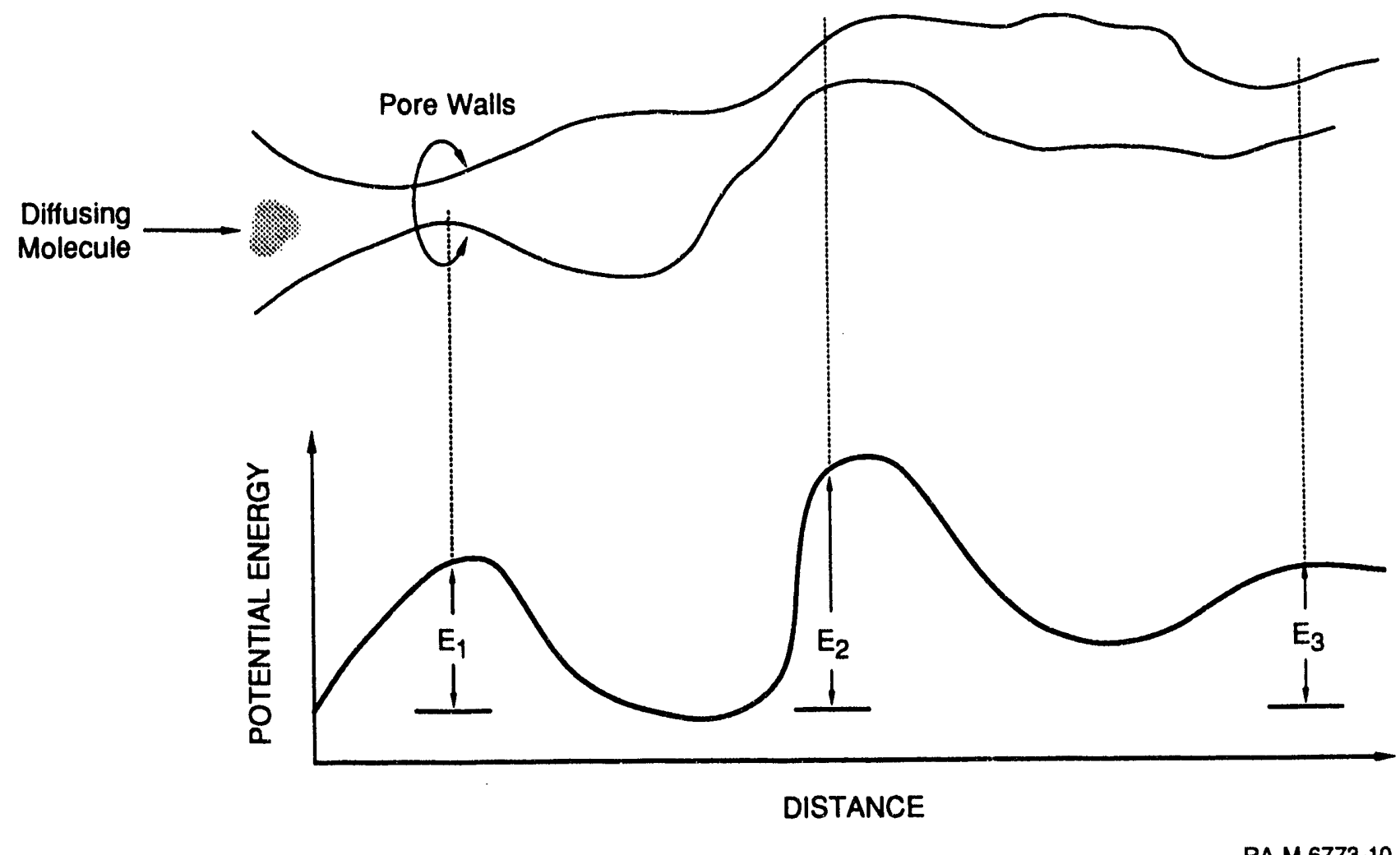

Figure 5. Conceptual diagram of diffusion through molecule-sized holes (molecular sieve diffusion). Molecules pass through constrictions and experience energy fields as a result of their own size and the nature of the pore walls. The rate of diffusion is likely controlled by the largest activation energy barrier. 
With this type of concept, the molecular sieving diffusion coefficient, $D_{i, m s}$, can be expected to follow the form

$$
D_{i, m s}=D_{i, m s}^{Q} \exp \left(-\frac{E_{i}}{R T}\right)
$$

Consequently, the temperature dependence of the permeation through a molecular sieving material can be expected to be an exponential one.

Furthermore, the magnitude of the activation energy barrier can be estimated by considering the energetics of adsorption, since, fundamentally, the passage through a small pore of molecular dimensions is governed by molecular interactions of the diffusing species with the pore surface atoms. The potential energy of the diffusing molecule is a result of several factors (Barrer, 1978): dispersion forces $\left(\phi_{D}\right)$, close range repulsion $\left(\phi_{R}\right)$, polarization $\left(\phi_{P}\right)$, field-dipole $\left(\phi_{F} \mu\right)$ interactions, and field gradient-quadruple interaction ( $\phi \mathrm{FQ})$. Mathematically, the total potential energy is the sum of these individual energies

$$
\phi=\phi_{D}+\phi_{R}+\phi_{P}+\phi_{F \mu}+\phi_{\mathrm{PQ}}
$$

Various expressions exist for these forces; all of them are attractive except the close-range repulsion forces, represented by $\phi_{R}$. The discussion can be simplified by considering only the simple attractive dispersion forces and the close-range repulsive forces. The terms $\phi_{D}$ and $\phi_{R}$ are commonly represented by the Lennard-Jones potential:

$$
\phi_{D}+\phi_{R}=-2 \varepsilon\left(\frac{r^{*}}{r}\right)^{6}+\varepsilon\left(\frac{r^{*}}{r}\right)^{12}
$$

or

$$
\phi_{D}+\phi_{R}=4 \varepsilon\left[\left(\frac{\sigma}{r}\right)^{12}-\left(\frac{\sigma}{r}\right)^{6}\right]
$$

where

$$
r^{*}=2^{1 / 6} \sigma
$$

In these equations, $\sigma$ is the "hard sphere" kinetic diameter, and $\varepsilon$ is the potential energy minimum when the intermolecular distance, $r$, is equal to $r^{*}$ (see Appendix IV of Hill, 1960). Equations 25 and 26 apply to interaction of two like molecules. Pairwise interaction rules for unlike molecules are as follows:

$$
\varepsilon_{\mathrm{AB}}=\left(\varepsilon_{\mathrm{A}} \varepsilon_{\mathrm{B}}\right)^{1 / 2}
$$

and 


$$
\sigma_{\mathrm{AB}}=\frac{1}{2}\left(\sigma_{\mathrm{A}}+\sigma_{\mathrm{B}}\right)
$$

Because of the 12th power of $r$ in Eq. 26, the potential energy goes up dramatically as $r$ gets smaller than $\sigma$. Some values of $\varepsilon$ and $\sigma$ are given in Table 3 ( $\mathrm{k}$ is the Boltzmann constant).

As an example, consider the diffusion of a hydrogen molecule through a molecule-sized hole in an inorganic membrane (Figure 6). As a first approximation, the potential energy of the diffusing species at the pore mouth will be the sum of the potentials for each surface-bound hydrogen atom

$$
\phi=8 \varepsilon_{\mathrm{H}_{2} / \mathrm{H}_{2}}\left[\left(\frac{\sigma}{\mathrm{r}}\right)^{12}-\left(\frac{\sigma}{\mathrm{r}}\right)^{6}\right]
$$

The minimum energy path for a diffusing molecule is exactly in the middle of the pore mouth. Hence, the value of $r$ for Eq. 30 is the pore radius, $\mathrm{r}_{\mathrm{p}}$, regardless of the size of the diffusing molecule. Also, the meaning of pore diameter is the centerline-to-centerline distance between surface atoms across the pore. If this pore diameter is $5.6 \AA$ (corresponding to a free distance of about $2.8 \AA$ from the outer edge of the surface hydrogen atoms), then for the diffusing hydrogen molecule the potential is

$$
\phi_{\mathrm{H}_{2}}=8 \varepsilon_{\mathrm{H}_{2} / \mathrm{H}_{2}}\left[\left(\frac{2.928}{2.8}\right)^{12}-\left(\frac{2.928}{2.8}\right)^{6}\right]
$$

or

$$
\phi_{\mathrm{H}_{2}}=8 \varepsilon_{\mathrm{H}_{2} / \mathrm{H}_{2}}(0.4022)
$$

Here, the spatial term has been kept separate $(0.4022)$; note that the potential is positive, indicating a slight repulsion of $\mathrm{H}_{2}$ from the pore. If a nitrogen molecule approaches the same pore, the potential is given by

$$
\phi_{\mathrm{N}_{2}}=8 \cdot \varepsilon_{\mathrm{N}_{2} / \mathrm{H}_{2}}\left[\left(\frac{\sigma_{\mathrm{H}_{2} / \mathrm{N}_{2}}}{2.8}\right)^{12}-\left(\frac{\sigma_{\mathrm{H}_{2} \mathrm{~N}_{2}}}{2.8}\right)^{6}\right]
$$

or

$$
\begin{aligned}
\phi_{\mathrm{N}_{2}} & =8 \cdot \varepsilon_{\mathrm{N}_{2} / \mathrm{H}_{2}}\left[\left(\frac{3.313}{2.8}\right)^{12}-\left(\frac{3.313}{2.8}\right)^{6}\right] \\
& =8 \cdot \varepsilon_{\mathrm{N}_{2} / \mathrm{H}_{2}}(4.785)
\end{aligned}
$$




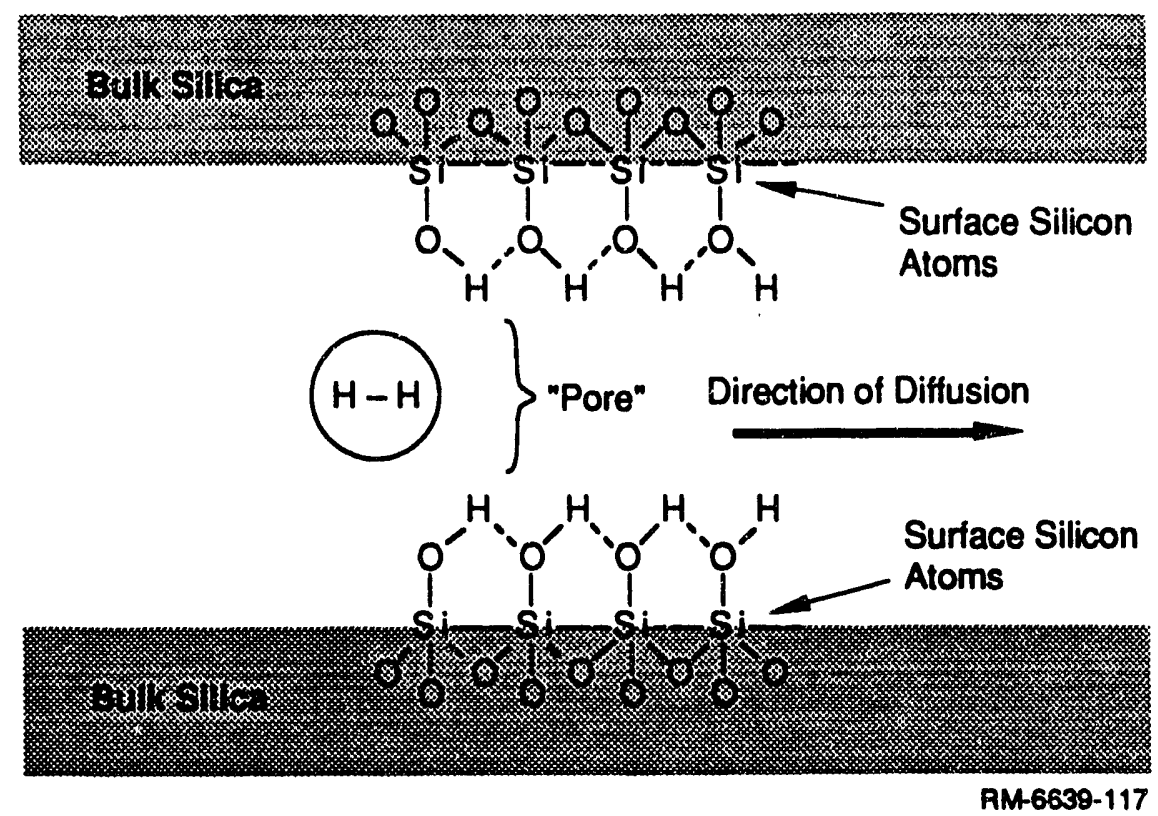

Figure 6. Detailed diagram of diffusion through molecular-sized pore.

The pore is an atomic cavity between surface hydroxyl groups on a silica surface. 
Here, the potential is positive, indicating a net repulsion of $\mathrm{N}_{2}$ from the pore. In addition, the magnitude of the repulsive "position" term in the potential (4.785) is 10 times larger than the repulsive position term for the diffusing hydrogen molecule (Eq. 32). Using the values for $\varepsilon$ from Table 3 and the "mixing rule" (Eq. 28), the potentials are given by

\begin{tabular}{|c|c|c|c|}
\hline & LENNARD-JONES & $\begin{array}{l}3 \\
\text { PARAMETERS }\end{array}$ & \\
\hline Molecule & $\varepsilon / k^{\circ}{ }^{\circ} \mathrm{K}$ & $\perp(\AA)$ & $\sigma(A)$ \\
\hline $\mathrm{He}$ & 10.22 & 2.869 & 2.556 \\
\hline $\mathrm{Ne}$ & 34.9 & 3.12 & 2.78 \\
\hline $\mathrm{H}_{2}$ & 37.00 & 3.287 & 2.928 \\
\hline $\mathrm{Ar}$ & 119.8 & 3.822 & 3.405 \\
\hline $\mathrm{O}_{2}$ & 118 & 3.88 & 3.46 \\
\hline $\mathrm{Kr}$ & 171 & 4.04 & 3.60 \\
\hline $\mathrm{N}_{2}$ & 95.05 & 4.151 & 3.698 \\
\hline $\mathrm{CH}_{4}$ & 148.2 & 4.285 & 3.817 \\
\hline$x_{e}$ & 221 & 4.60 & 4.10 \\
\hline
\end{tabular}

$$
\begin{gathered}
\phi_{\mathrm{H}_{2}}=1.643 \cdot 10^{-14} \mathrm{erg} \\
(237 \mathrm{cal} / \mathrm{mol})
\end{gathered}
$$

and

$$
\phi_{\mathrm{N}_{2}}=3.133 \cdot 10^{-13} \mathrm{erg}
$$

$(4510 \mathrm{cal} / \mathrm{mol})$

Hence, this pore provides almost no resistance to the diffusion of a hydrogen molecule but provides a $4.5 \mathrm{kcal} / \mathrm{mol}$ barrier to the diffusion of a nitrogen molecule.

Clearly, a full analysis of molecular sieving will take years of study, but it is important to observe that, since the term $\sigma$ in the Lennard-Jones potential is a typical measure of size and the ratios $(\sigma / \mathrm{r})^{12}$ and $(\sigma / \mathrm{r})^{6}$ appear in an exponential term (Eq. 23), molecules of only slightly different "size" ( $\sigma$ values) can have large differences in diffusion rate, a factor that leads to large selectivities. In fact, to a first approximation, the selectivity implied by the molecular sieving mechanism (Eq. 23) is given by 


$$
\alpha_{i j}=\frac{\exp \left\{-\frac{8 \varepsilon_{i s}}{k T}\left[\left(\frac{\sigma_{i s}}{r_{c}}\right)^{12}-\left(\frac{\sigma_{i s}}{r_{c}}\right)^{6}\right]\right\}}{\exp \left\{-\frac{8 \varepsilon_{j s}}{k T}\left[\left(\frac{\sigma_{j s}}{r_{c}}\right)^{12}-\left(\frac{\sigma_{j s}}{r_{c}}\right)^{6}\right]\right\}}
$$

where $\varepsilon_{\mathrm{is}}, \varepsilon_{\mathrm{js}}$ and $\sigma_{\mathrm{is}}, \sigma_{\mathrm{js}}$ are the Lennard-Jones parameters for species $\mathrm{i}$ and $\mathrm{j}$ for interaction with the surface, and $r_{c}$ is the pore radius of the pore that controls the diffusion of the faster of the two species $(i, j)$. For example, for the hydrogen and nitrogen calculation example described above, at $158^{\circ} \mathrm{F}$ (343 K), Eq. 38 yields

$$
\alpha_{\mathrm{H}_{2} \mathrm{~N}_{2}}=1060
$$

This value indicates that large separation factors are possible, in accord with observed data (see Way and Roberts, 1992). The theory is hampered by a substantial uncertainty in the correct value for $r_{c}$ in Eq. 38. Nevertheless, the theory makes clear why small pores on the order of the Lennard-Jones $\sigma$ parameter values can separate (molecularly "sieve") molecules that are less than one angstrom unit different in size.

\section{COMMERCIAL MANUFACTURING OF MOLECULAR SIEVE MEMBRANES}

Because of the extremely sensitive dependence of the selectivity on pore size (Ell. 38), one can expect the pore size control necessary for routine, reproducible manufacturing to be much more severe than for ordinary polymer membranes. Conversely, however, random structures such as ordinary polymer membranes cannot exhibit the selectivity possible with the molecular sieving mechanism. The attractiveness of the molecular sieving mechanism, in any case, will likely prove to be its most difficult aspect as well. 


\section{PERMEATION TEST APPARATUS}

This section describes the methods for permeation testing, including methods for mixing multicomponent gases and for holding single hollow glass fibers in a test cell. The methods of data reduction are also explained.

\section{FLOW SYSTEM FOR PERMEATION TESTS}

A plumbing system was constructed capable of mixing up to six gases, delivering this gas mixture to as many as four test cells, and analyzing the permeate and residue (nonpermeate) gas streams from each test cell (Figure 7). The central point of the apparatus was an oven (Barnstead/Thermolyne, Model 30400 , Dubuque, IA) capable of temperatures to $1800^{\circ} \mathrm{F}$. The oven cavity had dimensions of $14 \times 14 \times 14-1 / 2$ in. $(35.6 \times 35.6 \times 36.8 \mathrm{~cm})$. This cavity could accommodate four test cells each approximately $8 \mathrm{in} .(20.3 \mathrm{~cm})$ long.

The mass flow controllers were Brooks Model 5850E (Hatfield, PA). These controllers provide full scale flows of 20 to 500 standard cubic centimeters per minute ( $\mathrm{sccm}$ ) depending on the size of the internal orifices. The controllers were commanded with a Tylan-General Model RO28 (Torrance, CA) control box. This device also indicates the flow rates going through the controllers. The flow rate of the permeate and residue streams were measured with bubble flow meters. For the residue flows the bubble flow meter was a product supplied by Supelco (Bellefonte, PA, Model Z-0427), essentially a 500-mL burette. The typical residue (and feed) flow war about $100 \mathrm{sccm}$. For the permeate flows, the bubble flow meter was a product also supplied by Supelco (Model Z-3762), essentially a 500- $\mu \mathrm{L}$ burette. The typical permeate flow was 0.1 to $1.0 \mathrm{sccm}$. Helium was sometimes used on the permeate side to pick up the permeate and carry it readily to the chromatograph for analysis.

The composition of the residue and permeate streams were measured with gas chromatography (thermal conductivity detectors). The chromatograph was a Hewlett-Packard Model 5890, Series II, with two 10-port valves. We handled the injection sequence and data acquisition automatically with the Hewlett-Packard ChemStation computer control. We could acquire data on a 24- $h$ basis with this automated control. 


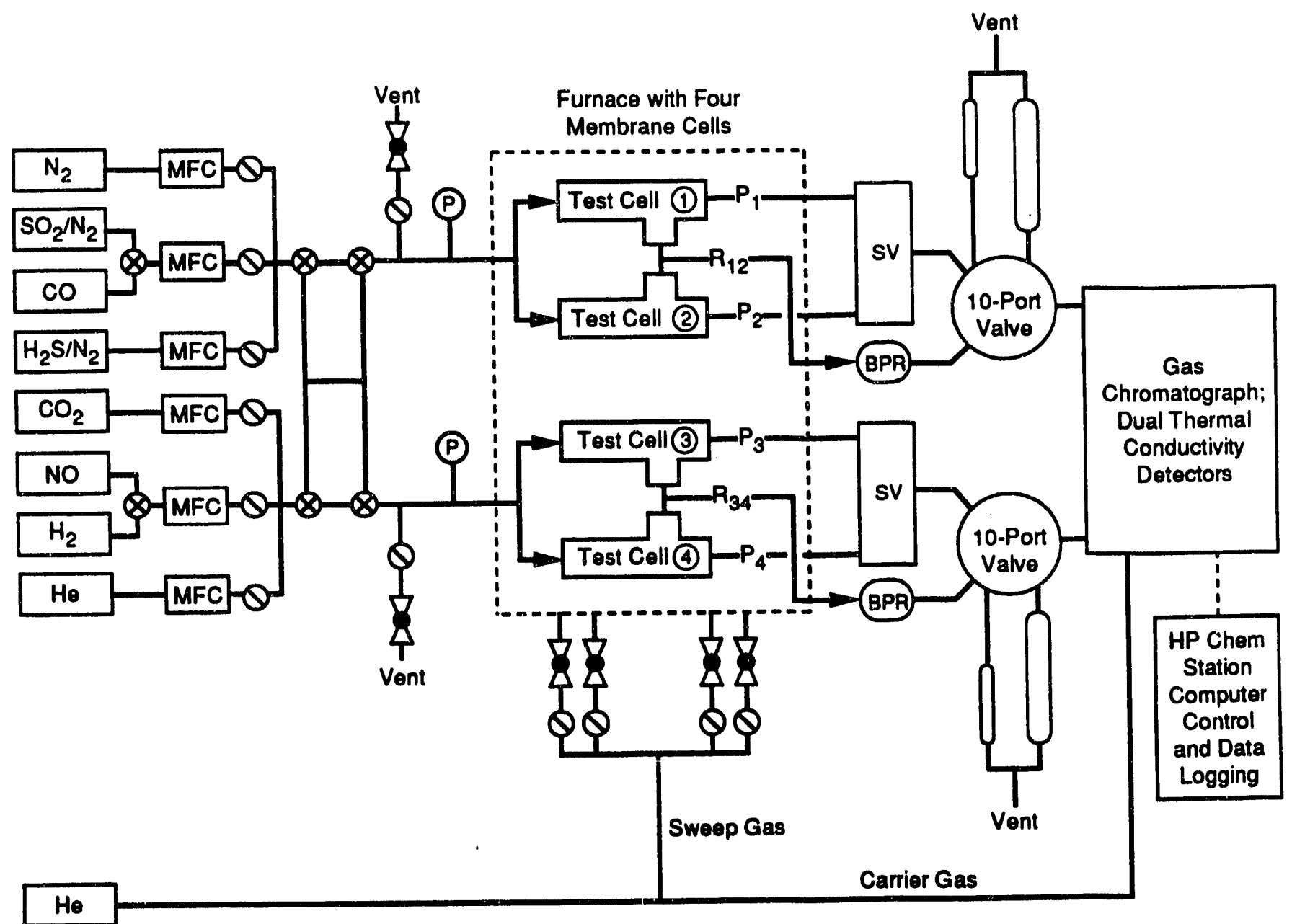

Legend

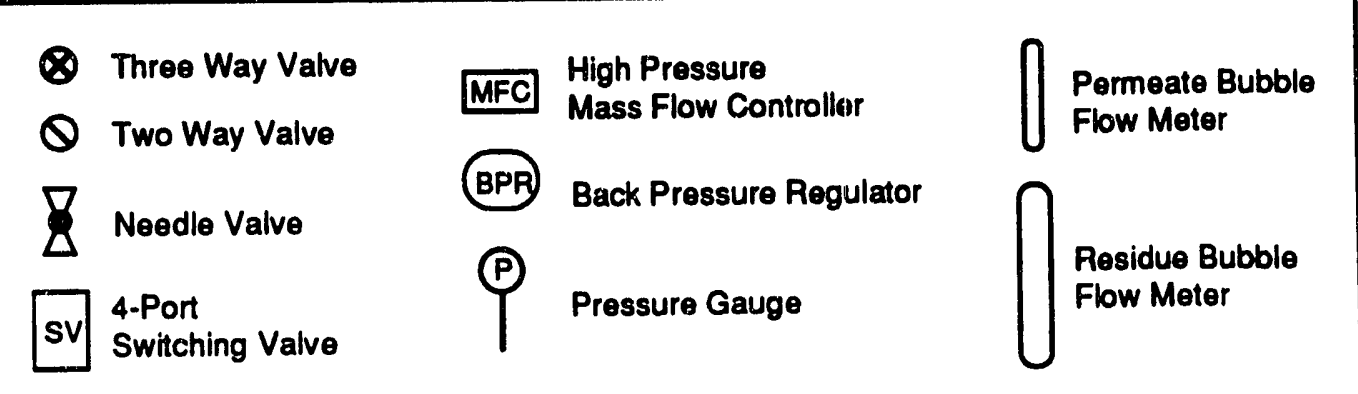

Figure 7. High temperature permeation apparatus.

A gas mixture can be sent to four permeation cells, or two different mixtures can be sent to two pairs of cells. (1), (2) , (3) , (4) - membrane cells 1 through $4 ; P_{1}, P_{2}, P_{3}, P_{4}$ - permeate streams 1 through 4; $R_{12}, R_{34}$-residue streams from cells 1 and 2 and from cells 3 and 4). 
The major subtlety of the plumbing system was that the plumbing inside the oven was quickly degraded by the high temperature test conditions (even though all components were 316 stainless steel). Two items were helpful to deal with these problems: (1) the oven was continually flushed with oxygen-depleted air (made with laboratory compressed air and a membrane air separator from A/G Technology, Needham, MA) and (2) a high temperature lubricant was used (Silver Goop, Crawford Fitting Company, Solon, $\mathrm{OH}$ ) on all fitting threads so that the test cells could be removed after each test without having to cut the stainless steel.

\section{SINGLE FIBER TEST CELLS}

Holding a single fiber for testing is simple in concept but tricky in practice, especially when the cells must withstand temperatures above $1000^{\circ} \mathrm{F}$ and pressures above 200 psia. Commercially available high temperature epoxies were out of the question, since the highest temperature rating available was $660^{\circ} \mathrm{F}$. Several epoxies were tried, but these failed to hold 200 psia pressure at temperatures $100^{\circ} \mathrm{tc} 300^{\circ} \mathrm{F}$ lower than their stated "service" temperatures. Inflexible inorganic media, such as alumina colloidal suspensions and various glasses, must have the same thermal expansion properties as the glass fibers themselves to avoid seal failure upon heating or cooling. Since silica has a very low coefficient of thermal expansion (CTE; Table 4), it is virtually impossible to match the CTE of our sealing material to that of the hollow glass fibers. To match the CTE exactly, silica itself could be used. However, the hollow fibers would melt in the process of making the seal, an unacceptable outcome.

After several epoxies aud alumina-based sealants were tested, it was concluded that any sealant capable of functioning above $600^{\circ}$ to $700^{\circ} \mathrm{F}$ and at several hundred psi pressure would necessarily crack the glass fiber. Therefore, it was necessary to devise a sealing strategy that worked even though the fiber was cracked. This seal strategy was called an "internal seal" for reasons explained below.

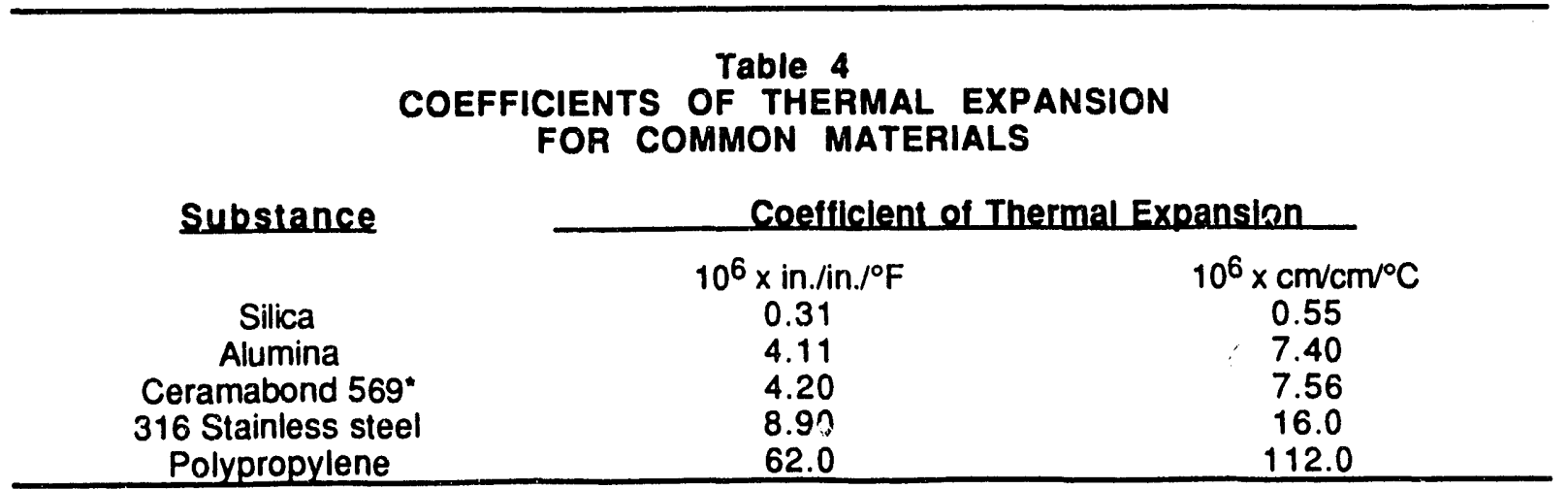

* Aremco Products, Ossining, NY 
To understand an "internal seal," it is necessary first to consider the (retrospectively) simple reasons a conventional seal method does not work with these fibers at high temperatures. A conventional seal method would consist of mounting the fiber in a tube, as in Figure 8, with the epoxy or other sealant (commonly known as "potting" compound in membrane jargon) surrounding the fiber on one end. Conventional fittings can be applied to this test cell to attach it to the system plumbing. Available high temperature epoxies failed to hold pressure above $350^{\circ} \mathrm{F}$. Therefore, inorganic sealants became imperative. To match the CTE of the sealant as closely as possible to that of the hollow fibers, an alumina mounting tube was chosen (Coors Ceramics, Golden, $\mathrm{CO}$ ) and an alumina-based colloidal sealant. Several of these sealants are available from Aremco Products (Ossining, NY) and Adhesive Products Corporation (Bronx, NY). Unexpectedly - and even unknown to the manufacturers-all such sealants were microporous when used and heated above $400^{\circ} \mathrm{F}$. These materials are regarded as sealants in their ordinary uses, but apparently they have never been tried before for gas-tight seals. Hence, a conventional seal method does not work because the available inorganic sealants with CTEs suitable for a nonglass mounting tube are, in fact, microporous.

The "fix" for this problem, at first glance, would appear to be to put a glaze over one end of the inorganic sealant (Figure 9). There are several "low" temperature inorganic glazes, that melt below $1000^{\circ} \mathrm{F}$ (available from Schott Glass, Corning Glass, and others). This simple fix does not work, however. With a glaze over the potting compound, what one observes is that gas flows readily out of the lumen of the fiber in a "forward pressurization" bubbling test (Figure 10a). Permeation through the membrane wall is so slow $(0.1$ to $1 \mathrm{cc} / \mathrm{min})$ that the observed gas flow could not be explained by permeation. In addition, when the cell was pressurized in the reverse direction, gas flowed only out the alumina tube, not down the fiber lumen (Figure 10b). The only consistent explanation for the observations made under "forward" and "reverse" pressurization was that the fiber must be broken inside the microporous inorganic sealant (Figure 11). This breakage was likely a result of the small but apparently significant CTE mismatch between the inorganic potting compound and the silica fibers.

Once one realizes it is impossible to match the CTE of the potting compound to that of the fibers themselves, it becomes apparent that a sealing technique is necessary which still allows for permeation testing even when the fibers are broken inside the microporous potting compound. The only way to achieve a good seal with the broken fiber inside the potting compound is to have the high pressure gas directly contact the sealing glaze. Thus, instead of having the sealing glaze outside the high pressure gas region, as in Figure 11 ("external" seal), the sealing glaze must be inside the high pressure gas region ("internal" seal). The resulting plumbing eventually devised to 


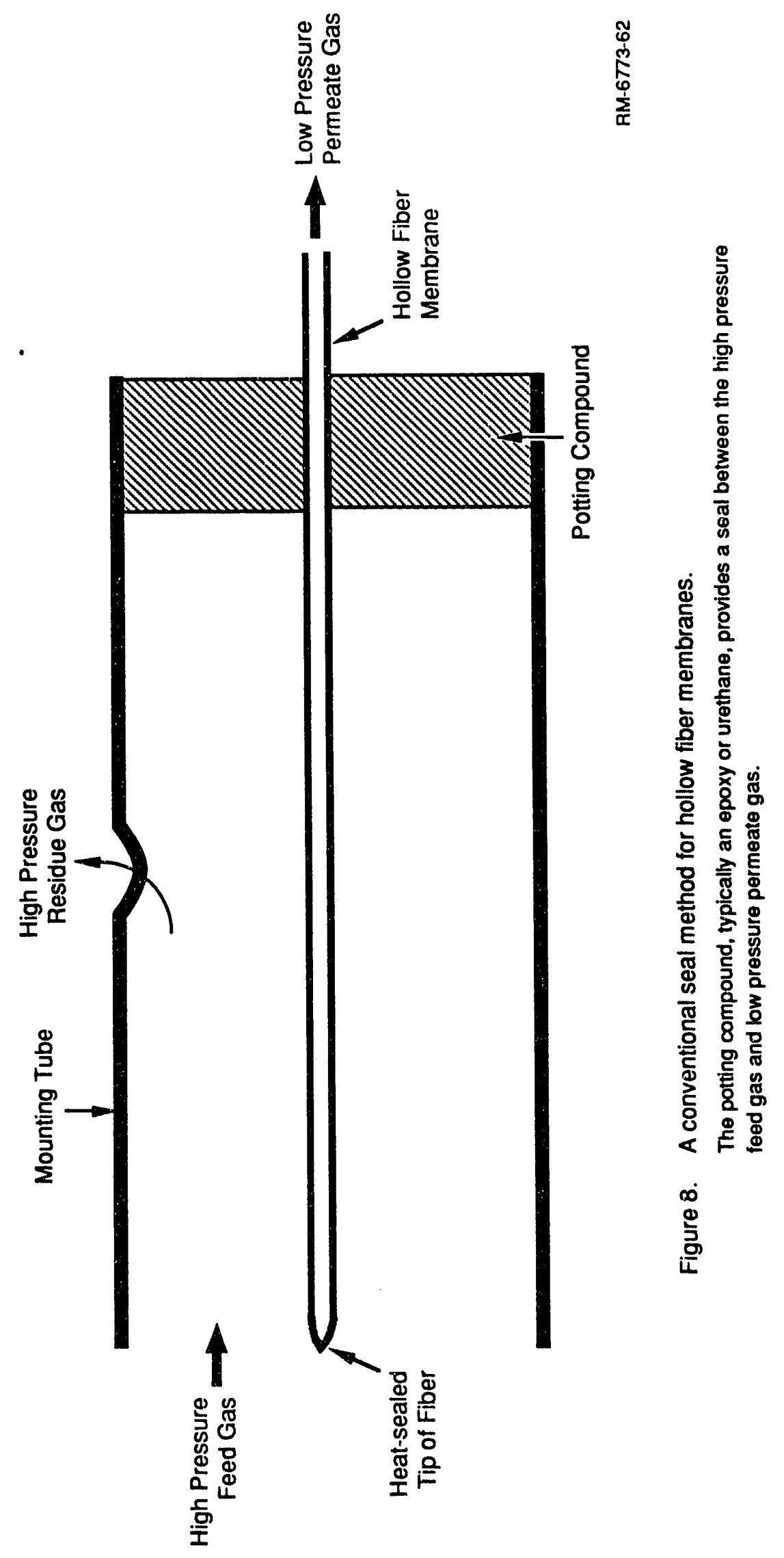




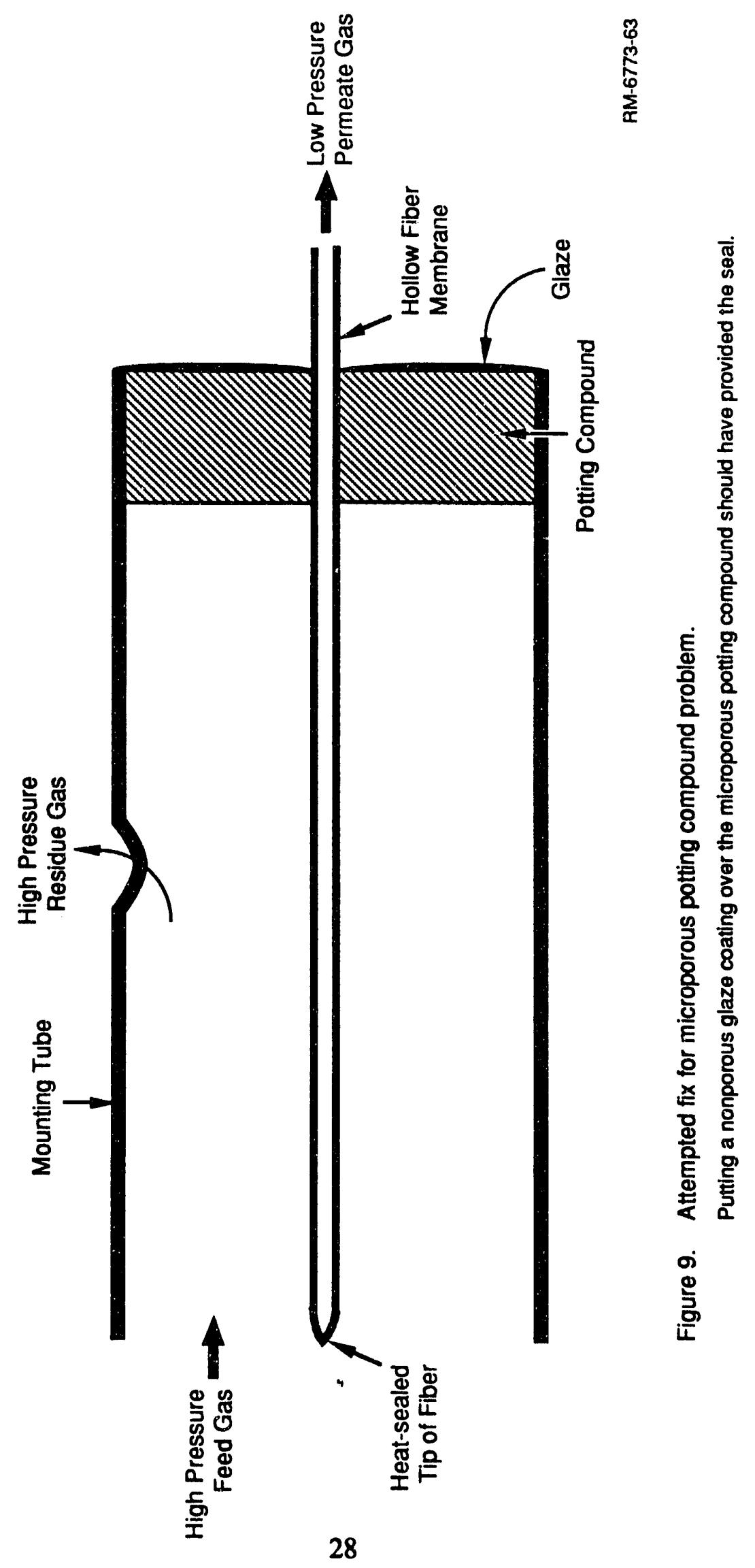




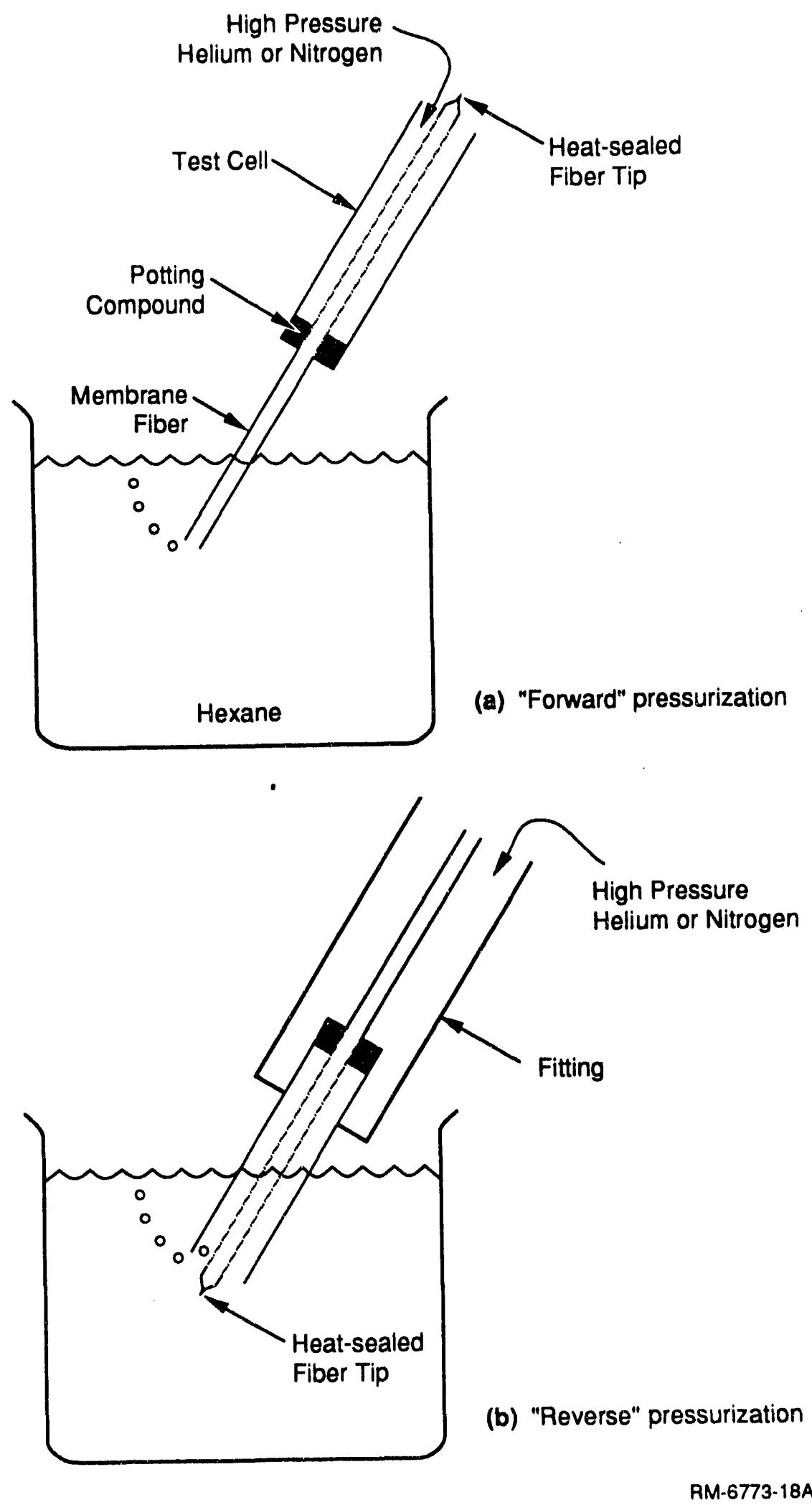

Figure 10. Arrangement of test for seal diagnosis.

In "forward" test mode, no bubbles should be seen unless fiber is broken; bubbles between the fiber and test cell body in "reverse" rest mode verify microporosity of potting compound and fiber breakage inside potting compound. 


\section{Resicuve}

Sit
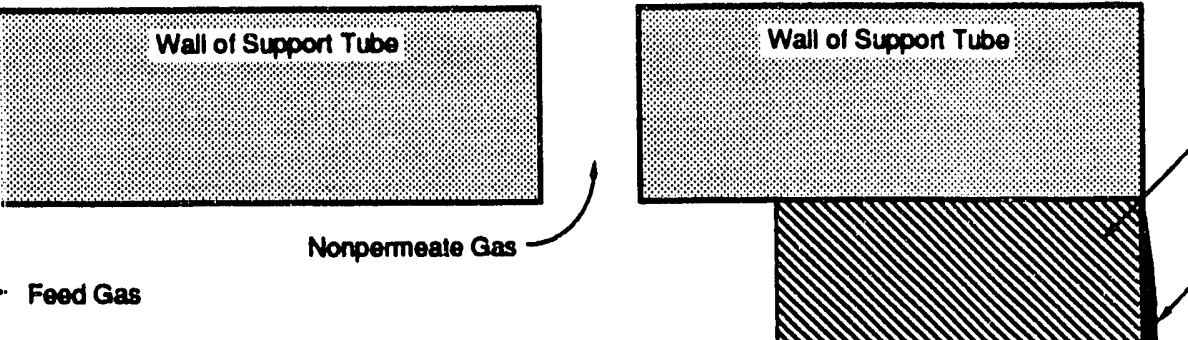

Inorganic Potting

Feod Gas

Sealing

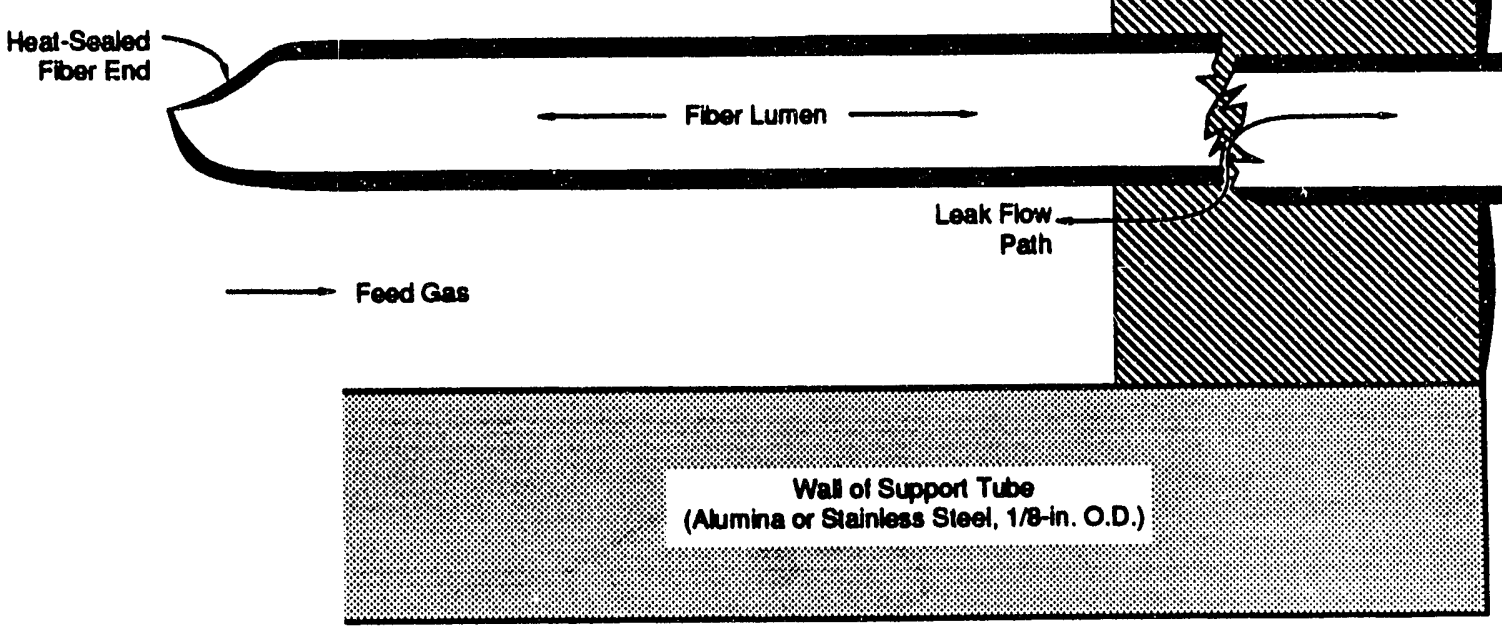

RA-146773-178

Figure 11. Detail of leak flow showing inadequacy of sealing glaze.

Inorganic potting material surrounds fiber. Feed gas is blocked from entering fiber lumen by heat seal on one end. Gas can exit the open fiber tip only if it passes through the fiber wall, either by permeation cr by flow through a crack or break. Rapid bubbling in reverse test mode (Figure 10b) indicated fiber breakage, such as shown here. 
accommodate the "internal" seal concept in practice included carbon-based ferrules (made of Grafoil $^{*}$; UCAR Carbon Company, Inc., Cleveland, $\mathrm{OH}$ ), one bored-through reducing union, and one threaded reducing port connectc: (Figure 12). To mount the fiber in the $1 / 8$-in. O.D. alumina support tube and to make the internal seal, a holder was built that made it possible not to handle the fiber directly during the preparation of the seal or insertion of the assembly in the permeation apparatus. By this means, fiber breakage could be avoided during the seal preparation. In Appendix B a step-by-step procedure is given for preparing the test cells with the internal seal. Two materials were necessary to make the final seal. The material touching the fiber had to be soft to avoid fiber breakage (Figure 13).

\section{DATA REDUCTION}

Raw data obtained during the permeation experiments consisted of the flow rate of each component of the feed gas, the feed gas pressure, the flow rate of the permeate gas, the composition of the permeate gas, and the permeation temperature. The length of the fiber was measured before the permeation experiment (typically $10 \mathrm{~cm}$ ). PPG Industries reported to us the inside and outside diameters of each fiber batch.

These data allowed calculation of the usual quantities of interest in permeation, that is, permeability and permeance. These terms are defined mathematically below. Permeability is of greater interest to those who wish to understand the permeation mechanisms, and permeance is of greater interest to those who want to know how many fibers will be required to process a given flow rate of feed gas (permeance is sometimes known as the pressure-normalized flux).

The helium sweep rate $\left(\sim 1 \mathrm{~cm}^{3} / \mathrm{min}\right)$ was much higher than the permeation rate $(\sim 1$ to $100 \mu \mathrm{L} / \mathrm{min})$. We used a helium sweep stream because no technology is known that is capable of measuring the sometimes very small flow rates coming from one fiber. Therefore, the data reduction is slightly more complicated than it would be otherwise. The following nomenclature is useful for explaining the data reduction:

$$
\begin{aligned}
& \Delta P_{i}=\text { Partial pressure driving force for species } i \\
& L=\text { Fiber length } \\
& N \quad=\text { Number of species inside lumen on permeate side } \\
& P_{\text {in }}=\text { Total pressure on inside of fiber (permeate gas) }
\end{aligned}
$$

* The material, Grafoil, is made by UCAR Carbon Company. The ferrules were made by Bay Seal, Hayward, CA, using Grafoil material. 


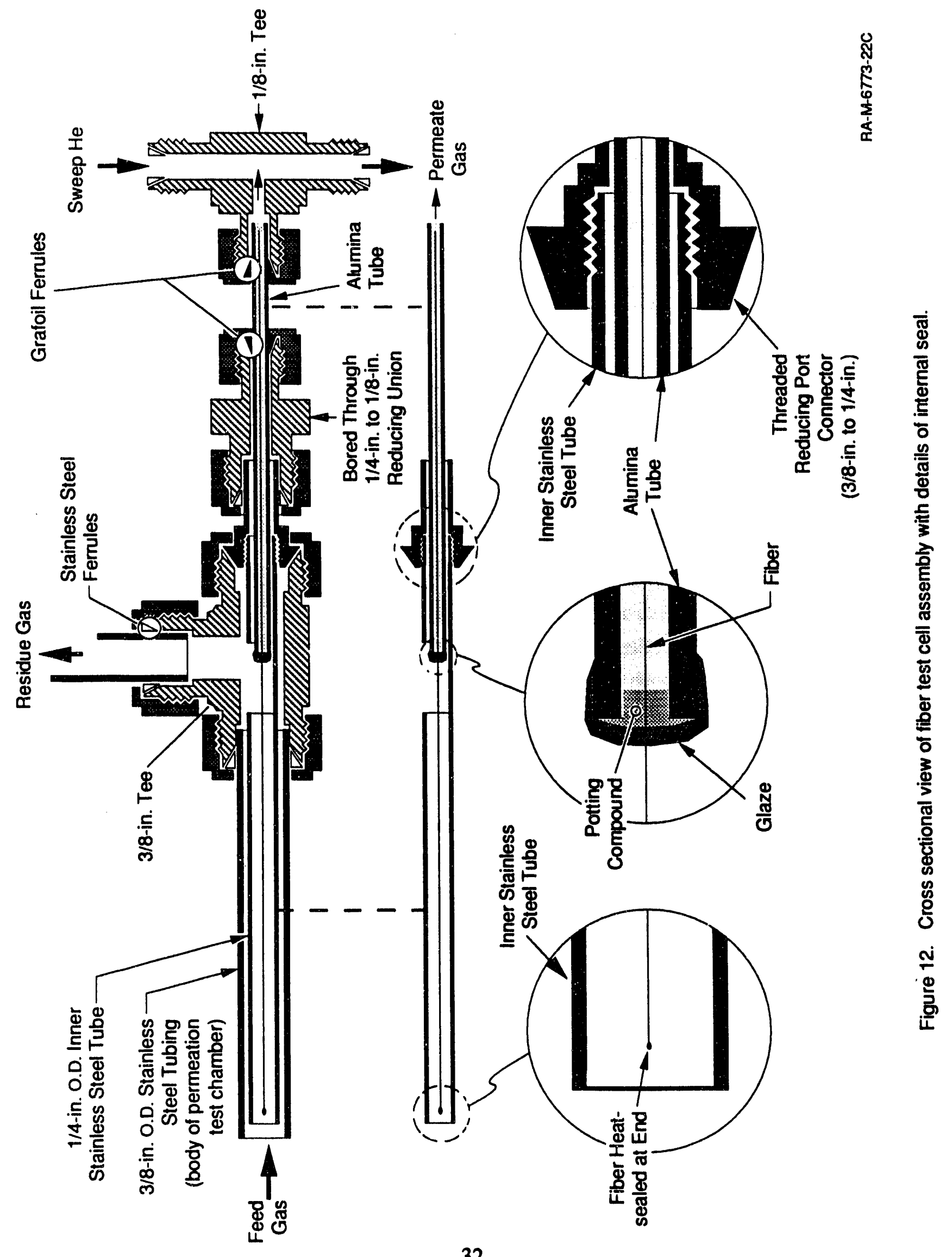




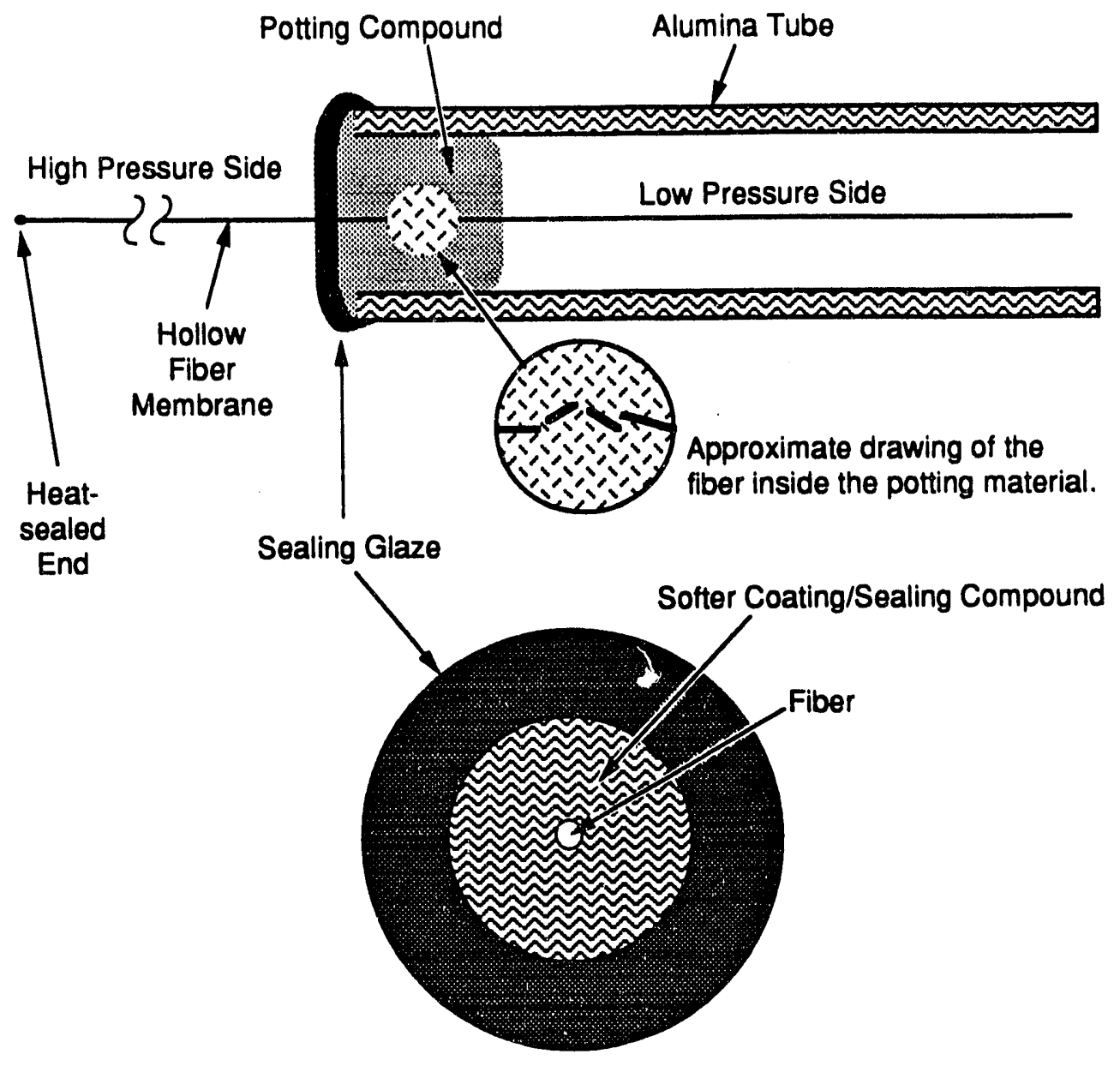

End-on View of Bagel Technique

Figure 13. Detail of two-material sealing technique ("bagel").

The glaze adheres well to the alumina tube, and the sealing compound adheres to the fiber without cracking the fiber. 
$P_{m}=$ Pressure at point of bubble flow meter measurement

$\mathrm{P}_{\text {out }}=$ Total pressure on outside of fiber (feed gas)

$\mathrm{Q}_{\mathrm{i}}=$ Permeate volumetric flow rate of species $\mathrm{i}$, referenced to $0^{\circ} \mathrm{C}, 1 \mathrm{~atm}$

$\mathrm{Q}_{\mathrm{m}}=$ Volumetric flow rate of gas measured at bubble flow meter (actual)

$r_{i}=$ Inside radius of fiber

$r_{0}=$ Outside radius of fiber

$\mathrm{T}_{\mathrm{m}}=$ Temperature at point of bubble flow meter measurement

$\mathrm{W}_{\mathrm{i}}=$ Molar flow rate of species $\mathrm{i}$ in the permeate stream

$\mathrm{W}_{\mathbf{S}}=$ Molar flow rate of sweep gas; a sweep gas species is used that is not present in the native permeate stream

$\mathrm{W}_{\mathrm{T}}=$ Total molar flow rate on permeate side going to chromatograph (sweep plus native permeate)

$\mathbf{X}_{\mathbf{i}}=$ Mole fraction of species $\mathrm{i}$ inside lumen at permeate exit

$\mathrm{XP}_{\mathrm{i}}=$ Mole fraction of species $\mathrm{i}$ in the permeate flow stream at the chromatograph (measured)

$\mathrm{XR}_{\mathrm{i}}=$ Mole fraction of species $\mathrm{i}$ in residue stream at chromatograph (measured)

The definition of permeance is the flux divided by the partial pressure driving force. In our case, the composition of gas inside the fiber lumen is not actually constant, nor is the total pressure inside the lumen necessarily constant, along the length of the fiber. Nevertheless, the composition of gas inside the fiber lumen is assumed to be the composition at the fiber exit, and the pressure is assumed to be atmospheric (the same as that measured at the bubble flow meter). With these assumptions, the permeance is given by

$$
\text { permeance of species } j=\frac{Q_{j}}{2 \pi r_{i} L \Delta P_{j}}
$$

Here the inside surface area $\left(2 \pi r_{i} L\right)$ is used to define the flux $\left(Q_{j}\right.$ divided by area).

The values of $r_{i}$ and $L$ are easily measured before the fiber is placed in the test cell. The volumetric flowrate of species $\mathrm{j}$ at $0^{\circ} \mathrm{C}$ and $1 \mathrm{~atm}$ is related to the total flowrate measured by the bubble flow meter by

$$
Q_{j}\left(0^{\circ} \mathrm{C}, 1 \mathrm{~atm}\right)=X P_{j} Q_{m}\left(\frac{273 K}{T_{m}}\right)\left(\frac{P_{m}}{1 \mathrm{~atm}}\right)
$$


The mole fraction $\mathrm{XP}_{\mathrm{j}}$ is measured directly by the chromatograph.

The quantity $\Delta \mathrm{P}_{\mathrm{j}}$ is the only term remaining to be calculated to complete the calculation of the permeance by Eq. 40 . This quantity is given by

$$
\Delta P_{j}=X R_{j} P_{\text {out }}-P_{\text {in }} X_{j}
$$

The pressure $\mathrm{P}_{\text {out }}$ is known (feed/residue pressure), the pressure $\mathrm{P}_{\text {in }}$ is known (atmospheric), and the mole fraction $\mathrm{XR}_{\mathrm{j}}$ is known (mixed by mass flow controllers and checked by chromatograph). The mole fraction $X_{j}$ (at the exit of the fiber lumen) is related to the measured permeate mole fractions at the chromatograph by

$$
X_{j}=\frac{X P_{j}}{\sum_{i=1}^{N} X P_{i}}
$$

All quantities on the right-hand side of Eq. 43 are measured. Therefore, $X_{j}$ can be calculated, $\Delta P_{j}$ can be calculated by Eq. 42 , and the permeance can be calculated by Eq. 40 . The selectivity of species $i$ to species $j, \alpha_{i j}$, is given by

$$
\alpha_{i j}=\left(\frac{X P_{i}}{X P_{j}}\right)\left(\frac{\Delta P_{j}}{\Delta P_{i}}\right)
$$

Further, the permeability of species $\mathrm{j}$ is given by multiplying the permeance by the effective wall thickness $r_{i} \ln \left(r_{0} / r_{i}\right)$ or

$$
\text { Permeability of species } j=\frac{Q_{j} \ln \left(r_{o} / r_{i}\right)}{2 \pi L \Delta P_{j}}
$$

These equations were used to reduce the data throughout the project. 


\section{PERMEATION RESULTS}

Permeation data were obtained on gases of interest to both coal combustion and gasification applications. Because of the limitations on the thermal and mechanical stability of the fibers, the highest temperature that could consistently be reached was $700^{\circ} \mathrm{F}$. Gases studied included $\mathrm{H}_{2} / \mathrm{CO}$ mixtures (bulk components of gasifier gas), $\mathrm{N}_{2} / \mathrm{CO}_{2}$ mixtures (bulk components of combustion), $\mathrm{N}_{2} / \mathrm{NH}_{3}$ mixtures (a bulk and trace component of gasifier gas), and a variety of pure component gases. All of the data shown below in figures are listed in tables in Appendix C.

\section{$\mathrm{H}_{2} / \mathrm{CO}$ MIXTURES}

Very high $\mathrm{H}_{2} / \mathrm{CO}$ selectivities (over 300 ) and reasonable $\mathrm{H}_{2}$ permeance values $\left(>10^{5}\right.$ Barrer $/ \mathrm{cm}$ ) were found in the temperature range $300^{\circ}$ to $700^{\circ} \mathrm{F}$. Also, the permeation properties of the fibers changed substantially the high temperature seal was prepared, and some: hysteresis was found for fibers heated to $700^{\circ} \mathrm{F}$.

The first tests were done with pure helium, then a $20 \% \mathrm{H}_{2} / 80 \% \mathrm{He}$ mixture, and then a $20 \% \mathrm{H}_{2}, 20 \% \mathrm{CO}, 60 \% \mathrm{He}$ mixture to see if these species seemed to permeate independently of each other. With two high temperature cells at $400^{\circ} \mathrm{F}$, we found no significant difference between the helium permeance values in any of the three gas mixtures nor between the $\mathrm{H}_{2}$ permeance values in the two tests that contained $\mathrm{H}_{2}$ in the feed (Table 5). Thes: two test cells do not answer all possible questions about competitive or non-ideal permeation behavior, but the absence of any significant effect made further exploration unjustifiable. Little competitive effects are expected because surface adsorption is likely negligible above $300^{\circ} \mathrm{F}$ to $400^{\circ} \mathrm{F}$.

For the rest of the tests, the mixture feed composition was $20 \% \mathrm{H}_{2}, 20 \% \mathrm{CO}$, and balance helium. This mixture allowed the behavior of the bulk constituents of gasifier gas to be studied without interference from various contaminants. The typical feed pressure was 215 psia. Six separate fibers were tested at these conditions. The permeation through fibers held in epoxied test cells was much higher than through fibers subjected to the high temperature seal preparation (Figure 14). Since the epoxy test cells cannot be tested much above $300^{\circ} \mathrm{F}$ and the cells with the internal seal have a very low permeance below $300^{\circ} \mathrm{F}$, data were obtained for the two types of test cells at only one common temperature, $300^{\circ} \mathrm{F}$. Here, the $\mathrm{H}_{2}$ and $\mathrm{CO}$ permeances are a factor of 10 lower and a factor of 1000 lower, respectively, for the test cells prepared with the high temperature 
Table 5

NON-INTERFERENCE TESTS FOR He, $\mathrm{H}_{2}$, AND CO PERMEATION

Temperature: $\quad 400^{\circ} \mathrm{F}$

Flber I.D: Cell 3

Permeance (Barrer/cm) In Given Gas Mixture

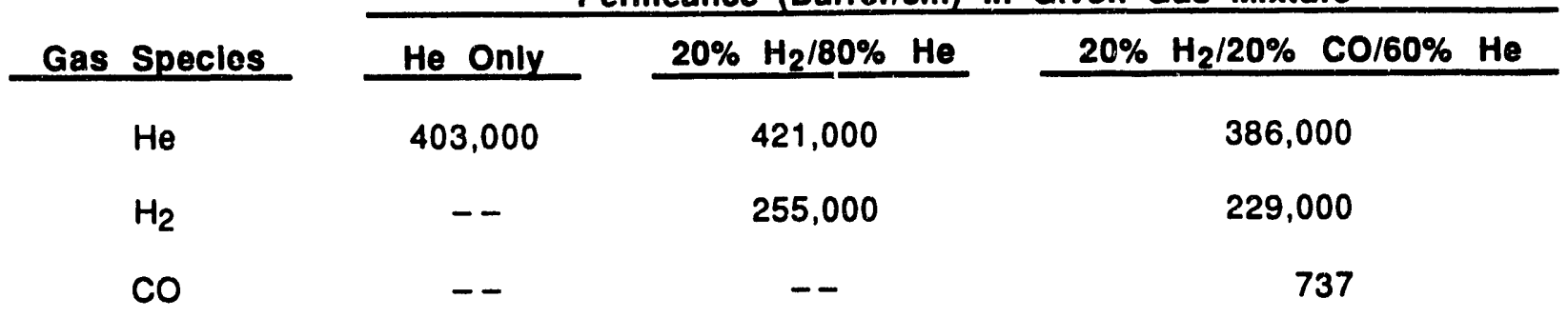

Temperature: $\quad 400^{\circ} \mathrm{F}$

FIber I.D: Cell 4

$\begin{array}{rrcr}\text { He } & 432,000 & 456,000 & 415,000 \\ \mathrm{H}_{2} & -- & 180,000 & 154,000 \\ \mathrm{CO} & -- & -- & 67\end{array}$




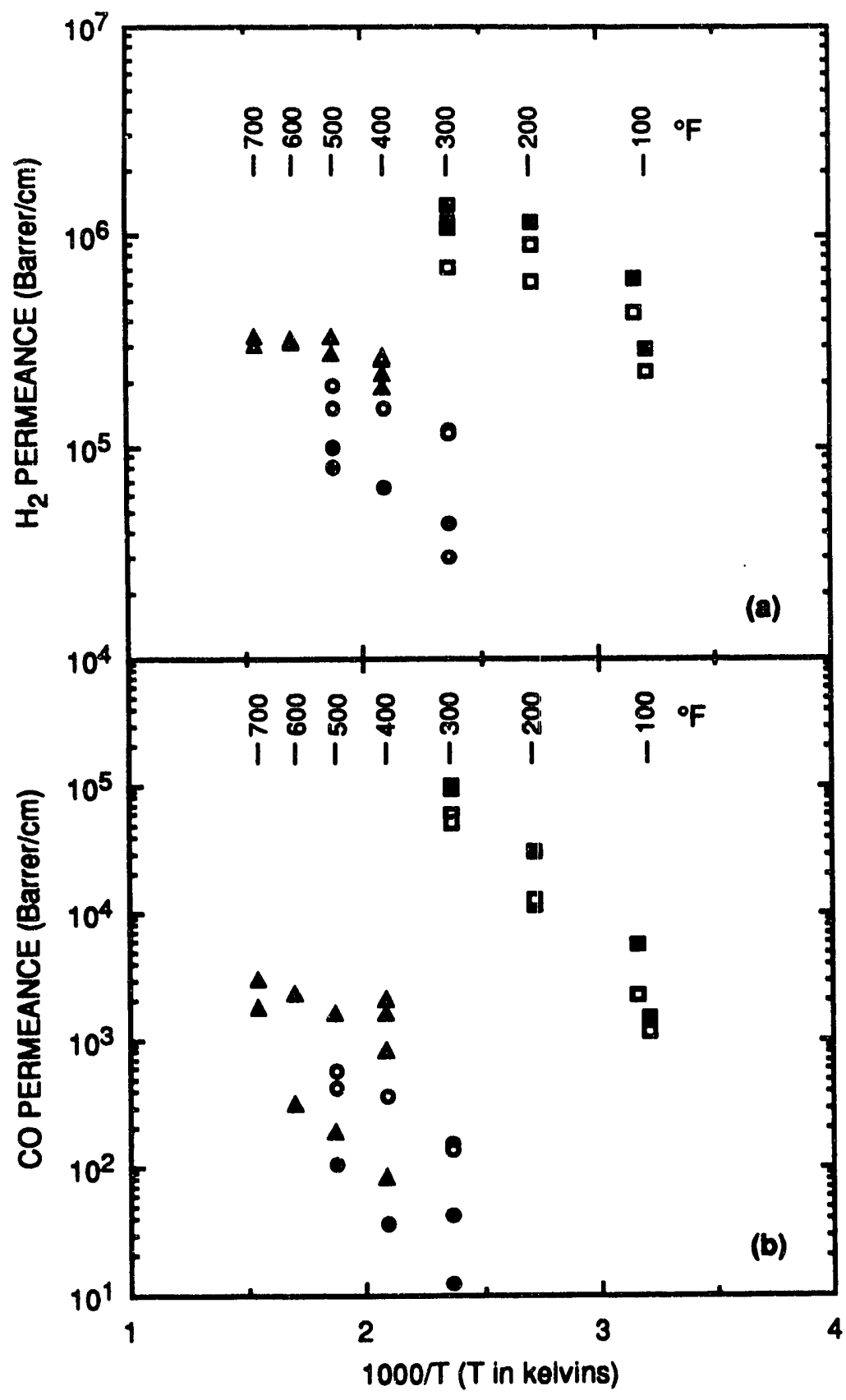

Fiber Numbers
-2-20-91-1
2-20-91-2 High
A 1-21-91-1 Tomp. Colls
$\Delta$ 1-21-91-2)
a 2-6-91-1\} Epoxy
- 2-6-91-2 $\}$ Test Colls

Figure 14. Influence of test cell preparation conditions on permeation performance.

Fibers subjected to glaze curing conditions had factor of 10 lower $\mathrm{H}_{2}$ permeance and a factor of 1000 lower $\mathrm{CO}$ permeance at $300^{\circ} \mathrm{F}$. 
seal. It is likely that, the fiber pore morphology changes during the preparation of the high temperature seal because of the thermal conditions (e.g., up to $900^{\circ} \mathrm{F}$ for $10 \mathrm{~min}$ during the cure of the glaze). The epoxied test cells cure at room temperature. Hence, the fibers held with epoxy are the "native" fibers, whereas the fibers subjected to the internal seal are essentially "heat treated" fibers.

Very high selectivities (over 1000) for $\mathrm{H}_{2}$ over $\mathrm{CO}$ were demonstrated by the fibers prepared with the high temperature seals (Figure 15). These high selectivities were accompanied by low permeance values, however, as is typical of the permeability/selectivity trade-off known in polymer membranes (Robeson, 1991). It not surprising to find an inverse relationship between $\mathrm{H}_{2}$ permeance and $\mathrm{H}_{2} / \mathrm{CO}$ selectivity. However, we did not expect the data for all fibers to fall so close together over the entire temperature range of $100^{\circ}$ to $700^{\circ} \mathrm{F}$. Nevertheless, in the temperature range $300^{\circ}$ to $500^{\circ} \mathrm{F}$, the fibers exhibit selectivities (over 500) well above those of commercially available membranes (typically 60 to 100 ) at hydrogen permeance values that are commercially feasible (about $10^{5} \mathrm{Barrer} / \mathrm{cm}$ ). Because of the small size of the PPG fibers (about 40 micrometers), the surface area of membrane per unit volume could, in module form, be a factor of 10 higher than that of commercially available hydrogen separation membranes. Therefore, the productivity per unit volume of a commercial module with PPG fibers could be the same as that of other commercially available modules but with a much higher selectivity. The fibers could also operate at process temperatures typical of refining applications ( $300^{\circ}$ to $\left.500^{\circ} \mathrm{F}\right)$, unlike polymer membrane systems. These fibers therefore have strong commercial potential in hydrogen separations in refining applications if a commercially durable module can be made.

A hysteresis phenomenon was found for high temperature cells (Figure 16a and b) but not for epoxy cells (Figure 17). The hysteresis was not significant for the high temperature cells, however, when the temperature was cycled between $300^{\circ}$ and $500^{\circ} \mathrm{F}$ (Figure 16a). The significant hysteresis can be attributed to the dehydroxylation of the silica internal pore surface at temperatures above about $500^{\circ} \mathrm{F}$ (see p. 626 of Iler, 1979). Thus, the fibers are commercially viable up to $500^{\circ} \mathrm{F}$. Even though the fibers can be tested up to $700^{\circ} \mathrm{F}$ and will withstand temperatures up to about $1000^{\circ} \mathrm{F}$, they may not be commercially viable above about $500^{\circ} \mathrm{F}$, since a significant hysteresis phenomenon could be very difficult to manage in a commercial setting.

\section{$\mathrm{N}_{2} / \mathrm{CO}_{2}$ MIXTURES}

The permeation was tested of $\mathrm{N}_{2}$ and $\mathrm{CO}_{2}$ with an $85 \% \mathrm{~N}_{2} / 15 \% \mathrm{CO}_{2}$ mixture and with $100 \% \mathrm{~N}_{2}$ and $100 \% \mathrm{CO}_{2}$. The concentration $15 \% \mathrm{CO}_{2}$ was chosen because this concentration is typical of a coal combustion exhaust gas. Nitrogen is the other major species in combustion 


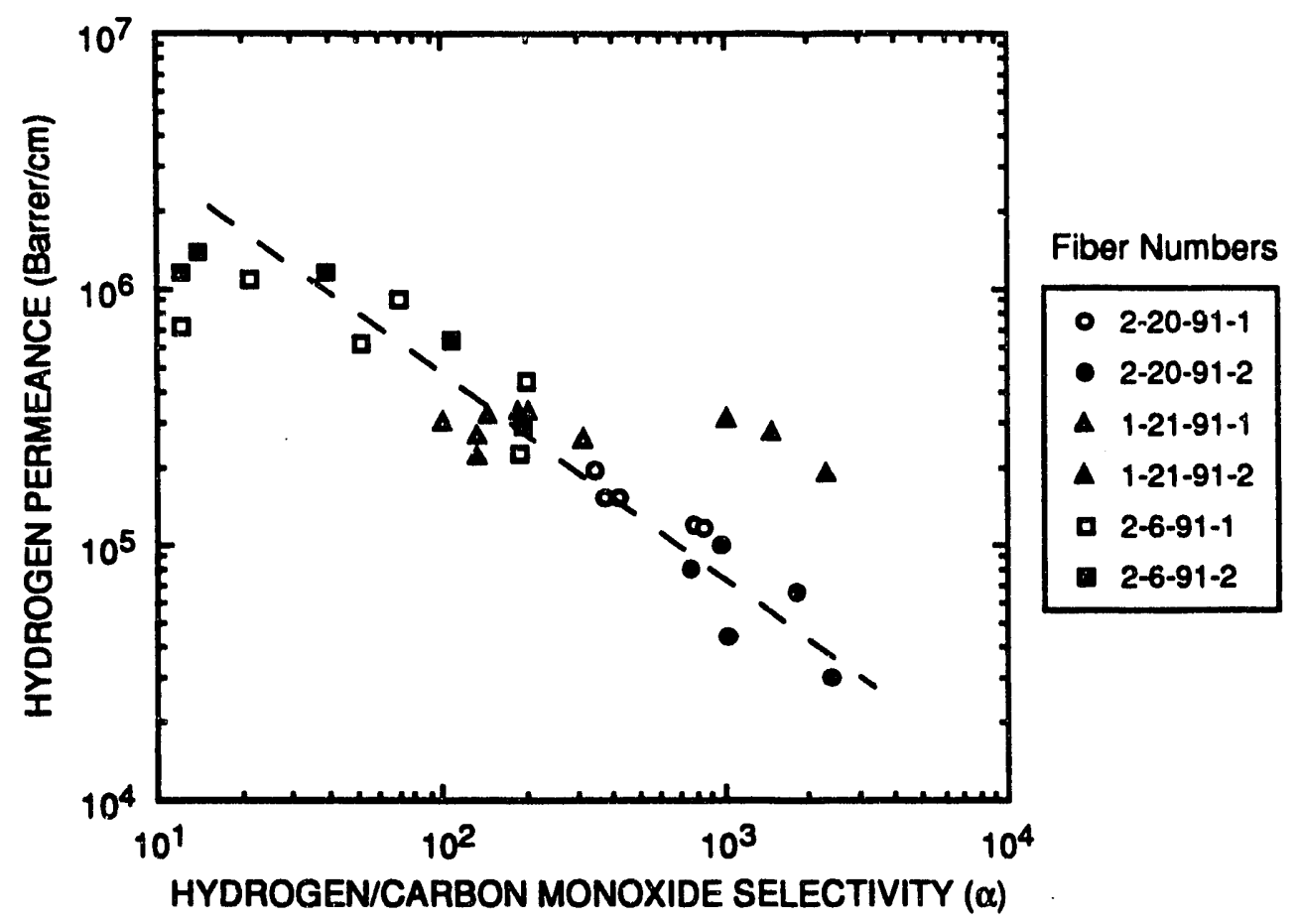

RAM-6773-65

Figure 15. Permeance/selectivity trade-off for $\mathrm{H}_{2} / \mathrm{CO}$ mixture separation.

The permeance/selectivity band is rather narrow despite a range of temperatures and two methods of test cell preparation. Equation of dashed line is $\mathrm{H}_{2}$ permeance $=1.763 \cdot 10^{7}(\alpha)^{-0.769}$. 


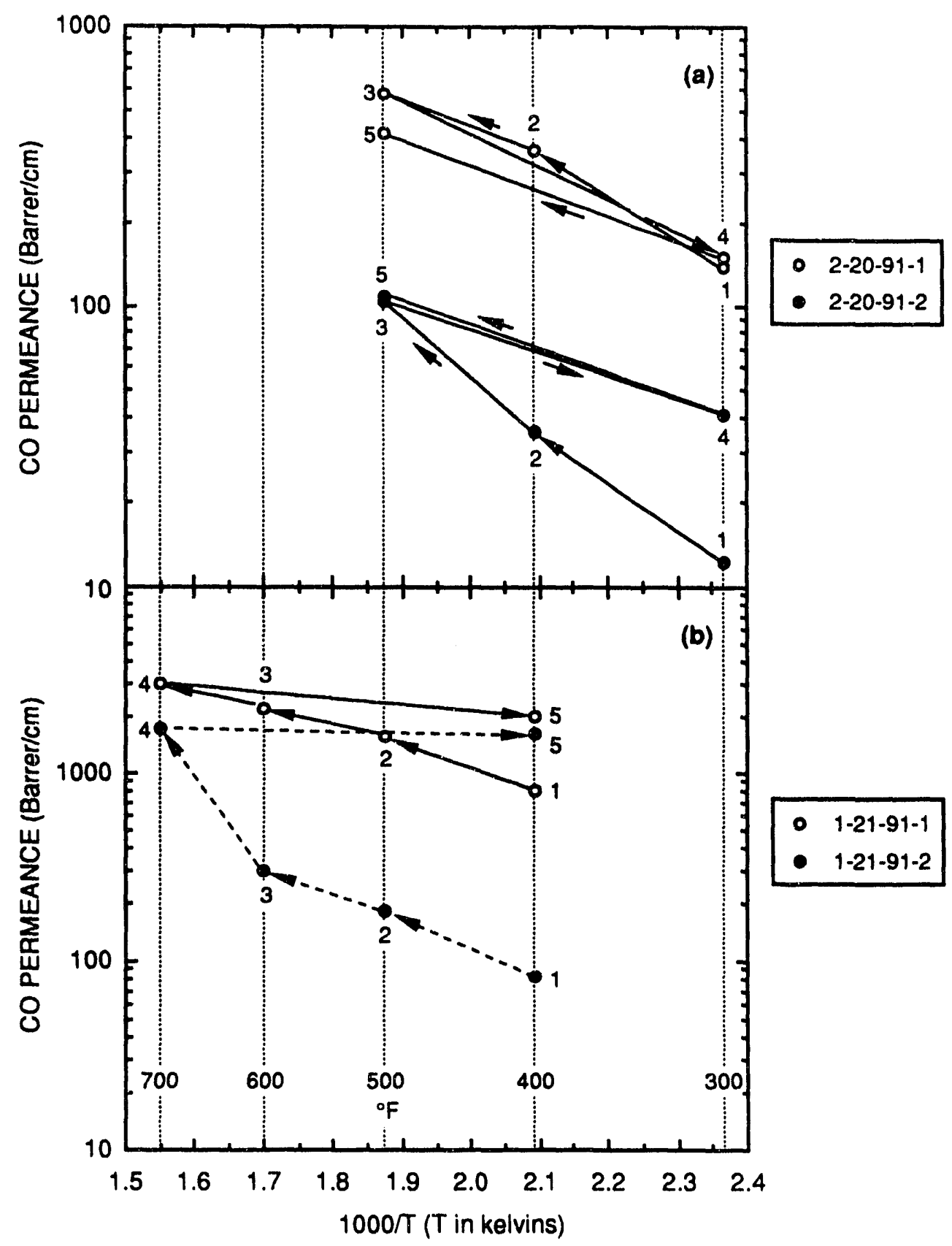

RAM-6773-66

Figure 16. Hysteresis phenomenon in high temperature cells.

Data points are numbered to show test sequence. 


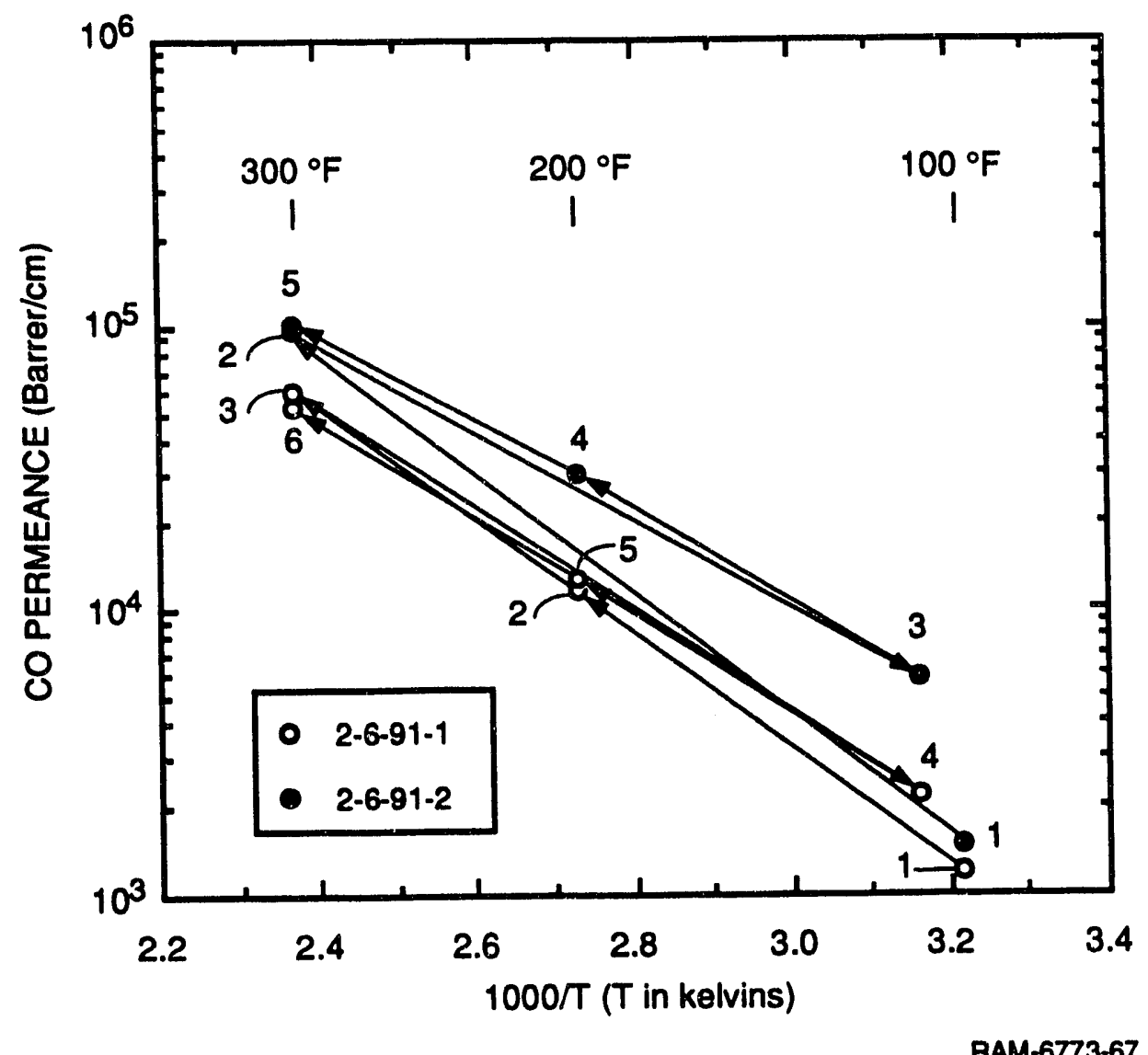

Figure 17. Hysteresis phenomenon in epoxy cells.

Numbered data points show test sequence. No significant hysteresis was evident. 
exhaust gas. Fibers were tested that were held with an epoxy and with a high temperature seal. The epoxy cells were tested between $158^{\circ}$ and $300^{\circ} \mathrm{F}$, and the high temperature cells were tested between $200^{\circ}$ and $700^{\circ} \mathrm{F}$.

The permeation rate of both $\mathrm{CO}_{2}$ and $\mathrm{N}_{2}$ through the epoxy cells was one to two orders of magnitude higher than through the high temperature cells (Figure 18), again indicating that the pore structure of the fiber walls is altered substantially during the preparation of the high temperature seal. The permeation properties of the two epoxy cells were identical, but those of the high temperature cells varied substantially even though all fibers were from the same batch. This behavior could be attributed to the strong effect of the high temperature sealing conditions on the fiber. Slight variations in the length of time under various heating conditions during this seal preparation can thereby make a large difference in the fiber performance. Despite the wide variation in the permeability of the high temperature cells, the $\mathrm{CO}_{2} / \mathrm{N}_{2}$ selectivity for each fiber was rather consistent (Table 6) and follows the formula

$$
\alpha_{\mathrm{CO}_{2} / \mathrm{N}_{2}}=8.70 \cdot 10^{-2} \exp \left(\frac{2470 \mathrm{~K}}{\mathrm{~T}}\right)
$$

The epoxy cells show the typical but gradual increase in permeance with temperature and an inverse dependence of $\mathrm{CO}_{2} / \mathrm{N}_{2}$ selectivity on $\mathrm{CO}_{2}$ permeance. However, the high temperature cells show a much more gradual decrease in $\mathrm{CO}_{2}$ permeance as the $\mathrm{CO}_{2} / \mathrm{N}_{2}$ selectivity increases (Figure 19). For the epoxy cells, the $\mathrm{CO}_{2}$ permeance, $\mathrm{QCO}_{2}$, is related to the $\mathrm{CO}_{2} / \mathrm{N}_{2}$ selectivity, $\alpha_{\mathrm{CO}_{2} / \mathrm{N}_{2}}$, by the formula

$$
\text { Epoxy cells: } \mathrm{QCO}_{2}=353,000\left(\alpha_{\mathrm{CO}_{2} / \mathrm{N}_{2}}\right)^{-0.159} \mathrm{Barrer} / \mathrm{cm}
$$

The power (-0.159) on the selectivity in Eq. 47 shows a gradual decrease in $\mathrm{QCO}_{2}$ with increased selectivity. For the high temperature cells, however, the $\mathrm{CO}_{2}$ permeance is remarkably constant, nearly independent of selectivity. Curve fits of the data for high temperature cells to a formula similar to Eq. 47 give selectivity exponents of $2.75 \times 10^{-2}, 1.63 \times 10^{-2}, 9.92 \times 10^{-2}$, and $2.31 \times 10^{-2}$, respectively, for Fibers $12-5-90-1,12-5-90-2,12-16-90-1$, and 12-16-90-2. This small dependence of $\mathrm{CO}_{2}$ permeance on selectivity can be attributed to the $\mathrm{CO}_{2}$ absorption being much more important as a transport mechanism in the high temperature cells. Consequently, as the temperature increases, $\mathrm{CO}_{2}$ permeance does not increase much, but the $\mathrm{N}_{2}$ permeance does increase, lowering the selectivity.

Pure component tests of $\mathrm{CO}_{2}$ and $\mathrm{N}_{2}$ permeation showed results essentially identical to the mixture data (Figure 20), indicating no synergism between these diffusing molecules. 


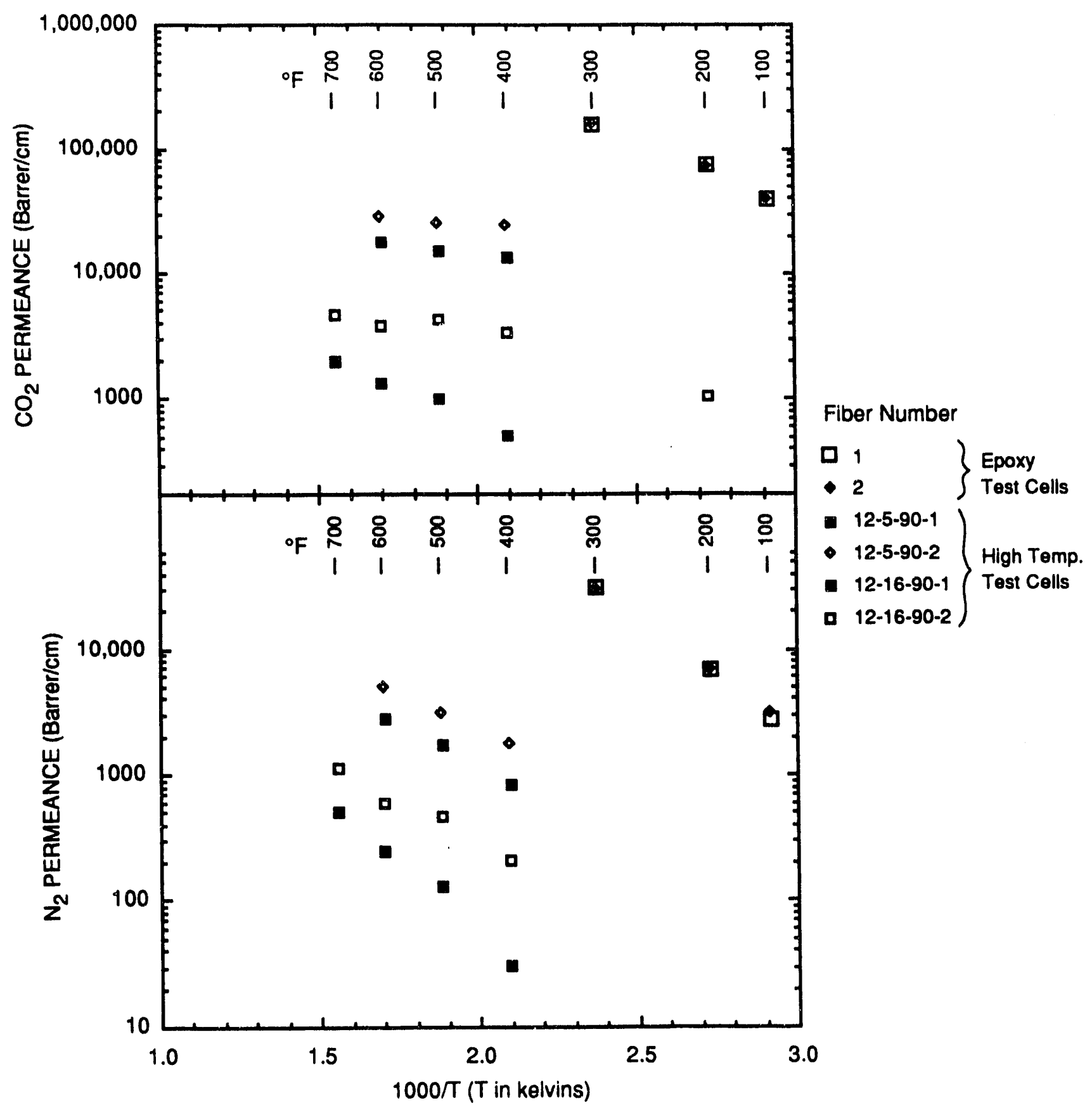

RAM-6773-69

Figure 18. Permeation of $\mathrm{N}_{2}$ and $\mathrm{CO}_{2}$.

Epoxy and high temperature cells, (85\% $\mathrm{N}_{2}, 15 \% \mathrm{CO}_{2}$ feed gas). 
Table 6

TEMPERATURE DEPENDENCE OF $\mathrm{CO}_{2} / \mathrm{N}_{2}$ SELECTIVITY WITH $15 \% \mathrm{CO}_{2} / 85 \% \mathrm{M}_{2}$ FEED MIXTURE; HIGH TEMPERATURE CELLS

Flber Number

\begin{tabular}{ccccc}
\cline { 2 - 5 } $\begin{array}{c}\text { Temperature } \\
\text { (F) }\end{array}$ & $12-5-90-1$ & $12 \cdot 5-90-2$ & $12-16-90-1$ & $12-16-90-2$ \\
\cline { 3 - 5 } 400 & 16.2 & 13.9 & 16.7 & 16.2 \\
500 & 8.8 & 8.2 & 7.9 & 9.0 \\
600 & 6.4 & 5.6 & 5.5 & 6.2 \\
700 & $\ldots$ & $\ldots$ & 3.9 & 4.2 \\
\hline
\end{tabular}

Exponential curve fit: selectivity $=8.70 \cdot 10^{-2} \exp (2470 \mathrm{~K} / \mathrm{T})$. 


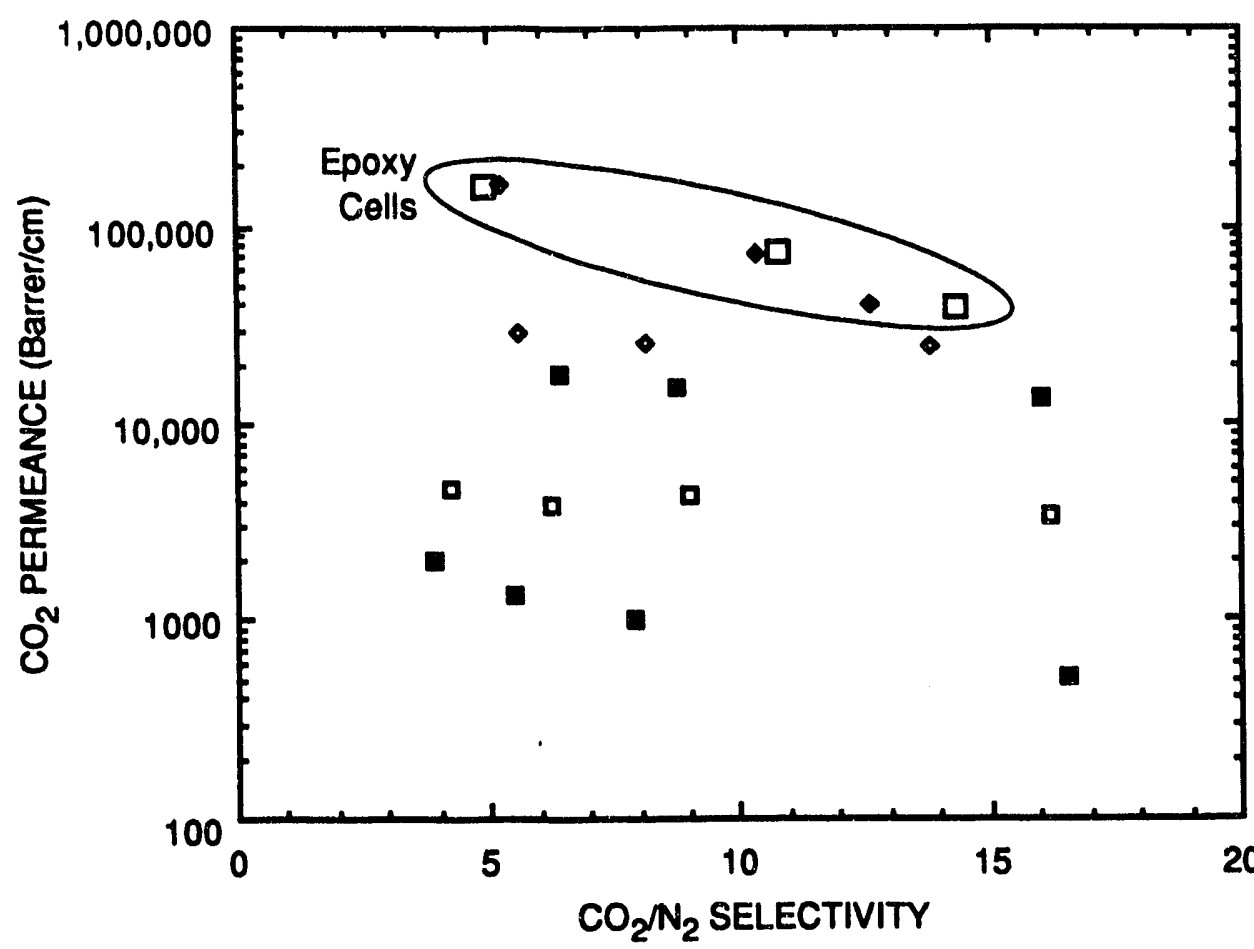

Fiber Number

( 1

2

12-5-90-1

- 12-5-90-2

- 12-16-90-1

- 12-16-90-2

Figure 19. Permeance/selectivity trade-off for $\mathrm{N}_{2}$ and $\mathrm{CO}_{2}$.

Epoxy and high temperature cells (85\% $\mathrm{N}_{2}, 15 \% \mathrm{CO}_{2}$ feed gas). The $\mathrm{CO}_{2}$ permeance is relatively flat for the high temperature test cells. Temperature increases to upper left.

46 


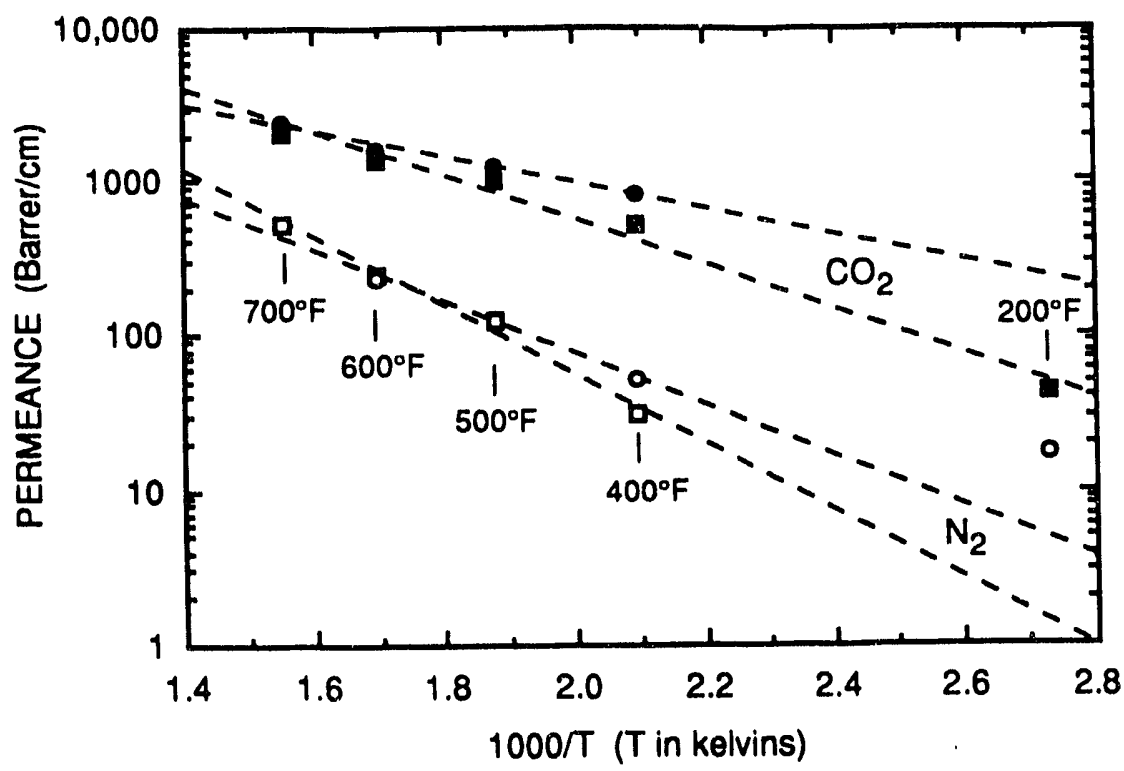

(a) Fiber 12-16-90-1

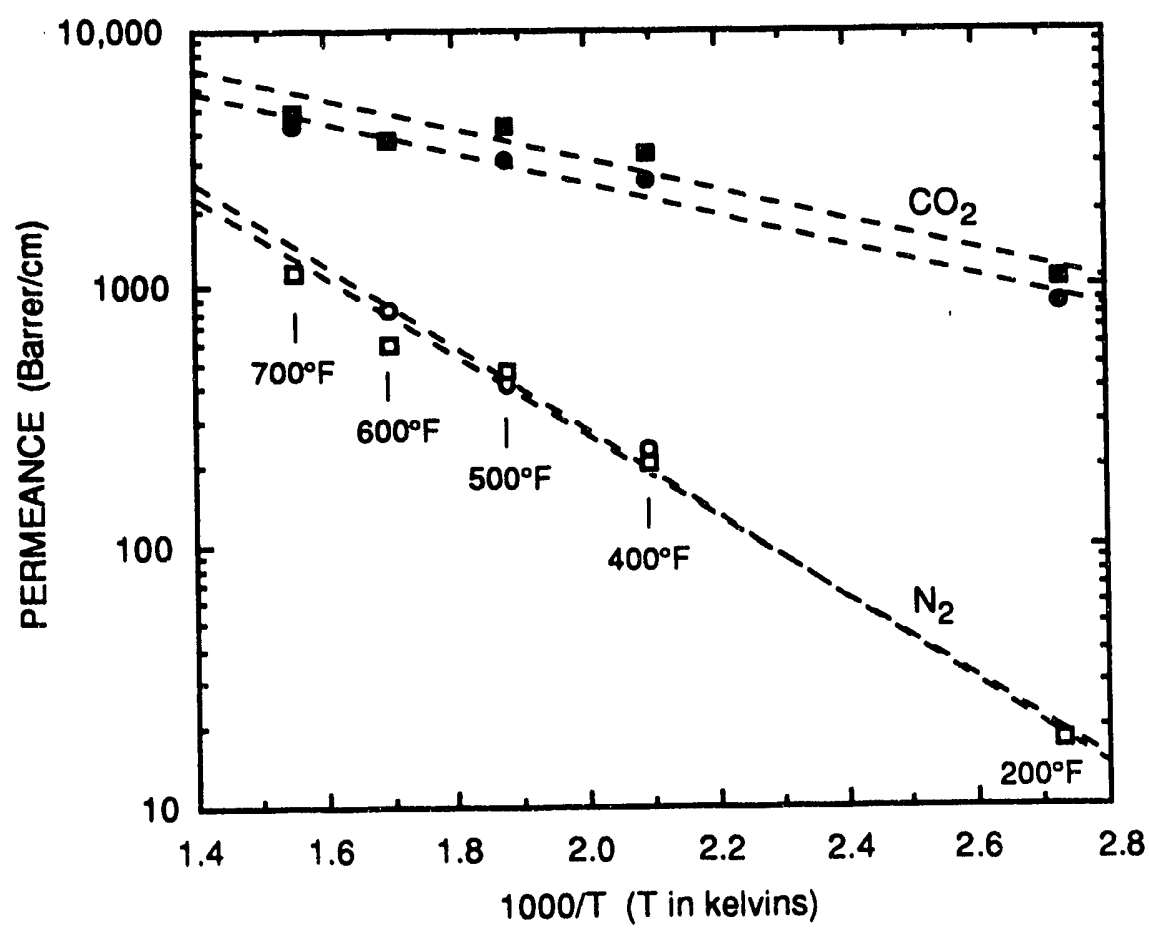

(b) Fiber 12-16-90-2

\begin{tabular}{|l|cc|}
\hline \multicolumn{1}{|c|}{ Feed } & \multicolumn{2}{|c|}{ Permeance } \\
& $\mathrm{CO}_{2}$ & $\mathrm{~N}_{2}$ \\
\hline Pure & $\bullet$ & 0 \\
Component & & \\
$15 \% \mathrm{CO}_{2} /$ & & 0 \\
$85 \% \mathrm{~N}_{2}$ & & 0 \\
\hline
\end{tabular}

RAM- $6773-70$

Figure 20. Permeation of $\mathrm{N}_{2}$ and $\mathrm{CO}_{2}$, (pure components) and $15 \% \mathrm{CO}_{2} / 85 \% \mathrm{~N}_{2}$ mixture. There is no apparent interference between these two permeating species. 
The temperature dependence of the permeance fits well to an activation energy form. In Tables 7 and 8, we list the Arrhenius parameters for the epoxy cells $\left(85 \% \mathrm{~N}_{2}, 15 \% \mathrm{CO}_{2}\right.$ feed mixture) and for the high temperature cells (pure component and mixture data). These parameters emphasize the larger permeance of the native fibers (epoxy cells) compared to the heat-treated fibers (high temperature cells) in that the $Q_{0}$ values are three to four orders of magnitude higher for the native fibers. However, the activation temperatures are roughly the same.

\section{$\mathbf{N H}_{3} / \mathbf{N}_{2}$ MIXTURES}

A feed mixture of $1.7 \% \mathrm{NH}_{3}, 15.8 \% \mathrm{He}$, and $82.5 \% \mathrm{~N}_{2}$ was used for these experiments at a feed pressure of 215 psia. Tests were performed with two fibers held in epoxy (Aremco 631) and with one fiber held in a high temperature test cell.

The native fibers (epoxy cells) had a factor of 10 higher permeance than the fibers held in a high temperature cell (Figure 21), as is typical of previous data. The data taken with epoxy cells were reproducible, and the two fibers agreed. Unfortunately, only one high temperature cell could be tested before the end of the project. Nevertheless, some trends became clear that bode well for these fibers at room temperature but not at coal gasification conditions. For example, the $\mathrm{NH}_{3}$ permeance is very high $\left(>10^{5}\right.$ Barrer $\left./ \mathrm{cm}\right)$ and the $\mathrm{NH}_{3} / \mathrm{N}_{2}$ selectivities are substantial $(>100)$ for temperatures below $200^{\circ} \mathrm{F}$. The small kinetic diameter of $\mathrm{NH}_{3}(2.6 \AA$, Appendix $\mathrm{D})$ and the degree of adsorption of $\mathrm{NH}_{3}$ on glass is responsible for the high permeance and selectivity. As the temperature rises, the adsorption can be expected to decrease substantially, so that, even though the diffusivity of the ammonia increases with temperature, the ammonia permeance does not increase much with temperature. Hence, the $\mathrm{NH}_{3} / \mathrm{N}_{2}$ selectivity decreases with temperature.

Consequently, the performance of the fibers at conditions of interest to DOE would likely not be particularly attractive for ammonia separation.

The permeance versus selectivity curve (Figure 22) is typical for the epoxy cells but very flat for the high temperature cells. As in the case of $\mathrm{CO}_{2}$ permeation, it appears that surface adsorption of ammonia is more important for transport of ammonia through high temperature cells than through epoxy cells.

\section{PURE COMPONENT DATA}

We had occasion to obtain a variety of pure component permeation data, particularly on helium since helium was often our starting point to verify operability of the system. Helium permeation through native fibers exceeded that through heated fibers by approximately a factor of 
Table 7

ARRHENIUS PARAMETERS FOR $\mathrm{CO}_{2}$ AND $\mathrm{N}_{2}$ FOR EPOXY CELLS

\begin{tabular}{|c|c|c|c|c|}
\hline \multirow[b]{2}{*}{ Cell } & \multicolumn{2}{|c|}{$\begin{array}{l}\text { Pre-exponentlal Factor, } Q_{0} \\
{\left[\mathrm{~cm}^{3}(\mathrm{STP}) / \mathrm{cm}^{2} \mathrm{~s} \mathrm{~cm} \mathrm{Hgl}\right.}\end{array}$} & \multicolumn{2}{|c|}{ Actlvation Temperature (K) } \\
\hline & $\mathrm{N}_{2}$ & $\mathrm{CO}_{2}$ & $\mathbf{N}_{2}$ & $\mathrm{CO}_{2}$ \\
\hline 1 & $1.24 \cdot 10^{9}$ & $5.57 \cdot 10^{7}$ & $4460 \pm 110$ & $2470 \pm 299$ \\
\hline 2 & $6.32 \cdot 10^{8}$ & $6.57 \cdot 10^{7}$ & $4200 \pm 62$ & $2540 \pm 270$ \\
\hline
\end{tabular}

Permeance $=Q_{0} \exp \left(-T_{a c t} / T\right), Q_{0}$ in Barrer/cm, $T$ in kelvins.

Fibers from PPG Blanket No. 909-67-01.

Table 8

ARRHENIUS PARAMETERS FOR $\mathrm{CO}_{2}$ AND $\mathrm{N}_{2}$ PURE COMPONENT

AND MIXTURE PERMEANCE DATA; HIGH TEMPERATURE CELLS

\begin{tabular}{|c|c|c|c|c|}
\hline \multirow[b]{2}{*}{ Flber Number } & \multicolumn{2}{|c|}{ Pure Component } & \multirow{2}{*}{$\frac{15 \% \mathrm{CO}_{2} / 85 \%}{Q_{0}}$} & \multirow{2}{*}{$\begin{array}{l}\text { Mixture } \\
\text { Tact }\end{array}$} \\
\hline & $Q_{0}$ & Tact & & \\
\hline \multicolumn{5}{|l|}{ Nitrogen } \\
\hline $12-16-90-1$ & 150,000 & 3,800 & $1,450,000$ & 5,080 \\
\hline $12-16-90-2$ & 452,000 & 3,700 & 144,000 & 3,100 \\
\hline \multicolumn{5}{|c|}{ Carbon Dloxide } \\
\hline $12-16-90-1$ & 45,000 & 1,930 & 403,000 & 3,300 \\
\hline $12-16-90-2$ & 39,800 & 1,370 & 46,100 & 1,340 \\
\hline
\end{tabular}

Permeance $=Q_{0} \exp \left(-T_{a c t} / T\right), Q_{0}$ in Barrer $/ \mathrm{cm}, T$ in kelvins.

Fibers from PPG Blanket No. 909-67-01. 


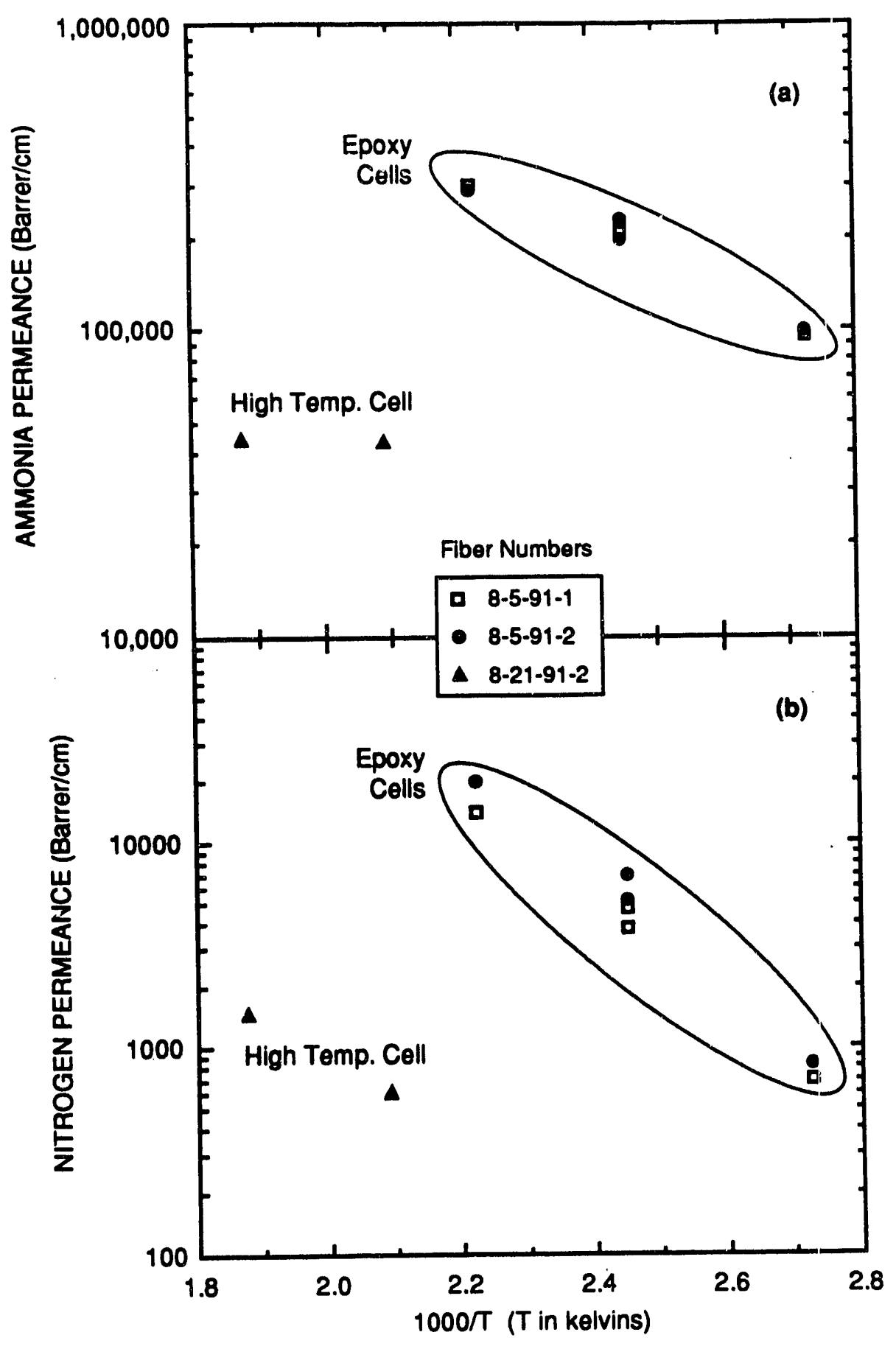

RAM-6.773-72

Figure 21. Performance of native fibers and high temperature cells for $\mathrm{NH}_{3}$ and $\mathrm{N}_{2}$.

Feed gas is $1.7 \% \mathrm{NH}_{3}, 82.5 \% \mathrm{~N}_{2}$, balance helium at 215 pisia. 


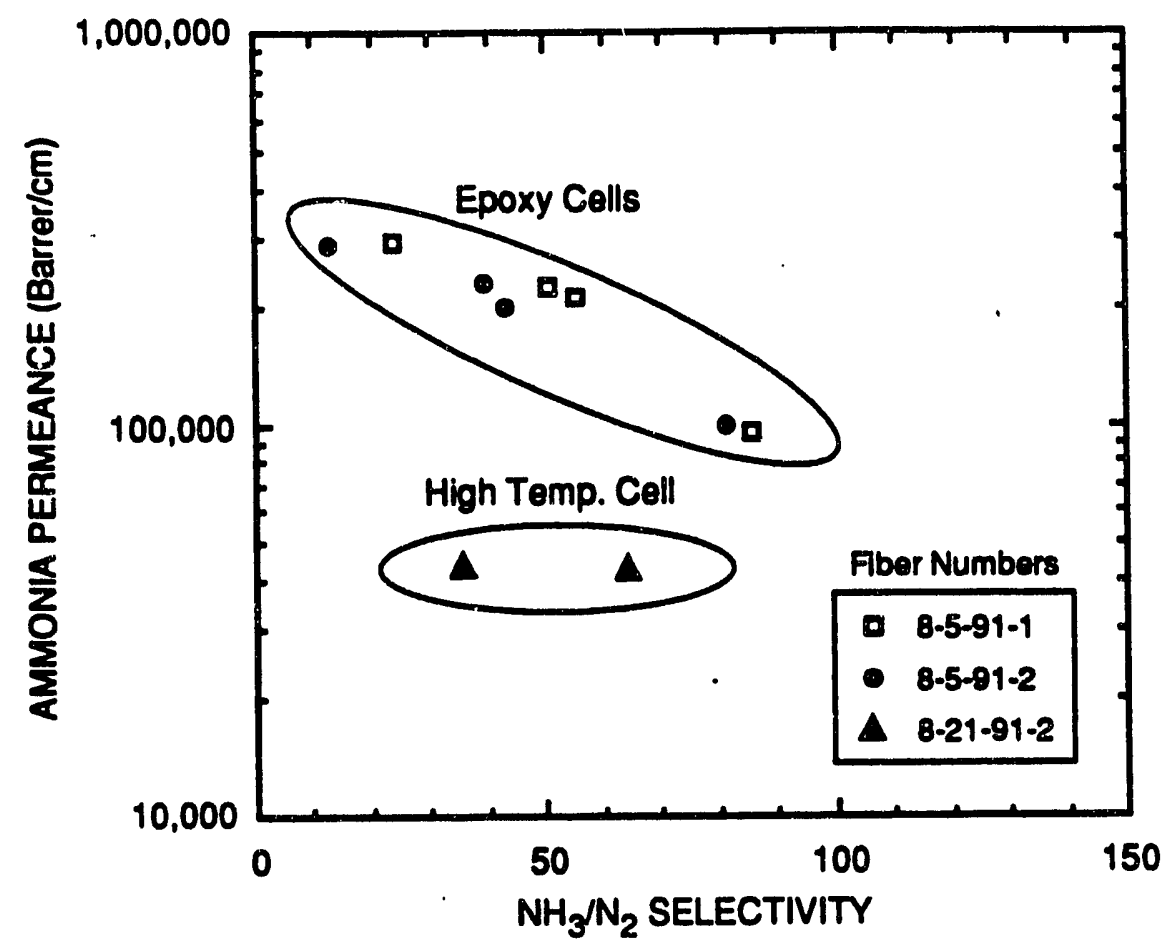

คAM-6773-23A

Figure 22. Permeance/selectivity trade-off for $\mathrm{NH}_{3} \mathrm{~N}_{2}$ permeation. Permeance of $\mathrm{NH}_{3}$ is remarkably flat for high temperature test coll. 
10 (Figure 23). The permeation roughly followed an exponential behavior but with a fairly low activation energy. The curve fits of the permeance for the epoxy cells and high temperature cells are as follows:

$$
\text { Epoxy cells: } Q_{H e}=1.86 \cdot 10^{7} \exp \left(\frac{-1000 \mathrm{~K}}{\mathrm{~T}}\right) \mathrm{Barrer} / \mathrm{cm}
$$

$$
\text { High temperature cells: } Q_{H e}=1.35 \cdot 10^{6} \exp \left(\frac{-660 \mathrm{~K}}{\mathrm{~T}}\right) \mathrm{Barrer} / \mathrm{cm}
$$

Helium permeates more rapidly than any other species we tested, as expected from its small molecular size ( $2.6 \AA)$.

To decide if it was reasonable to extrapolate our results into the temperature range of interest to DOE (i.e., $1000^{\circ} \mathrm{F}$ ), a group of fibers were heated at $1000^{\circ} \mathrm{F}$ for $24 \mathrm{~h}$ and then tested these in high temperature test cells. The preheated fibers behaved the same as those not preheated (Figure 24), implying that we can reasonably extrapolate our results to the DOE temperature range $\left(>1000^{\circ} \mathrm{F}\right)$.

Other pure component data for $\mathrm{CO}_{2}, \mathrm{~N}_{2}, \mathrm{CO}$, and $\mathrm{H}_{2}$ are given in Appendix $\mathrm{C}$. 


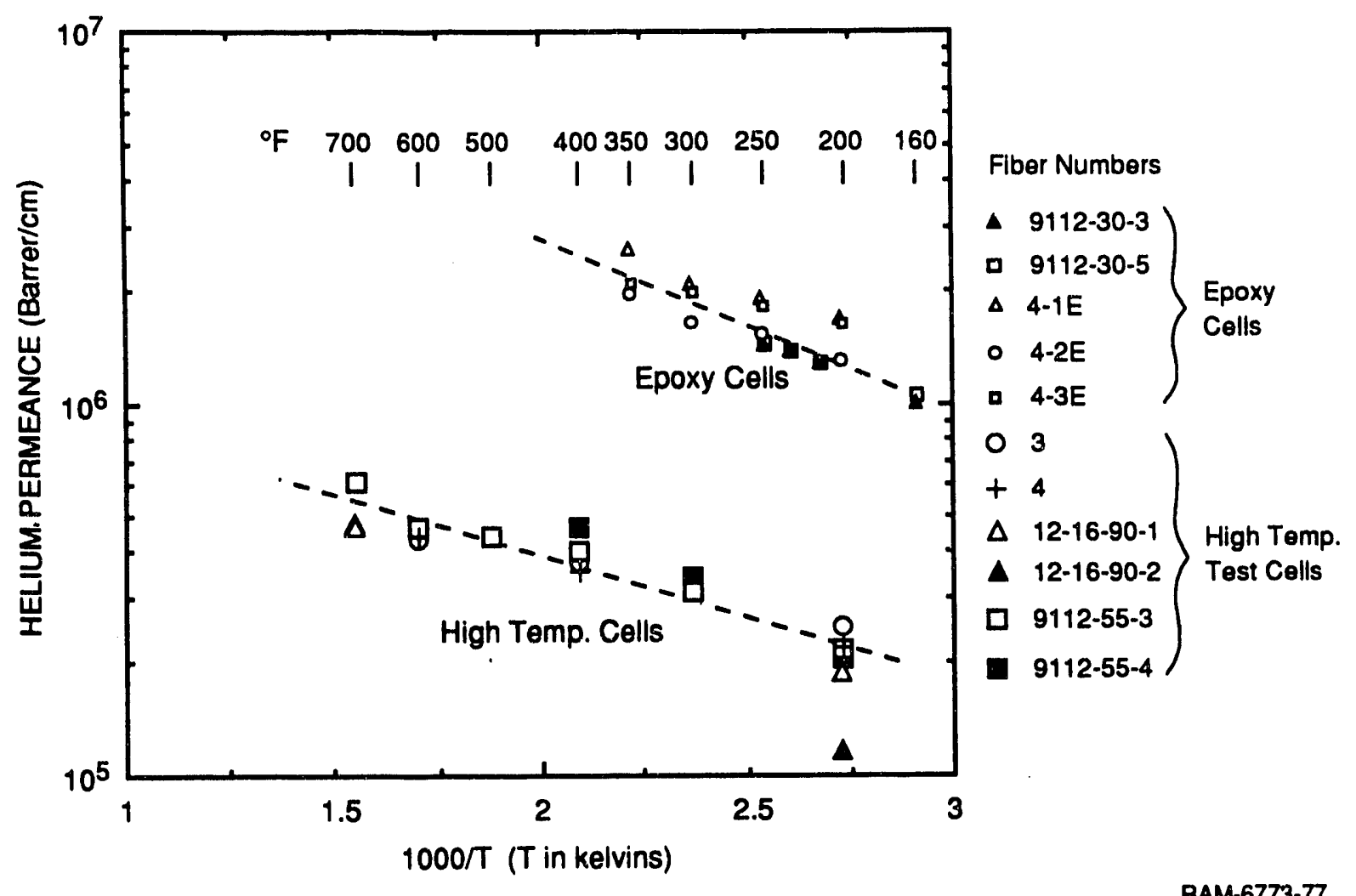

Figure 23. Comparison of helium permeation in epoxy cells and high temperature cells. 


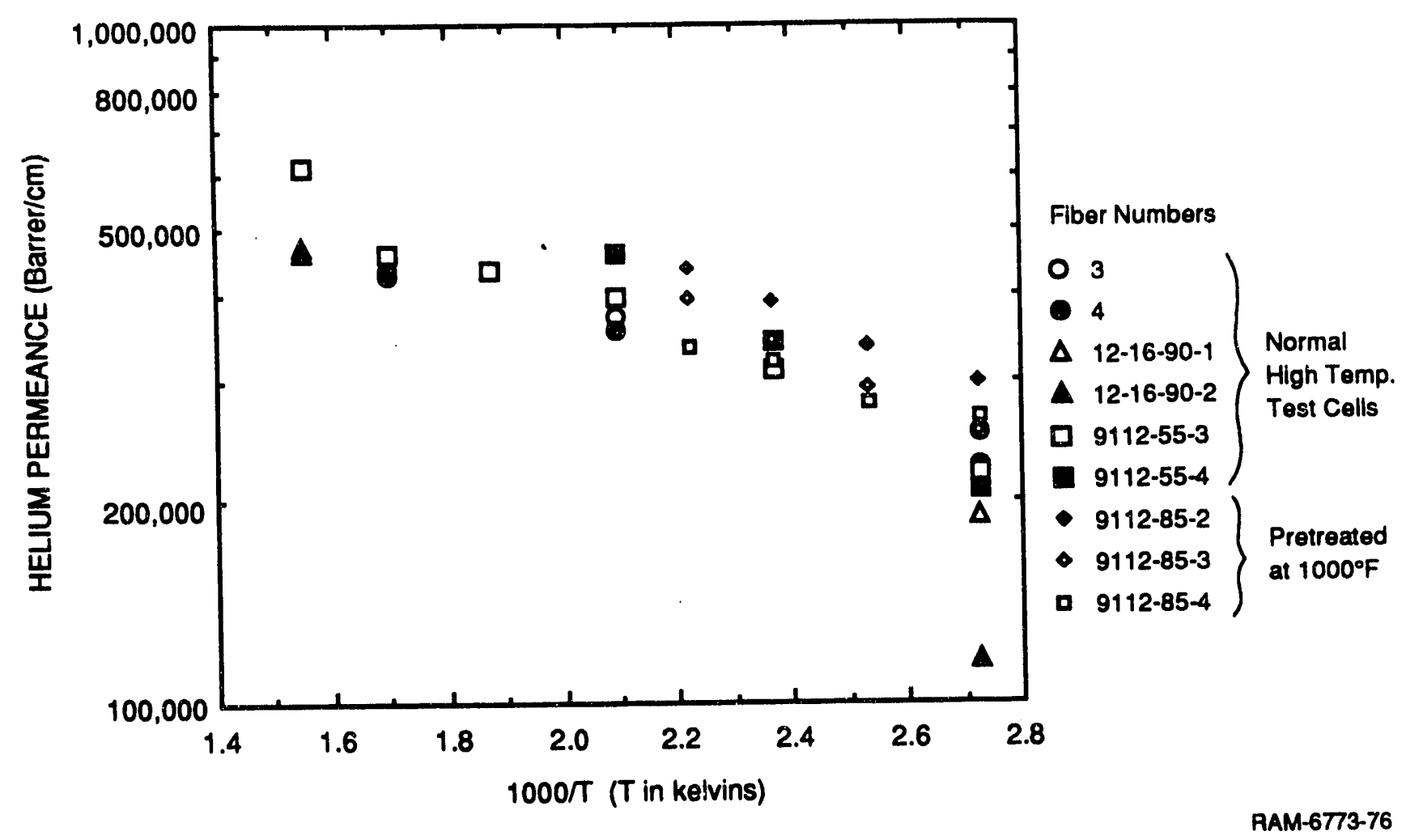

Figure 24. Comparison of normal high temperature cells to cells made with pretreated fibers.

Fibers pretreated to $1000^{\circ} \mathrm{F}$ behaved the same as fibers not treated to $1000^{\circ} \mathrm{F}$ but subjected to high temperature test cell preparation. 


\section{DISCUSSION AND CONCLUSIONS}

The glass fibers show very favorable properties for $\mathrm{H}_{2} / \mathrm{CO}$ separation in the temperature range $300^{\circ}$ to $500^{\circ} \mathrm{F}$ when prepared in a high temperature test cell. Therefore, the fibers may be immediately useful in the DOE gasification program for removing hydrogen from a gasifier product gas before a water-gas shift reactor (e.g., see Figures 47 and 48 in Baker, et al., 1990). The synthesis gas would have to be cooled to $500^{\circ} \mathrm{F}$ before entering the membrane, but this degree of cooling is much less than that required for conventional $\mathrm{H}_{2}$ separation processes and may be economically attractive.

The fibers are not suitable for operation at the high temperatures envisioned for most DOE applications $\left(>1000^{\circ} \mathrm{F}\right)$. The permeation drops to a very low value (essentially zero) if the fibers are heated beyond about $1400^{\circ} \mathrm{F}$. Additionally, there is no technology available for making a seal that holds 215 psia pressure above $700^{\circ} \mathrm{F}$. Indeed, much of the effort was expended on getting a seal to hold pressure up to $700^{\circ} \mathrm{F}$. Problems of the mismatch of the coefficients of thermal expansion between silica and all known nonsilica compounds will thwart any attempt to produce a seal at temperatures much above $700^{\circ} \mathrm{F}$. This issue will likely plague attempts to make hollow fiber membranes of any kind work at temperatures of interest to DOE.

The selectivities of the fibers for the key gas pairs $\mathrm{H}_{2} / \mathrm{CO}, \mathrm{CO}_{2} / \mathrm{N}_{2}$, and $\mathrm{NH}_{3} / \mathrm{N}_{2}$ are quite attractive at low to moderate temperatures but decrease substantially at temperatures above $700^{\circ} \mathrm{F}$. This phenomenon occurs because at high temperatures the permeating species are beginning to surmount rather easily the activation energy barriers imposed by the three-dimensional membrane pore structure. Hence, a material that would operate successfully under conditions of interest to DOE $\left(>1000^{\circ} \mathrm{F}\right)$ would need higher activation energy barriers for the species meant to be retained by the membrane.

The fibers exhibit molecular sieving properties leading to selectivities well above those possible with Knudsen barriers. Nevertheless, the conditions of interest to DOE put excessive demands on the material properties. Hence, the contributions of this work to DOE's program are (1) a demonstration that molecular sieving is possible at temperatures well above the temperatures at which polymer membranes operate, (2) identification of the outstanding $\mathrm{H}_{2} / \mathrm{CO}$ separation properties at moderate temperatures of possible immediate application in DOE's gasification program, and (3) identification of the serious materials issues DOE will face in attempting to use any hollow fiber membranes at temperatures above $700^{\circ} \mathrm{F}$ simultaneously with several hundred psi pressure. 


\section{REFERENCES}

Baker, R. W., C. M. Bell, P. Chow, J. Louie, J. M. Mohr, K. V. Peinemann, I. Pinnau, J. G. Wijmans, D. E. Gottschlich, and D. L. Roberts, "Low Cost Hydrogen/Novel Membrane Technology for Hydrogen Separation from Synthesis Gas," DOE/MC/22130-2983, October 1990.

Barch, H. W., and W. P. Marshall, "Method and Apparatus for Forming Hollow Fibers," US Patent 4,491,904, Assignee: PPG Industries, Inc., Pittsburgh, PA (July 17, 1990).

Barrer, R. M., Diffusion in and Through Solids, (Cambridge University Press, Cambridge, England, 1951).

Barrer, R. M., Zeolites and Clay Materials as Sorbents and Molecular Sieves (Academic Press, London, 1978).

Benedict, M., T. H. Pigford, and H. W. Levi, Nuclear Engineering (McGraw-Hill, New York, 1981).

Clark, A., The Theory of Adsorption and Catalysis (Academic Press, New York, 1970).

Hammel, J. J., "Porous Inorganic Siliceous-Containing Gas Enriching Material and Process of Manufacture and Use," US Patent 4,853,001, Assignee: PPG Industries, Inc., Pittsburgh, PA (August 1, 1989).

Hammel, J. J., W. J. Robertson, W. P. Marshall, H. W. Barch, B. Das, M. A. Smoot, and P. Beaver, "Process of Gas Enrichment with Porous Siliceous-Containing Material," US Patent 4,842,620, Assignee: PPG Industries, Inc., Pittsburgh, PA (June 27, 1989).

Hathaway, P. E., and M. E. Davis, "High Resolution, Quasi-Equilibrium Sorption Studies on Molecular Sieves," Catalysis Letters, 5, 333-348 (1990).

Hill, T. L., An Introduction to Statistical Thermodynamics (Addison-Wesley Publishing Company, Reading Massachusetts, 1960).

Horvath, G., and K. Kawazoe, "Method for the Calculation of Effective Pore Size Distribution in Molecular Sieve Carbon," J. Chem. Eng. Japan, 16, 420-425 (1983).

Hwang, S. T., M. S. Thesis, University of Iowa, Iowa City, IA, 1966.

Hwang, S. T., and K. Kammermeyer, Membranes in Separations (R. E. Krieger Publishing Company, Malabar, FL, 1984).

Iler, R. K., The Chemistry of Silica, (John Wiley and Sons, New York, 1979).

Kammermeyer, K., and D. D. Wyrick, "Effect of Adsorption in Barrier Separation," Ind. Eng. Chem., 50, 1309-1310 (1958).

Kammermeyer, K., "Gas and Vapor Separations by Means of Membranes," in Progress in Separation and Purification, Vol. I, E. S. Perry, Ed. (John Wiley and Sons, New York, 1968). 
Knudsen, M., Ann. Physik., 28, 75 (1909).

Myers, A. L., and J. M. Prausnitz, "Thermodynamics of Mixed Gas Adsorption," AIChEJ, 11, $121-127$ (1965).

Nakano, Y., Y. Tsuneshige, H. Shimizu, and T. Katou, "Control of the Micropores in Molecular Sieving Carbon (MSC) by Impregnation of Hydrocarbons and Heat Treatment," Int. Chem. Eng., 31, 342-350 (1991).

Reed, D. A., and G. Ehrlich, "Surface Diffusion, Atomic Jump Rates, and Thermodynamics," Surface Sci., 102, 588-609 (1981).

Robeson, L. M., "Correlation of Separation Factor Versus Permeability for Polymeric Membranes," J. Mem. Sci., 62, 165-85 (1991).

Smyth, H. D., Atomic Energy for Military Purposes (Princeton University Press, Princeton-NJ, 1946).

Sze, S. M., VLSI Technology (McGraw-Hill, New York, 1983).

Tock, R. W., and K. Kammermeyer, "Temperature--Separation Factor Relationships in Gaseous Diffusion," AlChEJ, 15, 715-718 (1969).

Uhlhorn, R. J. R., K. Keizer, A. J. Burggraaf, "Formation of and Gas Transport Mechanisms in Ceramic Membranes," American Chemical Society, Toronto, June 1988.

Way, J. D., M. Hassan, and A. A. King, "Molecular Sieving Silica Hollow Fiber Membranes for Gas Separations," to be submitted to J. Memb. Sci., 1992.

Way, J. D., and D. L. Roberts, "Hollow Fiber Inorganic Membranes for Gas Separation," Sep. Sci. Tech., 27, 29-41 (1992).

Yang, R. T., Gas Separation by Adsorption Processes (Buttersworth, Boston, 1987). 
Appendix A

DERIVATION OF CROSS TERM FOR

MULTICOMPONENT SURFACE DIFFUSION FROM IDEAL ADSORBED SOLUTION THEORY 


\section{DERIVATION OF CROSS TERM FOR MULTICOMPONENT SURFACE DIFFUSION FROM IDEAL ADSORBED SOLUTION THEORY}

\section{SUMMARY OF IDEAL ADSORBED SOLUTION THEORY}

Ideal adsorbed solution theory (IAS; Myers and Prausnitz, 1965) provides a sound basis to compute multicomponent isotherms from pure component data. In particular, IAS allows one to write an analytical expression for $\partial \mathrm{n}_{\mathrm{j}} / \partial \mathrm{P}_{\mathrm{j}}$ in terms of pure component isotherms and the known partial pressures in the gas phase, $P_{j}$ (see Eq. 9 in main text). The term $\partial n_{j} / \partial P_{j}$ can be called the "cross" term because nonzero values of $\partial n_{i} / \partial P_{j}$ allow a flux of species $j$ to give rise to a flux in species i.

First, it is important to record the relevant equations from IAS theory. The spreading pressure, $\pi$, of the adsorbed phase (the negative of surface tension) is a basic concept of any thermodynamics of an adsorbed phase. Ideal adsorbed solution theory establishes the equality of all of the surface pressures of each individual species at a fictitional "saturation partial pressure" of the pure component, $P_{i}^{o}(\pi)$. This idea serves to define the value $P_{i}^{o}(\pi)$. Then, the chemical potential of the adsorbed species becomes

$$
\mu_{i}=\mu_{i}^{o}(T)+R T \ln \left[\gamma_{i} x_{i} P_{i}^{o}(\pi)\right]
$$

where $\mathrm{x}_{\mathrm{i}}$ is the mole fraction of species $\mathrm{i}$ on the surface. The "ideal" part of IAS is to set the activity coefficients, $\gamma_{i}$, equal to 1 . Consequently, equilibrium between the gas and adsorbed phases can be written

$$
P_{i}=P_{i}^{0}(\pi) x_{i}
$$

where $P_{i}$ is the gas phase partial pressure of species $i$. More generally, the left-hand side of Eq. A-2 is the fugacity of species $I$ in the gas phase.

Another result of setting the activity coefficients equal to 1 is that there is no area change upon mixing. Consequently, the total moles of adsorbed gas is given by

$$
n_{t}=\left(\sum_{k=1}^{N} \frac{x_{k}}{n_{k}^{0}}\right)^{-1}
$$


where $n_{k}^{0}$ is the moles of pure component $k$ that would be adsorbed at the given spreading pressure. Hence, $n_{k}^{0}$ is known from the pure component isotherms $\left[n_{k}^{0}=n_{k}^{0}\left(P_{k}^{o}(\pi)\right]\right.$.

Since the sum of the mole fractions of all adsorbed species must add to 1 , the following $\mathrm{N}$ equations determine the spreading pressure and hence the composition of the adsorbed phase:

$$
\Psi_{1}^{\circ}\left(\mathrm{P}_{1}^{\mathrm{o}}\right)=\Psi_{2}^{\mathrm{o}}\left(\mathrm{P}_{2}^{\mathrm{o}}\right)=\cdots=\Psi_{\mathrm{N}}^{\mathrm{o}}\left(\mathrm{P}_{\mathrm{N}}^{\mathrm{o}}\right)
$$

(N-1 equations)

and

$$
\sum_{k=1}^{N} \frac{P_{k}}{P_{k}^{0}}=1
$$

where $\Psi_{\mathrm{i}}^{0}$ is the (dimensionless) spreading pressure.

Once the spreading pressure is known, the $P_{i}^{0}$ values are known, the $n_{i}^{o}$ values can be computed from the pure component isotherms, and finally, the moles of each species adsorbed per unit mass of adsorbent can be computed from

$$
\frac{n_{i}}{n_{t}}=x_{i}
$$

which yields (from Eqs. A-2 and A-3)

$$
n_{i}=\left(\frac{P_{i}}{P_{i}^{0}}\right)\left(\sum_{k=1}^{N} \frac{P_{k}}{P_{k}^{0} n_{k}^{0}}\right)^{-1}
$$

Equations A-4, A-5, and A-7 [along with pure component isotherm data $n_{k}^{0}=F\left(P_{k}^{0}\right)$ ] suffice to compute the $n_{i}$ values for any given gas phase mixture (partial pressures $P_{1}, P_{2}, \ldots, P_{N}$ ).

\section{Computation of $\partial \mathrm{N}_{\mathrm{I}} / \partial \mathbf{P}_{\mathrm{J}}$}

First, using Eq. A-7, we have

$$
\begin{aligned}
\frac{\partial n_{i}}{\partial P_{j}} & =\frac{n_{i}}{P_{i}^{0}} \frac{\partial P_{i}}{\partial P_{j}}-\frac{P_{i} n_{l}}{\left(P_{i}^{0}\right)^{2}} \frac{\partial P_{i}^{o}}{\partial P_{j}} \\
& -\frac{P_{i} n_{i}^{2}}{P_{i}^{0}} \frac{\partial}{\partial P_{j}}\left(\sum_{k=1}^{N} \frac{P_{k}}{P_{k}^{o} n_{k}^{0}}\right)
\end{aligned}
$$

(Eq. A-3 has been used to simplify the notation). 
The partial derivative in the third term on the right-hand side of Eq. A-8 is

$$
\frac{\partial}{\partial P_{j}}\left(\sum_{k=1}^{N} \frac{P_{k}}{P_{k}^{o} n_{k}^{0}}\right)=\sum_{k=1}^{N}\left[\frac{1}{P_{k}^{o} n_{k}^{0}} \frac{\partial P_{k}}{\partial P_{j}}-\frac{P_{k}}{n_{k}^{0}\left(P_{k}^{o}\right)^{2}} \frac{\partial P_{k}^{o}}{\partial P_{j}}-\frac{P_{k}}{P_{k}^{o}\left(n_{k}^{0}\right)^{2}} \frac{\partial n_{k}^{0}}{\partial P_{j}}\right]
$$

In Eqs. A-8 and A-9, certain terms are equal to either zero or one as follows:

$$
\frac{\partial P_{i}}{\partial P_{j}}=\delta_{i j}
$$

and

$$
\frac{\partial P_{k}}{\partial P_{j}}=\delta_{k j}
$$

Here, $\delta_{i j}$ is the Kronnicker Delta function defined to be equal to one if $i$ equals $j$ and equal to zero otherwise. With these definitions, Eqs. A-8 and A-9 combine to

$$
\begin{aligned}
& \frac{\partial n_{i}}{\partial P_{j}}=\frac{n_{t}}{P_{i}^{0}} \delta_{i j}-\frac{P_{i} n_{l}}{\left(P_{i}^{0}\right)^{2}} \frac{\partial P_{i}^{0}}{\partial P_{j}} \\
& -\frac{P_{i} n_{t}^{2}}{P_{i}^{0}} \frac{1}{P_{j}^{0} n_{j}^{0}}+\frac{P_{i} n_{l}^{2}}{P_{i}^{0}} \sum_{k=1}^{N}\left[\frac{P_{k}}{n_{k}^{0}\left(P_{k}^{o}\right)^{2}} \frac{\partial P_{k}^{o}}{\partial P_{j}}+\frac{P_{k}}{P_{k}^{o}\left(n_{k}^{0}\right)^{2}} \frac{\partial n_{k}^{0}}{\partial P_{j}}\right]
\end{aligned}
$$

Hence, the value of $\partial n_{j} / \partial P_{j}$ in Eq. A-12 can be computed if the derivatives $\partial n_{k}^{0} / \partial P_{j}$ and $\partial P_{k}^{0} / \partial P_{j}$ are known.

The partial derivatives $\partial \mathrm{n}_{\mathrm{k}}^{0} \partial \mathrm{P}_{\mathrm{j}}$ can be found from pure component isotherms and $\partial \mathrm{P}_{\mathrm{k}}^{\circ} \partial \mathrm{P}_{\mathrm{j}}$ as follows:

$$
\frac{\partial n_{k}^{0}}{\partial P_{j}}=\sum_{m=1}^{N} \frac{\partial N_{k}^{0}}{\partial P_{m}^{o}} \frac{\partial P_{m}^{o}}{\partial P_{j}}=\frac{\partial n_{k}^{0}}{\partial P_{k}^{0}} \frac{\partial P_{k}^{o}}{\partial P_{j}}
$$

Here, the summation in Eq. A-13 was simplified by the observation

$$
\frac{\partial n_{k}^{o}}{\partial P_{m}^{0}}=0 \text { for } k \neq m
$$


The terms $\partial n_{k}^{0} \partial \partial P_{k}^{0}$ are known from pure component isotherms. Consequently, the only remaining expression that we need is for the terms $\partial \mathrm{P}_{\mathrm{k}}^{0} / \partial \mathrm{P}_{\mathrm{j}}$.

In a system with $\mathrm{N}$ species, there are $\mathrm{N} \times \mathrm{N}$ partial derivatives of the form $\partial \mathrm{P}_{\mathrm{k}}^{0} / \partial \mathrm{P}_{\mathrm{j}}($ all $\mathrm{k}$, all j). These partial derivatives are found from Eqs. A-4 and A-5. Equation A-4, differentiated with respect to $P_{i}$, gives $N \times(N-1)$ equations of the form

$$
\begin{gathered}
\frac{\partial \Psi_{1}^{0}}{\partial P_{1}^{o}} \frac{\partial P_{1}^{o}}{\partial P_{i}}=\frac{\partial \Psi_{2}^{o}}{\partial P_{2}^{0}} \frac{\partial P_{2}^{\prime \prime}}{\partial P_{i}}=\cdots=\frac{\partial \Psi_{N}^{o}}{\partial P_{N}^{o}} \frac{\partial P_{N}^{o}}{\partial P_{i}} \\
\text { (all } \mathrm{i}, N x \text { (N-1) equations) }
\end{gathered}
$$

Equation $A-5$, differentiated with respect to $P_{i}$, gives $N$ equations of the form

$$
\begin{aligned}
& \frac{1}{P_{i}^{0}}=\sum_{k=1}^{N} \frac{P_{k}}{\left(P_{k}^{0}\right)^{2}} \frac{\partial P_{k}^{o}}{\partial P_{i}} \\
& \text { (all i, N equations) }
\end{aligned}
$$

Equations A-15 and A-16 represent $N \times N$ equations for the $N \times N$ unknowns $\partial P_{k}^{0} / \partial P_{j}$.

To simplify the expressions, note that the definition of $\Psi_{i}^{0}$ is

$$
\Psi_{\mathrm{i}}^{0}=\int_{0}^{P_{\mathrm{i}}^{0}} \frac{\mathrm{n}(\varepsilon)}{\varepsilon} \mathrm{d} \varepsilon
$$

so that

$$
\frac{\partial \Psi_{i}^{0}}{\partial P_{i}^{0}}=\frac{n_{i}^{o}\left(P_{i}^{o}\right)}{P_{i}^{o}}
$$

Consequently, the $\mathrm{N} \times \mathrm{N}$ equations are

$$
\frac{n_{1}^{o}\left(P_{1}^{o}\right)}{P_{1}^{o}} \frac{\partial P_{1}^{o}}{\partial P_{i}}=\frac{n_{2}^{o}\left(P_{2}^{o}\right)}{P_{2}^{o}} \frac{\partial P_{2}^{o}}{\partial P_{i}}=\cdots=\frac{n_{N}^{o}\left(P_{N}^{o}\right)}{P_{N}^{o}} \frac{\partial P_{N}^{o}}{\partial P_{i}}
$$

with

$$
\frac{1}{P_{i}^{0}}=\sum_{k=1}^{N} \frac{P_{k}}{\left(P_{k}^{0}\right)^{2}} \frac{\partial P_{k}^{0}}{\partial P_{i}}
$$

A-4 
These $\mathrm{N} \times \mathrm{N}$ equations can be written in matrix form as follows:

$$
[\mathrm{A}] \cdot[\mathrm{X}]=[\mathrm{B}]
$$

where the matrix $A$ has the entries

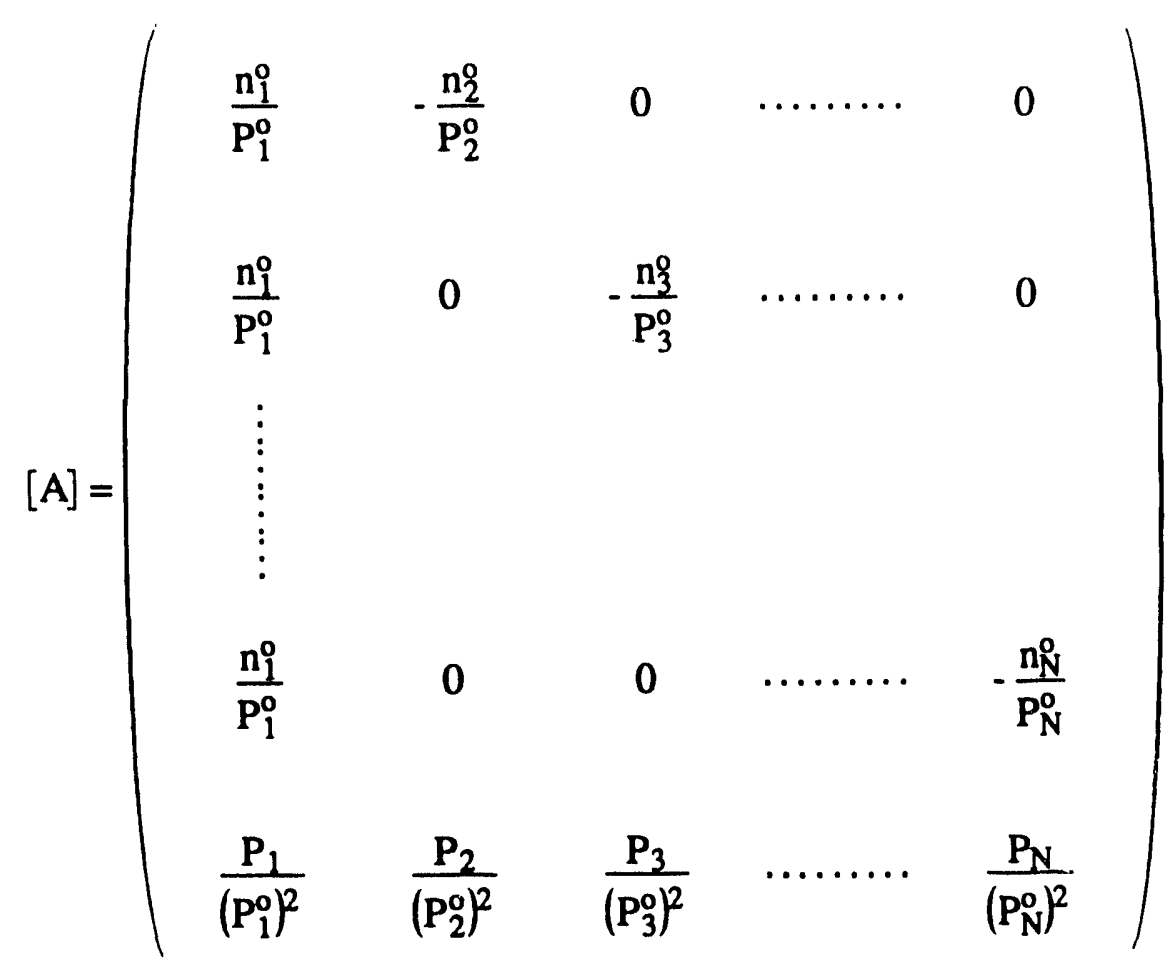

and the matrix $B$ has the entries

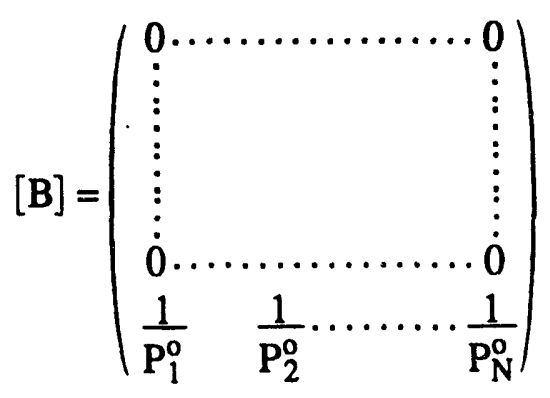

and the matrix of partial derivatives has the form*

* A shorthand notation for the matrix $[X]$ can be derived from the observation that the element in row $\mathrm{m}$, column $\mathrm{n}$ of matrix $[X]$ is given by $\partial \mathrm{P}_{m}^{\circ} / \partial \mathrm{P}_{\mathrm{n}}$. Hence, $X_{m n}=\partial \mathrm{P}_{\mathrm{m}}^{\circ} / \partial \mathrm{P}_{\mathrm{n}}$.

$$
\text { A-5 }
$$




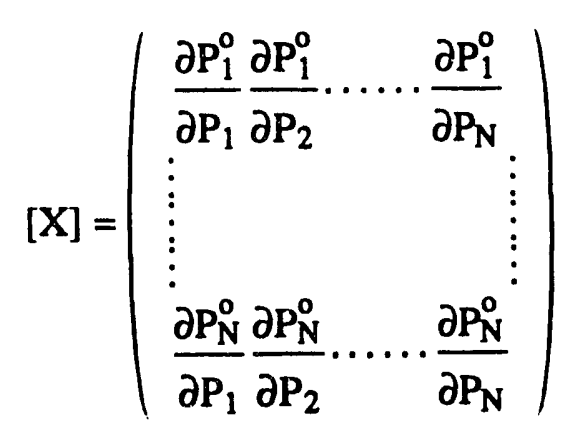

Mathematically, then

$$
[\mathrm{X}]=[\mathrm{A}]^{-1} \cdot[\mathrm{B}]
$$

Now, returning to the original objective, (i.e., to find $\partial \mathrm{n}_{\mathrm{i}} / \partial \mathrm{P}_{\mathrm{j}}$ ), Eqs. A-12 and A-13 can be combined to find

$$
\begin{aligned}
\frac{\partial n_{i}}{\partial P_{j}}= & \frac{n_{t}}{P_{i}^{0}} \delta_{i j}-\frac{P_{j} n_{t}}{\left(P_{i}^{o}\right)^{2}} \frac{\partial P_{i}^{o}}{\partial P_{j}}-\frac{P_{i} n_{l}^{2}}{P_{i}^{0} P_{j}^{o} n_{j}^{o}} \\
& +\frac{P_{j} n_{l}^{2}}{P_{i}^{o}} \sum_{k=1}^{N}\left[\left(\frac{1}{P_{k}^{o}}+\frac{1}{n_{k}^{o}} \frac{\partial n_{k}^{o}}{\partial P_{k}^{o}}\right) \frac{P_{k}}{n_{k}^{0} P_{k}^{0}} \frac{\partial P_{k}^{o}}{\partial P_{j}}\right]
\end{aligned}
$$

where all quantities are known as a function of the independent variables $P_{i}$ by way of Eqs. A-3, A-4, A-5, A-24, and pure component isotherm data [which yield $n_{k}^{0}\left(P_{k}^{0}\right)$ and $\partial n_{k}^{0} / \partial P_{k}^{0}$ ].

Finally, the flux is given by substituting Eq. A-25 into Eq. 9 in the main text. 


\section{REFERENCES}

Myers, A. L., and J. M. Prausnitz, "Thermodynamics of Mixed Gas Adsorption," AIChE J, 11, 121-127 (1965).

Reed, D. A., and G. Ehrlich, "Surface Diffusion, Atomic Jump Rates, and Thermodynamics," Surface Sci., 102, 588-609 (1981). 
Appendix B

PROCEDURE FOIR MAKING HIGH TEMPERATURE TEST CELLS WITH INTERNAL SEAL 


\section{TECHNIQUE FOR HIGH TEMPERATURE CELL PREPARATION WITH INTERNAL SEAL}

The following procedure explains in detail how the high temperature test cells were made for permeation testing. Figures in the main text will be helpful for understanding this procedure.

\section{MATERIALS (PER CELL)}

About 12 in. of PPG fiber

Densified alumina tube, 1/8-in. I.D. x11/16-in. O.D., 3-1/2 in. long (Coors

Ceramic, Golden, $\mathrm{CO}$ )

Metal shell (1/4 in. O.D., 316 stainless steel tube)

Grafoil ferrule, $1 / 8$ in.

Fiber threading rod

5-Minute Epoxy (Devcon Corporation, Danvers, MA)

Aremco 569 Inorganic Adhesive (Aremco Products, Inc., Ossining, NY)

Aremco 569 Thinner (Aremco Products, Inc., Ossining, NY)

Tripod cell holder (holds three cells; see Figure B-1)

6-in. Disposable cotton applicators

Cotronics $1529 \mathrm{H}$ High Temperature Sealer (Cotronics Corporation, Brooklyn, NY)

Corning 7583 Inorganic Glaze (Corning Glass, Corning, NY)

2-Ethoxy ethanol

Curing oven with at least a three-stage programmable ramp and dwell controller

Tube furnace and quartz tube capable of $1000^{\circ} \mathrm{F}$.

\section{MATERIAL DESCRIPTION AND PROPERTIES}

A variety of sealants, glazes, and potting compounds were used as described below. 


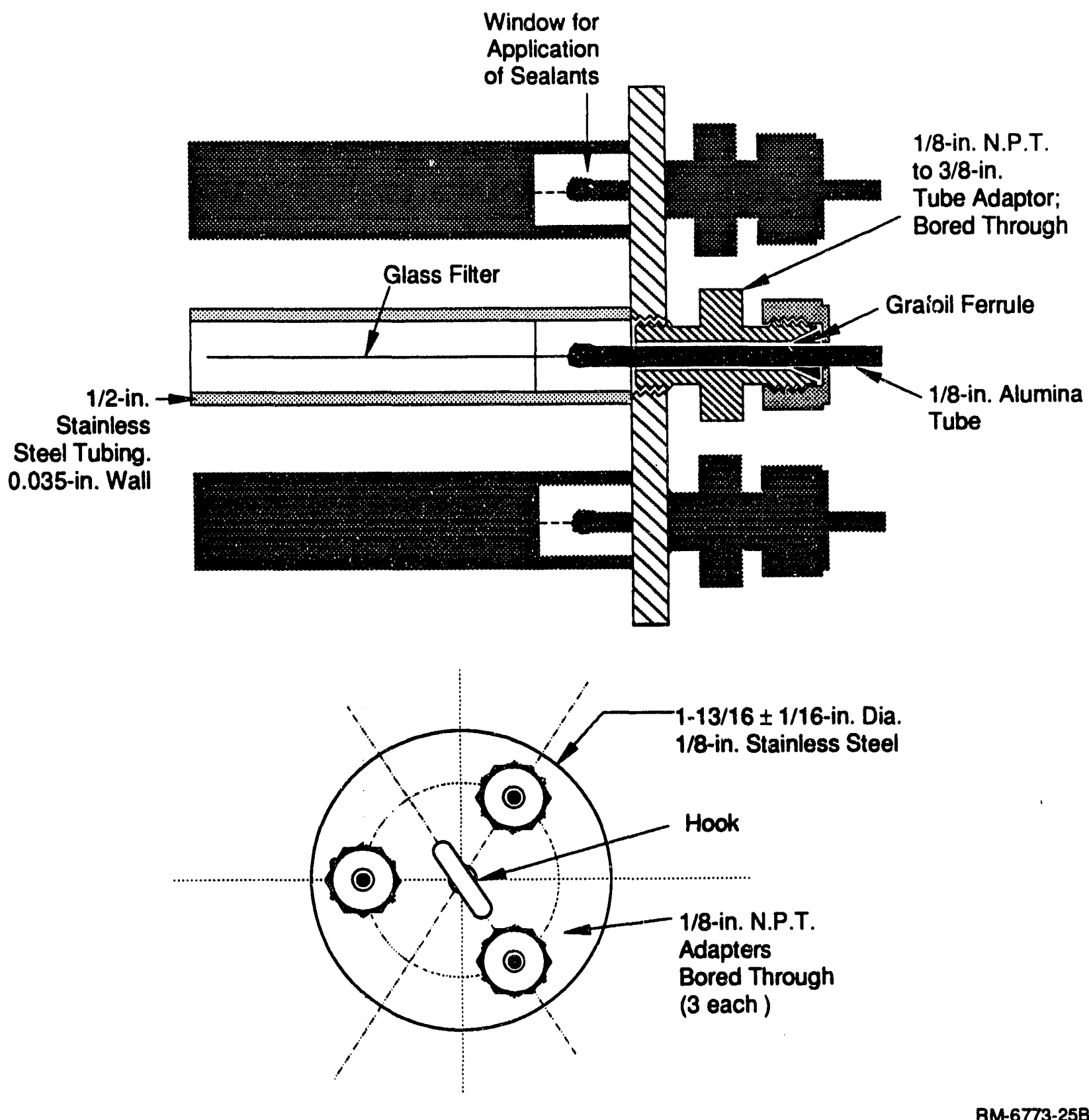

RM-6773-25B

Figure B-1. Schematic diagram of tripod fiber holder.

High temperature test cells were prepared in this tripod. The tripod ft in our curing fumace, so fibers were never handled after being placed in the tripod holder (see text of this Appendix). 


\section{Aremco 569 Inorganic Adhesive}

Aremco 569 High Temperature Inorganic Adhesive ("569") is an alumina based inorganic adhesive that is reported to have less than $1 \%$ porosity after curing (any porosity is too much in our application). It has a coefficient of thermal expansion of $4.2 \times 10^{-6} \mathrm{in} . / \mathrm{in} . / \mathrm{F}$ (compared to $4.11 \times 10^{-6}$ in./in. $/{ }^{\circ} \mathrm{F}$ for $\mathrm{Al}_{2} \mathrm{O}_{3}$ ). The 569 continues to lose weight for about 12-16 hours after application. The thinner is believed to be a suspension of alumina particles in a mixture of organic solvents and water.

\section{Duraseal 1529H High Temperature Sealer}

Cotronics Duraseal 1529H High Temperature Sealer ("1529H") is a catalyzed silicone polymer dissolved in toluene. $1529 \mathrm{H}$ forms a resilient, silicone rubber-like coating that is rated to $900^{\circ} \mathrm{F}$. The material does not adhere well to smooth surfaces such as densified alumina. $1529 \mathrm{H}$ has a shelf-life of only six months, after which the catalyst comes out of solution and does not completely redissolve when the bottle is shaken.

\section{Corning 7583 Glaze}

Corning 7583 Lead Zinc Borosilicate Devitrifying Sealing Glass ("7583") is used for sealing ceramic semiconductor components at $900^{\circ} \mathrm{F}$. Unlike Duraseal $1529 \mathrm{H}$, it adheres well to fire-polished alumina and is rated to a sufficiently high temperature for use as an interface between the $1529 \mathrm{H}$ and the densified alumina tube. Corning 7583 comes as a white powder, we dissolve it in 2-ethoxy ethanol and paint this solution on the cells.

\section{INITIAL PREPARATION AND CELL ASSEMBLY}

Carefully wipe all dust and particles off the bench top. Tum off the air conditioner and any other draft sources. On the right-hand side of the workspace, lay down a sufficient number of 12-in.-long fibers.

1. Insert the alumina rod into the metal shell and slip a new Grafoil ferrule and 1/8-in. nut over the rod. The Grafoil ferrules and nuts can be reused after some experience, but initially it is recommended to start with a new set.

2. Align one end of the alumina rod to be about midway into the slot in the metal shell and gently hand tighten the 1/8-in. nut.

3. Insert the fiber threading rod through the alumina tube so that both ends of the rod stick out, and lay the whole assembly on the benchtop. 
4. Repeat the above steps for as many cells as desired.

\section{FIBER THREADING}

Fiber threading is probably the most time-consuming part of the cell-making process. After mixing a small amount of 5-Minute epoxy in a disposable aluminum boat, proceed as follows:

1. Put a drop of 5-Minute epoxy on the end of the fiber threading rod opposite the $1 / 8$ in. nut and glue a fiber to it.

2. Let glue harden for about 20 minutes. The longer the glue is left to harden, the less chance the fiber will come loose during the threading step.

3. Test the glue in the aluminum boat for hardness. If it is still sticky, wait.

4. Gently pull the threading rod and attached fiber through the metal shell. Make sure the fiber enters the alumina tube smoothly. Pull threading rod all the way out of the alumina tube, so that about 2 in. of the fiber is sticking out of the rod end and the rest of the fiber is out the other end. Cut the fiber loose from the threading rod with a pair of scissors. Cut the excess fiber from the other end so that an inch of fiber sticks out the ends of the metal shell.

5. Scrape away the dried epoxy from the threading rod with a sharp object.

\section{FIBER POTTING PROCEDURE}

1. Shake the bottle of Aremco 569 thoroughly. It is a very viscous material and tends to get more viscous as the thinner evaporates.

2. Use a scupula to transfer a small amount of 569 into a disposable vial. Wipe the scupula clean.

3. Clamp a cell at about a 45-degree angle, using a clamp and ring stand. Loosen the 1/8-in. nut until the alumina tube can be turned by hand. Make sure the fiber does not slip down the tube.

4. Using the wooden end of a 6-in. disposable cotton applicator, pick up some 569 from the vial.

5. While slowly turning the alumina tube, fill the annular space around the fiber with the 569, taking care not to touch the fiber with the stick. The easiest method is to anchor the fiber to one point on the edge of the annular space, then fill the empty space where the fiber is not. Then allow the 569 to flow around the fiber and enclose it. This step will take some practice. Try to get most of the 569 to go down the inside of the tube, rather than forming a large protruding head.

6. Place the cell in the tripod cell holder, taking care not to break off the end of the fiber that is sticking out of the metal shell.

7. Leave the cell in the holder overnight. 


\section{CURING PROCEDURE}

1. Cure at $120^{\circ} \mathrm{C}$ for two hours. Ramp at $100^{\circ} \mathrm{C} / \mathrm{h}$ or at about $2^{\circ} \mathrm{C} / \mathrm{min}$.

2. Cure at $350^{\circ} \mathrm{C}$ for four hours, using the same ramping rate.

\section{APPLICATION PROCEDURE}

1. Dissolve a small amount of 7583 in 2-ethoxy ethanol. Test the consistency of the solution on a glass plate. It should be paintable but not so thin that it runs down the glass.

2. Mount a cell in a clamp at a 45-degree angle as before and loosen the $1 / 8$-in. nut until the alumina tube can be turned by hand.

3. Paint the 569/alumina interface with a fine brush, but be careful to leave about a 1/16-in. radius around the fiber unpainted. Do not touch the fiber with the brush.

4. Place the cell back in the tripod holder, and allow it to dry overnight.

\section{CURING PROCEDURE}

1. With the quartz tube in the furnace, let the temperature come to equilibrium at $500^{\circ} \mathrm{C}$.

2. Remove the top of the quartz tube and lower the cell holder carefully into the tube. Put the top of the quartz tube back on.

3. Wait until the furnace temperature reaches $500^{\circ} \mathrm{C}$ again, then wait five more minutes.

4. Shut off the furnace and mount the quartz tube on a ring stand away from the furnace. Let it cool down to room temperature.

Repeat the 7583 application and curing procedures to obtain two coats.

\section{H APPLICATION PROCEDURE}

1. Shake the bottle of $1529 \mathrm{H}$ well.

2. Mount the metal shell at about a 45-degree angle in a ring stand as before.

3. Dip a small brush in the bottle of $1529 \mathrm{H}$, then allow a drop of the liquid to flow around the fiber.

4. Rotate the alumina tube and brush along the sides of the seal.

5. Brush off the excess $1529 \mathrm{H}$.

6. Let dry at room temperature for two hours. 


\section{H CURING PROCEDURE}

1. Cure in the oven at $120^{\circ} \mathrm{C}$ for one hour. Ramp at $5^{\circ} \mathrm{C} / \mathrm{min}$.

2. Cure at $170^{\circ} \mathrm{C}$ for four hours, using same ramp.

Repeat application and curing procedure three times to obtain four coats of $1529 \mathrm{H}$. 


\section{Appendix C}

TABULATIONS OF DATA; ALL MIXTURE AND PURE COMPONENT MEASUREMENTS

C-1: $\mathrm{H}_{2} / \mathrm{CO}$ MEASUREMENTS

C-2: $\mathrm{N}_{2} / \mathrm{CO}_{2}$ MEASUREMENTS

C-3: $\mathbf{N H}_{3} / \mathbf{N}_{2}$ MEASUREMENTS

C-4: $\mathrm{O}_{2} / \mathrm{N}_{2}$ MEASUREMENT

C-5: HELIUM MEASUREMENTS

C-6: VARIOUS PURE COMPONENT MEASUREMENTS 


\section{Appendix C-1: $\mathrm{H}_{2} / \mathrm{CO}$ MEASUREMENTS}

C-1 


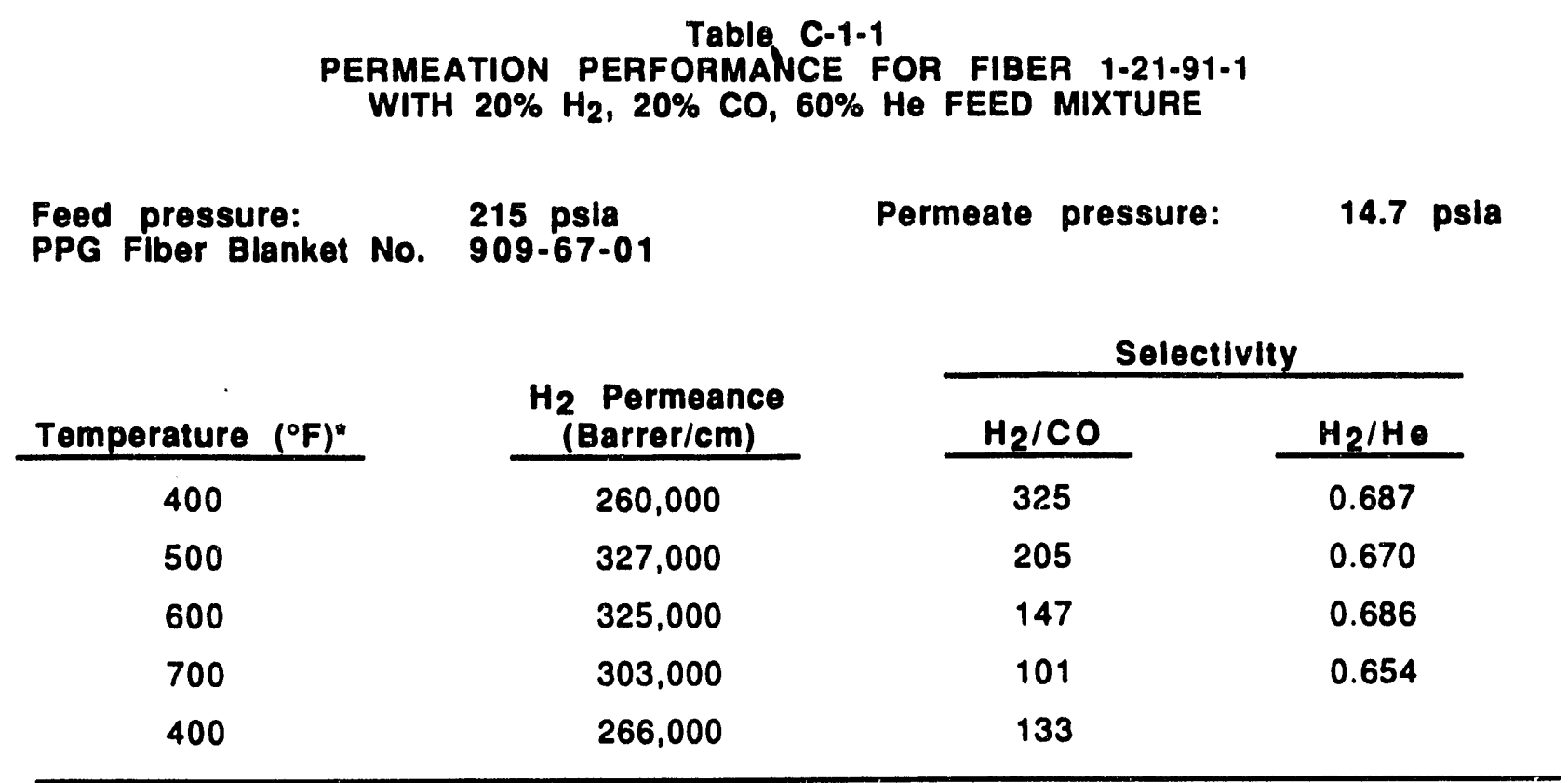

- Temperatures listed in chronological sequence.

Table C-1-2

PERMEATION PERFORMANCE FOR FIBER 1-21-91-2

WITH $20 \% \mathrm{H}_{2}, 20 \% \mathrm{CO}, 60 \%$ He FEED MIXTURE

Feed pressure: 215 psla

PPG Flber Blanket No. 909-67-01

Permeate pressure: $\quad 14.7$ psla

\begin{tabular}{cc} 
Temperature $\left({ }^{\circ} \mathbf{F}\right)^{*}$ & $\begin{array}{c}H_{2} \text { Permeance } \\
\text { (Barrer/cm) }\end{array}$ \\
\hline 400 & 193,000 \\
500 & 278,000 \\
600 & 315,000 \\
700 & 332,000 \\
400 & 221,000
\end{tabular}

\begin{tabular}{cc}
\multicolumn{2}{c}{ Selectivity } \\
\hline$H_{2} / \mathrm{CO}$ & $H_{2} / \mathrm{He}^{2}$ \\
2,340 & 0.483 \\
1,510 & 0.527 \\
1,040 & 0.559 \\
190 & 0.551 \\
136 & 0.525
\end{tabular}

- Temperatures listed in chronological sequence. 
Table C-1.3

PERMEATION PERFORMANCE FOR FIBER 2-20-91-1

WITH $20 \% \mathrm{H}_{2}, 20 \% \mathrm{CO}, 60 \%$ He FEED MIXTURE

Feed pressure: 215 psla

FPG Fiber Blanket No. 909-67-01

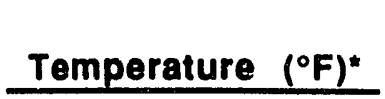

300

400

500

300

500
$\mathrm{H}_{2}$ Permeance

(Barrer/cm)

117,000

153,000

199,000

119,000

156,000
Permeate pressure:

14.7 psla

Selectivity

\begin{tabular}{ccc}
\hline $\mathrm{H}_{2} / \mathrm{CO}$ & & $\mathrm{H}_{2} / \mathrm{He}$ \\
850 & & 0.501 \\
428 & & 0.528 \\
347 & & 0.533 \\
792 & & 0.486 \\
375 & & 0.485
\end{tabular}

- Temperatures listed in chronological sequence.

\section{Table C-1-4 \\ PERMEATION PERFORMANCE FOR FIBER 2-20-91-2 \\ WITH $20 \% \mathrm{H}_{2}, 20 \%$ CO, $60 \%$ He FEED MIXTURE}

Feed pressure:

PPG FIber Blanket No. 909-67-01

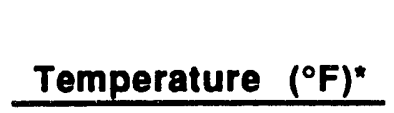

300

400

500

300

500

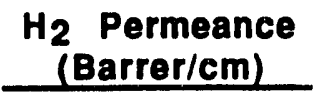

30,000

65,000

101,000

43,000

81,000

Permeate pressure:

14.7 psia

- Temperatures listed in chronological sequence.

Selectivity

\begin{tabular}{|c|c|}
\hline $\mathrm{H}_{2} / \mathrm{CO}$ & $\mathrm{H}_{2} / \mathrm{He}_{\mathrm{e}}$ \\
\hline 2,420 & 0.331 \\
\hline 1,840 & 0.386 \\
\hline 974 & 0.424 \\
\hline 1,050 & 0.338 \\
\hline 759 & 0.403 \\
\hline
\end{tabular}


Table C.1.5

PERFORMANCE OF FIBER 2-6-91-1 POTTED IN HIGH TEMPERATURE EPOXY

Feed pressure: 215 psla

PPG Fiber Blanket No. 909-67-01

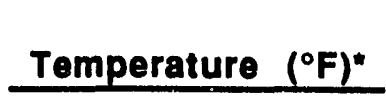

100

200

300

110

200

300

\section{$\mathrm{H}_{2}$ Permeance \\ (Barrer/cm)}

226,000

606,000

714,000

442,000

902,000

$1,095,000$
Permeate pressure: $\quad 14.7$ psla

Selectivity

\begin{tabular}{ccc}
\hline$H_{2} / \mathrm{CO}$ & & $H_{2} / H_{0}$ \\
190 & & 0.679 \\
52 & & 0.961 \\
12 & - \\
197 & 0.713 \\
71 & 0.941 \\
21 & & 1.068
\end{tabular}

- Temperatures listed in chronological sequence.

Table C-1-6

PERFORMANCE OF FIBER 2-6-91-2 POTTED IN HIGH TEMPERATURE EPOXY

Feed pressure: 215 psla

PPG Fiber Blanket No. 909-67-01

Temperature $\left({ }^{\circ} \mathrm{F}\right)^{*}$

100

200

300

110

200

300
$\mathrm{H}_{2}$ Permeance
(Barrer/cm)

291,000

$1,167,000$

628,000

$1,183,000$

$1,415,000$
Permeate pressure:

14.7 psia

\section{Selectivity}

$\begin{array}{ccc}\mathrm{H}_{2} / \mathrm{CO} & & \mathrm{H}_{2} / \mathrm{He}_{0} \\ 194 & & 0.644 \\ - & - \\ 12 & 0.900 \\ 108 & 0.827 \\ 39 & 1.022 \\ 14 & & 1.114\end{array}$

- Temperatures listed in chronological sequence. 
Appendix C-2: $\mathrm{N}_{2} / \mathrm{CO}_{2}$ MIXTURES

C-5 
Table C.2-1

PERFORMANCE DATA FOR CELLS MADE WITH EPOXY SEAL

$\begin{array}{llll}\text { Feed Pressure: } & 215 \text { psla } & \text { Feed Composition: } 85 \% \mathrm{~N}_{2} ; 15 \% \mathrm{CO}_{2} \\ \text { Permeate Pressure: } & 14.7 \text { psla } & \end{array}$ PPG Blanket No. 909-67-01A

\begin{tabular}{|c|c|c|c|c|}
\hline Cell No. & $\begin{array}{c}\text { Temperature } \\
\left({ }^{\circ} \mathrm{F}\right) \\
\end{array}$ & $\begin{array}{c}\text { Nitrogen } \\
\text { Permeance } \\
\text { (Barrer/cm) } \\
\end{array}$ & $\begin{array}{c}\mathrm{CO}_{2} \\
\text { Permeance } \\
\text { (Barrer/cm) } \\
\end{array}$ & $\begin{array}{l}\text { Selectlvity } \\
\left(\mathrm{CO}_{2} / \mathrm{N}_{2}\right) \\
\end{array}$ \\
\hline $\begin{array}{l}1 \\
1 \\
1 \\
2 \\
2 \\
2\end{array}$ & $\begin{array}{l}158 \\
200 \\
300 \\
158 \\
200 \\
300\end{array}$ & $\begin{array}{r}2,770 \\
6,700 \\
31,700 \\
3,020 \\
6,800 \\
29,900\end{array}$ & $\begin{array}{r}39,600 \\
73,100 \\
156,000 \\
38,300 \\
70,600 \\
157,000\end{array}$ & $\begin{array}{r}14.3 \\
10.9 \\
4.9 \\
12.7 \\
10.4 \\
5.2\end{array}$ \\
\hline
\end{tabular}

Pure Component Data

\begin{tabular}{|c|c|c|c|c|}
\hline Cell No. & $\begin{array}{l}\text { Temperature } \\
\text { (०F) }\end{array}$ & $\begin{array}{l}\text { Nitrogen } \\
\text { Permeance } \\
\text { (Barrer/cm) }\end{array}$ & $\begin{array}{c}\mathrm{CO}_{2} \\
\text { Permeance } \\
\text { (Barrer/cm) }\end{array}$ & $\begin{array}{l}\text { Selectlvity } \\
\left(\mathrm{CO}_{2} / \mathrm{N}_{2}\right)\end{array}$ \\
\hline $\begin{array}{l}1 \\
2\end{array}$ & $\begin{array}{l}200 \\
200\end{array}$ & $\begin{array}{l}6,780 \\
6,770\end{array}$ & $\begin{array}{l}81,500 \\
96,100\end{array}$ & $\begin{array}{l}12.0 \\
14.2\end{array}$ \\
\hline
\end{tabular}

Table C-2-2

PERMEANCE OF FIBER 12-5-90-1 TO $\mathrm{CO}_{2}$ AND $\mathrm{N}_{2}$

(Barrer/cm)

$\begin{array}{lll}\text { Feed pressure } & 215 \text { psla } & \text { Feed composition: } 15 \% \mathrm{CO}_{2} / 85 \% \mathrm{~N}_{2} \\ \text { Permeate pressure: } & 14.7 \text { psla }\end{array}$

\begin{tabular}{|c|c|c|c|}
\hline Temperature ( $\left.{ }^{\circ} \mathrm{F}\right)$ & $\mathrm{CO}_{2}$ & $\mathrm{~N}_{2}{ }^{*}$ & $\begin{array}{l}\text { Selectlvity } \\
\left(\mathrm{CO}_{2} / \mathrm{N}_{2}\right) \\
\end{array}$ \\
\hline 400 & 13,600 & 849 & 16.2 \\
\hline 500 & 15,400 & 1,760 & 8.8 \\
\hline 600 & 18,300 & 2,880 & 6.4 \\
\hline
\end{tabular}

- $\mathrm{N}_{2}$ in-leakage measured at $400^{\circ} \mathrm{F}$, equivalent to permeance of 223 Barrer $/ \mathrm{cm}$. 
Table C-2-3

PERMEANCE OF FIBER 12-5-90-2 TO $\mathrm{CO}_{2}$ AND $\mathrm{N}_{2}$

(Barrer/cm)

Feed pressure

Permeate pressure:

Temperature $\left({ }^{\circ} \mathrm{F}\right)$

400

500

600

700

800
215 psla

14.7 psla
Feed composition: $15 \%$

$\mathrm{CO}_{2} / 85 \% \mathrm{~N}_{2}$ 
Tabie C-2-5

PERMEANCE OF FIBER 12-16-90-2 TO $\mathrm{CO}_{2}$ AND $\mathrm{N}_{2}$

(Barrer/cm)

Feed pressure:

215 psia

PPG Flber Blanket No. 909-67-01

Permeate pressure: 14.7 psia

\begin{tabular}{|c|c|c|c|c|c|c|}
\hline \multirow[b]{2}{*}{$\begin{array}{c}\text { Temp. } \\
\text { ( } \mathrm{F} \text {. }\end{array}$} & \multicolumn{2}{|c|}{ Pure Component } & \multirow[b]{2}{*}{$\begin{array}{c}\mathrm{N}_{2} \\
\text { Leak }\end{array}$} & \multicolumn{2}{|c|}{$15 \% \mathrm{CO}_{2} / 85 \%$} & \multirow{2}{*}{$\begin{array}{c}\mathrm{N}_{2} \text { Mixture } \\
\text { Selectivity } \\
\left(\mathrm{CO}_{2} / \mathrm{N}_{2}\right) \\
\end{array}$} \\
\hline & $\mathrm{CO}_{2}$ & $\mathrm{~N}_{2}$ & & $\mathrm{CO}_{2}$ & $\mathrm{~N}_{2}$ & \\
\hline 200 & 860 & 18 & 40 & 1,060 & - & - \\
\hline 400 & 2,650 & 232 & 65 & 3,370 & 208 & 16.2 \\
\hline 500 & 3,160 & 415 & 100 & 4,250 & 474 & 9.0 \\
\hline 600 & 3,770 & 813 & 178 & $3,770^{*}$ & $606^{*}$ & 6.2 \\
\hline 700 & 4,260 & - & & 4,760 & 1,130 & 4.2 \\
\hline
\end{tabular}

"Not included in fit. 
Appendix C-3: $\quad \mathbf{N H}_{3} / \mathbf{N}_{2}$ MIXTURES

C-9 
Feed mixture: $1.7 \% \mathrm{NH}_{3}, 15.8 \% \mathrm{He}, 82.5 \% \mathrm{~N}_{2}$ PPG Fiber Blanket No. 909-67-01
Permeate pressure: 14.7 psla

Feed pressure: 215 psla
Fiber 8-5-91-1

\begin{tabular}{|c|c|c|c|}
\hline \multirow{2}{*}{$\begin{array}{l}\text { Temp. } \\
\left({ }^{\circ} \mathrm{F}\right)^{*}\end{array}$} & \multicolumn{2}{|c|}{$\begin{array}{l}\text { Permeance } \\
\text { (Barrer/cm) }\end{array}$} & \multirow{2}{*}{$\begin{array}{c}\alpha \\
\left(\mathrm{NH}_{3} / \mathrm{N}_{2}\right) \\
\end{array}$} \\
\hline & $\mathrm{NH}_{3}$ & $\mathbf{N}_{2}$ & \\
\hline 200 & 95,600 & 696 & 137.4 \\
\hline 275 & 224,000 & 4,740 & 47.3 \\
\hline 350 & 295,000 & 14,200 & 20.8 \\
\hline 275 & 209,000 & 3,830 & 54.4 \\
\hline
\end{tabular}

- Data shown in chronological order.
Flber 8-5-91-2

\begin{tabular}{|c|c|c|}
\hline \multicolumn{2}{|c|}{$\begin{array}{l}\text { Permeance } \\
\text { (Barrer } / \mathrm{cm} \text { ) }\end{array}$} & \multirow{2}{*}{$\begin{array}{c}\alpha \\
\left(N_{3} / N_{2}\right)\end{array}$} \\
\hline $\mathrm{NH}_{3}$ & $\mathrm{~N}_{2}$ & \\
\hline 99,900 & 818 & 122.2 \\
\hline 229,000 & 6,870 & 33.4 \\
\hline 289,000 & 19,700 & 14.6 \\
\hline 197,000 & 5,240 & 37.5 \\
\hline
\end{tabular}

Table C-3-2

PERMEATION Behavior OF STANDARD CELLS

(FIber 8-21-91-2; Barrer/cm)

Feed mixture: $1.7 \% \mathrm{NH}_{3}, 15.8 \% \mathrm{He}, 82.5 \% \mathrm{~N}_{2}$ PPG Flber Blanket No. 909-67-01

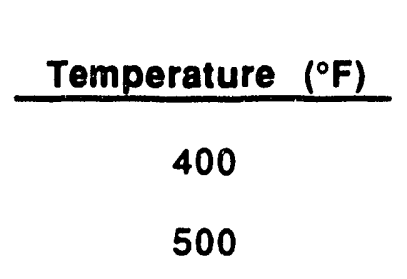

Permeate pressure: 14.7 psla Feed pressure: 215 psla

-

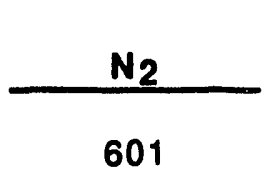

\begin{tabular}{c}
$\begin{array}{c}\text { Selectlvity } \\
\left(\mathrm{NH}_{3} / \mathrm{N}_{2}\right)\end{array}$ \\
\hline 71.5 \\
30.3
\end{tabular}


Appendix C-4: $\mathbf{O}_{2} / \mathbf{N}_{2}$ MIXTURES

C-11 
Table C-4-1

SYNTHETIC AIR SEPARATION WITH EPOXIED CELLS

Temperature: $158^{\circ} \mathrm{F}$

Feed Pressure 115 psla

Permeate Pressure 14.7 psla

Nitrogen

Permeance

Cell

1

2
(Barrer/cm)

4,110

4,729
Feed Composition: $21 \% \mathrm{O}_{2}$

$79 \% \mathrm{~N}_{2}$
Selectivity

$\left(\mathrm{O}_{2} / \mathrm{N}_{2}\right)$

4.0

C- 12 
Appendix C-5: HELIUM, PURE COMPONENT DATA 
Table C-5-1

PURE COMPONENT HELIUM PERMEANCE OF HIGH

TEMPERATURE TEST CELLS

(Barrer/cm)

Feed pressure: 215 psla

PPG Fiber Blanket No. 909-67-01

Permeate pressure: 14.7 psla

\begin{tabular}{|c|c|c|c|c|}
\hline Elber Number & $200^{\circ} \mathrm{F}$ & $400^{\circ} \mathrm{F}$ & $600^{\circ} \mathrm{F}$ & $600^{\circ} \mathrm{F}^{*}$ \\
\hline 3 & 249,000 & 370,000 & 426,000 & 一 \\
\hline 4 & 222,000 & 354,000 & 436,000 & 356,000 \\
\hline
\end{tabular}

- Data taken after 18 days at $600^{\circ} \mathrm{F}$.

Table C-5-2

PURE COMPONENT HELIUM PERMEANCE DATA

FOR FIBERS 12-16-90-1 AND 12-16-90-2

Feed pressure:

PPG Fiber Blanket No. 909-67-01

Permeate pressure: 14.7 psia

Permeance (Barrer/cm)

Elber Number

$12-16-90-1$

$12-16-90-2$ $200^{\circ} \mathrm{F}$

189,000

115,000 $700^{\circ} \mathrm{F}$

460,000

468,000

C-14 
Table C-5-3

PERMEATION DATA FOR FIBERS MADE WITH INORGANIC SEALS (215 psla Feed Pressure)

Sample I.D.

3-18 IGSEb

9112-55-3 IGS

9112-55-4 IGS
Temperature $\left({ }^{\circ} \mathrm{F}\right)^{\mathrm{a}}$

200

250

300

350

200

200

300

400

500

600

700

200

300

400
Hellum Permeance (Barrer/cm)

113,000

134,000

168,000

265,000

175,000

218,000

311,000

398,000

437,000

462,000

618,000

207,000

340,000

462,000

a. Data shown in chronological order.

b. Epoxy was necessary to seal a small leak. 


\section{Table C-5-4 \\ DATA FOR FIBERS MADE WITH INORGANIC SEALS}

Feed pressure: 215-245 psla

PPG Flber Blanket No. 909-67-01

Sample I.D.

9112-57-1 IGS

$9112-71-5$ IGS

$9112-57-3$ IS

200

300

400

200

200

400

800
Permeate pressure: 14.7 psia

Hellum Permeance

(Barrer/cm)

119,000

224,000

338,000

542,000

807,000

101,000

216,000

394,000

580,000

772,000

970,000

$1,433,000$ 


\title{
Table C.5-5
}

PERMEATION DATA FOR FIBERS SEALED WITH AREMCO 662 SEALANT

\author{
Feed pressure: 215 psia \\ PPG Flber Blanket No. 909-67-01 \\ Permeate pressure: 14.7 psla
}

Sample I.D.

Temperature ( $\left.{ }^{\circ} \mathrm{F}\right)$

9112-79-1 IS

200

400

Hellum Permeance

(Barrer/cm)

9112-79-2 IS

200

265,000

400

$1,125,000$

9112-79-3 IS

200

205,000

400

709,000 


\section{Table C-5-6 \\ PERMEATION DATA FOR FIBERS PREHEATED TO $1000^{\circ} \mathrm{F}$}

Feed pressure: 215 psla

PPG Flber Blanket No. 909-67-01

Sample 1.D.

9112-85-2 IE

$1000^{\circ} \mathrm{F}$ for $24 \mathrm{~h}$

9112-85-3 IE

$1000^{\circ} \mathrm{F}$ for $24 \mathrm{~h}$

9112-85-4 IE

$1000^{\circ} \mathrm{F}$ for $24 \mathrm{~h}$
Temperature ( ${ }^{\circ} \mathrm{F}$ )

200

250

300

350

200

250

300

350

200

250

300

350
Permeate pressure: 14.7 psia

Hellum Permeance (Barrer/cm)

297,000

335,000

388,000

436,000

251,000

291,000

341,000

391,000

264,000

276,000

319,000

336,000 
Table C-5-7

HELIUM PERMEATION DATA FOR FIBERS HELD IN EPOXY-SEATED TEST CELLS

Feed pressure: 215 psla

Permeate pressure: 14.7 psla

PPG Fiber Blanket No. 909-67-01

Sample I.D.

4-1E

4-2E
Temperature $\left({ }^{\circ} \mathrm{F}\right)$

200

250

300

350

200

200

250

300

350

200

250

300

350

200
Helium Permeance

(Barrer/cm)

$1,670,000$

$1,900,000$

$2,100,000$

$2,260,000$

$1,620,000$

$1,320,000$

$1,-00,000$

$1,660, v 00$

$1,970,000$

$1,640,000$

$1,840,000$

$2,010,000$

$2,130,000$

$1,620,000$ 
Table C-5-8

HELIUM PERMEATION DATA FOR EPOXY TEST CELLS

Feed pressure:

245 psla

PPG Fiber Blanket No. 890-18-01*

Permeate pressure: 14.7 psla

Fiber Number

9112-30-3

9112-30-5

\begin{tabular}{c} 
Temperature $\left({ }^{\circ} \mathrm{F}\right)$ \\
\hline 158 \\
212 \\
230 \\
248
\end{tabular}

158

212

230

248
Hellum Permeance

(Barrer/cm)

$$
\begin{array}{r}
995,000 \\
1,280,000 \\
1,370,000 \\
1,430,000
\end{array}
$$

$1,060,000$

$1,290,000$

$1,390,000$

$1,450,000$

$¥ 33.8 \mu \mathrm{m}$ O.D., $24 \mu \mathrm{m}$ I.D. 
Appendix C-6: VARIOUS PURE COMPONENT DATA

C-21 


\section{Table C-6-1 \\ PURE COMPONENT DATA FOR FIBER 8914-08-10*}

(Pure gas permeance in Barrer/cm measured at 315 psla)

\begin{tabular}{|c|c|c|c|c|c|}
\hline Temperature ( $\left.{ }^{\circ} \mathrm{F}\right)$ & $\mathrm{He}$ & $\mathrm{H}_{2}$ & $\mathrm{CO}_{2}$ & $\mathbf{N}_{2}$ & Co \\
\hline 77 & 24,800 & 32,100 & $\cdots$ & 257 & 1,040 \\
\hline 104 & 299,000 & 185,000 & 39,300 & 1,420 & $\cdots$ \\
\hline 158 & $1,040,000$ & 523,000 & 97,700 & 3,210 & 8,370 \\
\hline
\end{tabular}

Fiber O.D. $=69 \mu \mathrm{m}$

Fiber I.D. $=57 \mu \mathrm{m}$ 
Table C-6-2

CARBON DIOXIDE PERMEATION DATA.

Flber Identifler: $\quad 890-18-01$

Feed pressure: 215 psla

Elber Number

9112-30-3

9112-30-5

$\frac{\begin{array}{c}\text { Temperature } \\ \text { (으) }\end{array}}{158}$

212

230

248

158

212

230

248
Permeate pressure: 14.7 psla

\begin{tabular}{c} 
Carbon Dioxide \\
Permeance \\
(Barrer/cm) \\
\hline
\end{tabular}

23,700

36,750

36,750

78,900

66,900

72,300

101,000

112,000

13,100

21,000

22,300

63,000

76,200

69,600

93,200

105,000

104,000

114,000 
Table $C \cdot 6 \cdot 3$

CARBON DIOXIDE PERMEATION DATA FOR BASELINE FIBERS WITH EPOXY SEALS

Feed pressure:

215 psia

Permeate pressure: 14.7 psla

PPG FIber Blanket No. 909-67-01

\begin{tabular}{ccc} 
Sample 1.D. & $\begin{array}{c}\text { Temperature } \\
(\text { (F) }\end{array}$ & $\begin{array}{c}\text { CO2 Permeance } \\
\text { (Barrer/cm) }\end{array}$ \\
\cline { 2 - 2 } $4-1 E$ & 200 & 296,000 \\
250 & 389,000 \\
300 & 493,000 \\
350 & 554,000 \\
$4-3 E$ & & \\
& 200 & 261,000 \\
& 250 & 347,000 \\
& 300 & 420,000 \\
& 350 & 486,000
\end{tabular}

Table C-6-4

PERMEANCE OF FIBER 12-16-90-1 TO $\mathrm{CO}_{2}$ AND $\mathrm{N}_{2}$

(Barrer/cm)

Feed pressure: 215 psla $\quad$ Permeate pressure: 14.7 psla

PPG Flber Blanket No. 909-67-01

Pure Component

Temperature $\left({ }^{\circ} \mathrm{F}\right)$

200

400

500

600

700

\begin{tabular}{cc}
\multicolumn{2}{c}{ Pure Component } \\
\cline { 1 - 2 } $\mathrm{CO}_{2}$ & $\mathrm{~N}_{2}$ \\
\cline { 2 - 2 } $\mathrm{\cdots}$ & $17^{*}$ \\
806 & 52 \\
1,220 & 123 \\
1,600 & 233 \\
2,360 & -
\end{tabular}

- N2 permeance is below the chromatograph's limit of detection. 


\section{Table C-6-5}

PEAMEANCE OF FIBER $12-16-90-2$ TO $\mathrm{CO}_{2}$ AND $\mathrm{N}_{2}$

(Barrer/cm)

Feed pressure: 215 psla $\quad$ Permeate pressure: 14.7 psia

PPG Flber Blanket No. 909-67-01

Temperature $\left({ }^{\circ} \mathrm{F}\right)$

200

400

500

600

700
Pure Component

\begin{tabular}{cr}
\multicolumn{2}{c}{ Pure Component } \\
\hline $\mathrm{CO}_{2}$ & $\frac{\mathrm{N}_{2}}{860}$ \\
\cline { 2 - 2 } 2,650 & 18 \\
232
\end{tabular}

3,160

415

3,770

813

4,260

Table C-6.6

PERMEATION PERFORMANCE OF CARBON MONOXIDE

Feed Pressure: 215 psia

Permeate Pressure: 14.7 psia

PPG Fiber Blanket No. 909-67-01

\section{CO Permeance (Barrer/cm)}

Temperature $\left({ }^{\circ} \mathrm{F}\right)$

400

500

600

400
Flber 1.21-91.1

4,260

4,400

6,430

2,820
Flber 1-21-91-2

3,860

4,020

5,670

2,580 
Appendix D

KINETIC DIAMETERS OF VARIOUS MOLECULES 
TABLE D-1

KINETIC DIAMETERS OF VARIOUS MOLECULES

\begin{tabular}{|c|c|}
\hline Gas_Molecule & $\begin{array}{c}\text { KInetlc Dlameter } \\
\sigma(A) \\
\end{array}$ \\
\hline $\mathrm{He}$ & 2.6 \\
\hline $\mathrm{NH}_{3}$ & 2.6 \\
\hline $\mathrm{H}_{2} \mathrm{O}$ & 2.65 \\
\hline $\mathrm{Ne}$ & 2.75 \\
\hline $\mathrm{H}_{2}$ & 2.89 \\
\hline NO & 3.17 \\
\hline $\mathrm{Cl}_{2}$ & 3.2 \\
\hline $\mathrm{C}_{2} \mathrm{H}_{2}$ & 3.3 \\
\hline $\mathrm{CO}_{2}$ & 3.3 \\
\hline $\mathrm{N}_{2} \mathrm{O}$ & 3.3 \\
\hline Ar & 3.40 \\
\hline $\mathrm{O}_{2}$ & 3.46 \\
\hline $\mathrm{Br}_{2}$ & 3.5 \\
\hline $\mathrm{H}_{2} \mathrm{~S}$ & 3.6 \\
\hline $\mathrm{SO}_{2}$ & 3.6 \\
\hline $\mathrm{Kr}$ & 3.60 \\
\hline $\mathrm{N}_{2}$ & 3.64 \\
\hline co & 3.76 \\
\hline $\mathrm{CH}_{4}$ & 3.8 \\
\hline $\mathrm{C}_{2} \mathrm{H}_{4}$ & 3.9 \\
\hline $\mathrm{Xe}$ & 3.96 \\
\hline $\mathrm{C}_{3} \mathrm{H}_{8}$ & 4.3 \\
\hline$n-\mathrm{C}_{4} \mathrm{H}_{10}$ & 4.3 \\
\hline $\mathrm{CF}_{2} \mathrm{Cl}_{2}$ & 4.4 \\
\hline $\mathrm{C}_{3} \mathrm{H}_{6}$ & 4.5 \\
\hline $\mathrm{C}_{4} \mathrm{H}_{8}$ & 4.5 \\
\hline $\mathrm{CF}_{4}$ & 4.70 \\
\hline $\mathrm{C}_{6} \mathrm{H}_{6}$ & 5.85 \\
\hline Cyclo- $\mathrm{C}_{6} \mathrm{H}_{12}$ & 6.0 \\
\hline
\end{tabular}



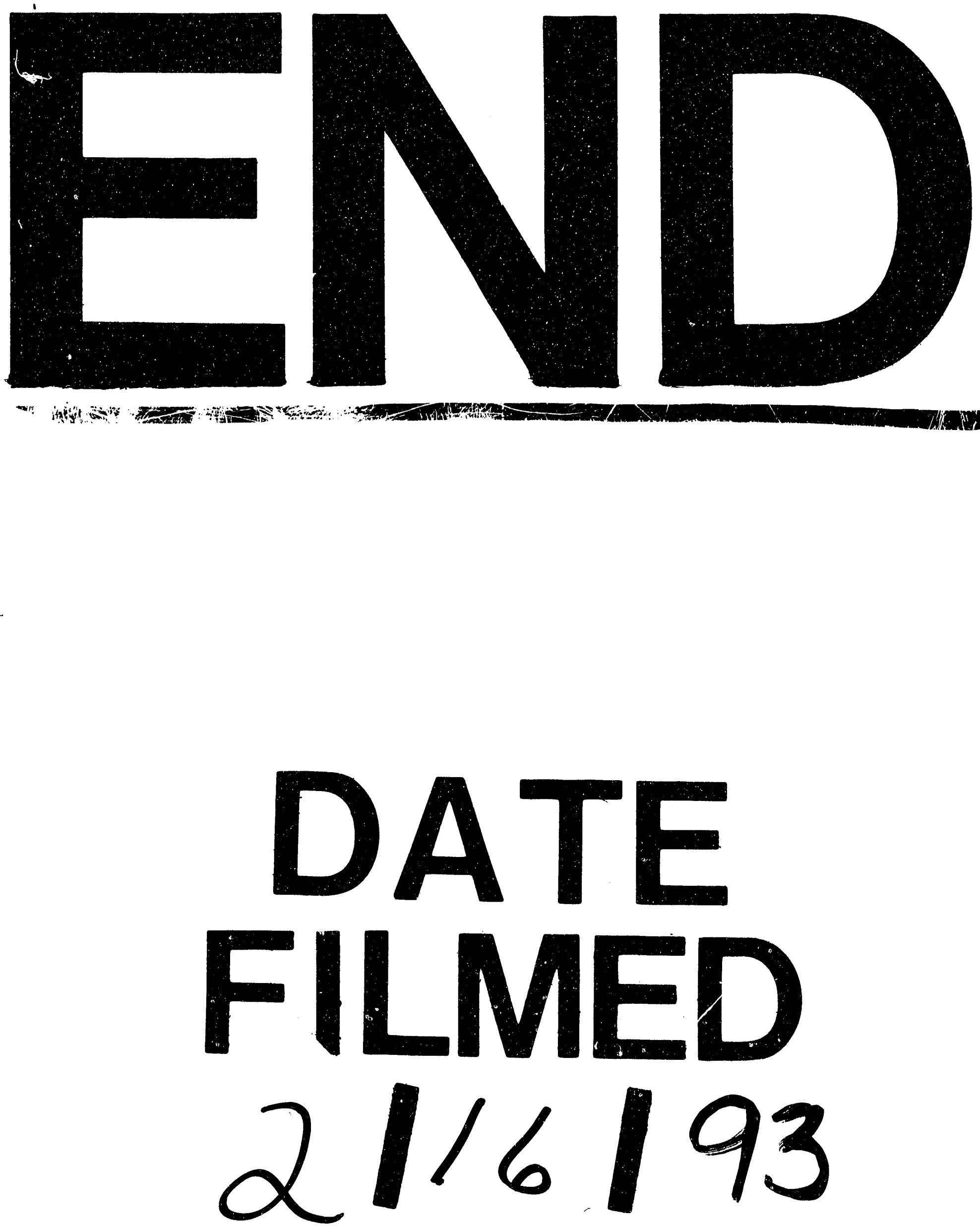
